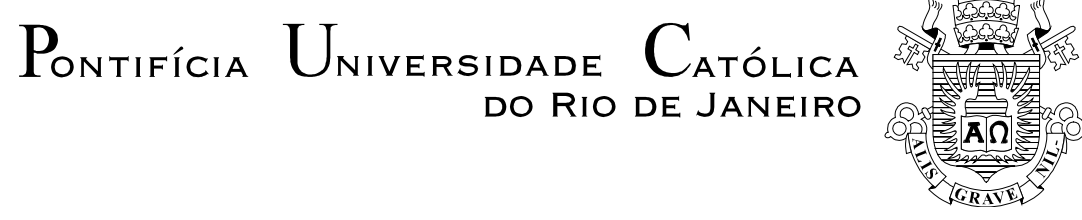

Gabriel Alcântara Bomfim

Modelagem da Data de Entrada em Produção de Poços de Petróleo Utilizando Inferência Fuzzy

Dissertação de Mestrado

Dissertação apresentada como requisito parcial para obtenção do grau de Mestre pelo Programa de PósGraduação em Engenharia de Produção da PUC-Rio.

Orientador: Prof. Fernando Luiz Cyrino Oliveira Co-orientador: Prof. Antônio Orestes de Salvo Castro 


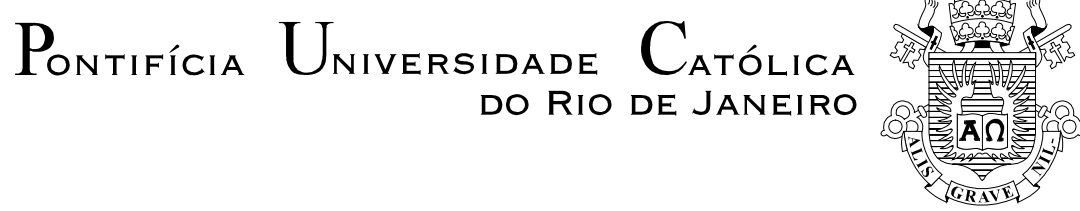

Gabriel Alcântara Bomfim

\section{Modelagem da Data de Entrada em Produção de Poços de Petróleo Utilizando Inferência Fuzzy}

Dissertação apresentada como requisito parcial para obtenção do grau de Mestre pelo Programa de PósGraduação em Engenharia de Produção da PUC-Rio. Aprovada pela Comissão Examinadora abaixo assinada.

Prof. Fernando Luiz Cyrino Oliveira Orientador Departamento de Engenharia Industrial - PUC-Rio

Prof. Antônio Orestes de Salvo Castro Co-orientador Universidade do Estado do Rio de Janeiro

Prof. Marley Maria Bernardes Rebuzzi Vellasco Departamento de Engenharia Elétrica - PUC-Rio

Prof. Virgílio José Martins Ferreira Filho Universidade Federal do Rio de Janeiro

Prof. Márcio da Silveira Carvalho Coordenador Setorial do Centro Técnico Científico - PUC-Rio 
Todos os direitos reservados. É proibida a reprodução total ou parcial do trabalho sem autorização da universidade, da autora e do orientador.

\section{Gabriel Alcântara Bomfim}

Graduou-se em Engenharia de Produção pela Faculdade Área 1 em Salvador em 2011. MBA em Gestão de Projetos pela Fundação Getúlio Vargas em 2014. É Engenheiro de Produção na Petrobras, atuando no Controle da Produção corporativo na modelagem e implementação de processos, conformidade legal, gestão de sistemas de informação e previsão e análise de risco da produção de petróleo.

Ficha Catalográfica

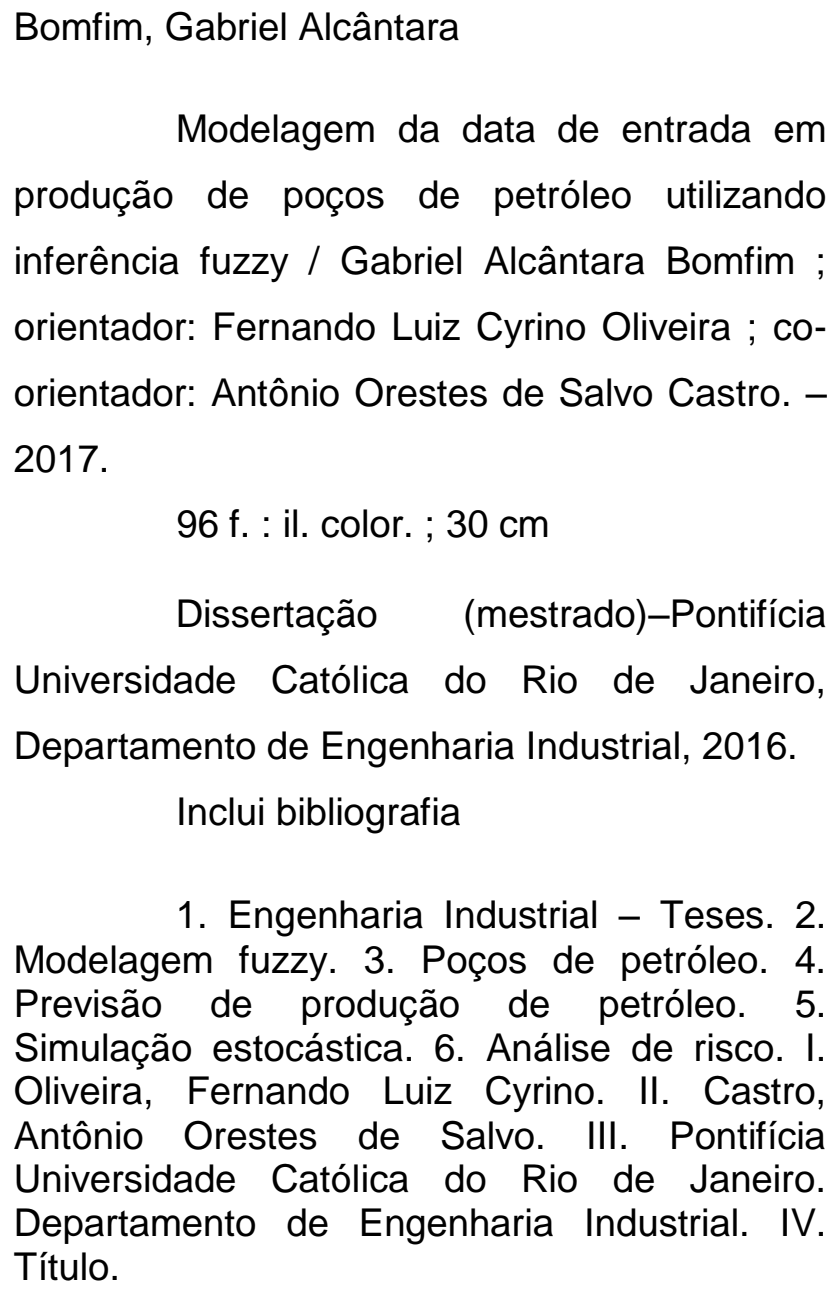

1. Engenharia Industrial - Teses. 2. Modelagem fuzzy. 3. Poços de petróleo. 4. Previsão de produção de petróleo. 5. Simulação estocástica. 6. Análise de risco. I. Oliveira, Fernando Luiz Cyrino. II. Castro, Antônio Orestes de Salvo. III. Pontifícia Universidade Católica do Rio de Janeiro. Departamento de Engenharia Industrial. IV. Título. 


\section{Agradecimentos}

"Ao Senhor Deus Todo Poderoso, Criador dos céus e da terra, por este tão sonhado presente. Toda honra e toda glória seja dada a Ele, o Rei!

A minha mãe, pelas orações incessantes, por acreditar no poder transformador da educação, por sonhar e lutar bravamente por este sonho.

A minha noiva Marina, pelo amor e apoio essenciais para conclusão deste trabalho.

Ao meu irmão, pela coragem e fortaleza.

A minha avó, por estar comigo em todos os momentos.

Ao meu avô (in memoriam), pelo exemplo de integridade e de cuidado com o próximo.

Ao meu orientador Fernando Cyrino, por acreditar no meu trabalho desde o início e pelos redirecionamento precisos que permitiram a construção deste trabalho.

Ao meu co-orientador e amigo Orestes, pelo encorajamento, incentivo e apoio decisivos para que eu fizesse o mestrado e pelo seu exemplo de profissionalismo e dedicação.

Aos Engenheiros Fernando Ramos, Denis Krambeck, Vitor Lima e Dauro Conti pelo apoio fundamental para viabilizar o desenvolvimento deste trabalho.

A Petrobras por insistir no aprimoramento da capacidade técnica dos seus funcionários.

A todos da gerência GIA-E\&P/PCO/POG, pelo apoio, amizade e ambiente enriquecedor.

A professor Marley, pelas aulas inspiradoras de Lógica Fuzzy.

Ao meus amigos, pelo companheirismo que nos torna uma grande família apesar da distância.

A Cláudia da secretaria do Departamento de Engenharia Industrial da PUC-Rio, pelo suporte excelente.

A todos do Departamento de Engenharia Industrial da PUC-Rio pela organização e extremo profissionalismo.

Deus abençoe a todos, muito obrigado!" 


\section{Resumo}

Bomfim, Gabriel Alcântara; Oliveira, Fernando Luiz Cyrino (Orientador); Castro, Antônio Orestes de Salvo (Co-orientador). Modelagem da Data de Entrada em Produção de Poços de Petróleo Utilizando Inferência Fuzzy. Rio de Janeiro, 2017. 96p. Dissertação de Mestrado - Departamento de Engenharia Industrial, Pontifícia Universidade Católica do Rio de Janeiro.

A previsão de produção é uma das etapas mais críticas do planejamento de curto prazo das empresas de exploração e produção de petróleo. O volume de petróleo que será produzido, denominado meta de produção, influencia diretamente todas as ações das empresas e tem crítico impacto em relação ao mercado. Percebe-se, portanto, a importância da aplicação de modelos que permitam considerar incertezas e avaliar o risco destas previsões. Esta modelagem estocástica tem sido realizada através de um modelo de simulação que considera quatro dimensões de variáveis: Potencial Produtivo Instalado, Entrada de Novos Poços, Parada Programada para Manutenção e Eficiência Operacional. Dentre as dimensões do modelo, a Entrada de Novos Poços é uma das mais sensíveis ao resultado final da previsão por apresentar grande incerteza. Desse modo, este trabalho tem por objetivo desenvolver um sistema de inferência fuzzy para prever a data de entrada em produção de poços de petróleo. O sistema é concebido integrado ao modelo de simulação visando aumentar a sua precisão. Os resultados mostram que o sistema de inferência fuzzy é aplicável à previsão da entrada de novos poços e que o seu uso eleva a acurácia das previsões de produção.

\section{Palavras-chave}

Modelagem Fuzzy; Poço de Petróleo; Previsão de Produção de Petróleo; Simulação Estocástica; Análise de Risco. 


\section{Abstract}

Bomfim, Gabriel Alcântara; Oliveira, Fernando Luiz Cyrino (Advisor); Castro, Antônio Orestes de Salvo (Co-Advisor). Modeling Oil Well Production Start Date using Fuzzy Inference. Rio de Janeiro, 2017. 96p. Dissertação de Mestrado - Departamento de Engenharia Industrial, Pontifícia Universidade Católica do Rio de Janeiro.

Production forecasting is one of the most critical stages in short-term planning in upstream oil companies. The oil volume that will be produced, called production target, directly influences all companies' actions and impact critically their market image. Therefore, it is noticed the importance of using models to consider uncertainties to evaluate production forecasting risks. This stochastic approach has been done through a simulation model which consider four dimensions of variables: installed production potential, new wells entry, scheduled maintenance program, and operational efficiency. Among those dimensions, the new wells entry is one of the most sensitive to the simulation results, because of its high degree of uncertainty. Thus, this work aims to develop a fuzzy inference system to forecast the new wells production start date. The system is designed integrated to the simulation model in order to increase its accuracy. The results show that the fuzzy inference system can be used to forecast wells production start date and its use increases oil production forecasting accuracy.

\section{Keywords}

Fuzzy Modeling; Oil Well; Oil Production Forecasting; Stochastic Simulation; Risk Analysis. 


\section{Sumário}

1 Introdução 13

1.1. Considerações Iniciais 13

1.2. Motivação 14

1.3. Objetivo 14

1.4. Descrição do Trabalho $\quad 15$

1.5. Organização da Dissertação 16

2 Revisão Bibliográfica $\quad 18$

2.1. Análise de Decisão e Risco na Exploração e Produção de Petróleo 18 2.2. Tratamento das Incertezas $\quad 24$

2.2.1. Uso Sistemático da Teoria da Probabilidade 25

2.2.2. Simulação Estocástica 26

2.2.3. Planejamento de Experimentos 31

2.3. A Teoria Fuzzy 32

2.3.1. Modelagem Fuzzy 33

2.3.2. Aplicação de Modelos Fuzzy Linguísticos 35

2.3.3. Lógica Fuzzy na Exploração e Produção de Petróleo 38

3 Metodologia de Previsão de Produção de Petróleo 42

3.1. Risco da Previsão de Produção de Petróleo 42

3.2. Potencial Produtivo Instalado 43

3.3. Entrada de Novos Poços 46

3.4. Parada Programada para Manutenção 49

3.5. Eficiência Operacional $\quad 51$

3.6. Modelo Conceitual e Analítico 52

3.7. Exemplo de Previsão de Produção de Petróleo 54

4 Modelagem da Data de Entrada em Produção de Poços 56

4.1. Data de Entrada em Produção de Poços 56

4.2. Dimensão Empresarial 58

4.3. Dimensão Técnica 60

4.3.1. Dimensão Técnica de Construção 61

4.3.2. Dimensão Técnica de Interligação 63 
5 Resultados 68

5.1. Sintonia do Sistema de Inferência Fuzzy 68

5.2. Validação do Sistema de Inferência Fuzzy 71

5.3. Previsão de Produção de Petróleo 73

6 Conclusão e Considerações Finais 78

7 Referências Bibliográficas $\quad 81$

8 Apêndice A 88

8.1. Conjuntos Clássicos e Fuzzy 88

8.2. Variáveis Linguísticas $\quad 89$

8.3. Operações com Conjuntos Fuzzy 91

8.4. Lógica de Inferência Tradicional e Fuzzy 92

8.5. Sistemas de Inferência Fuzzy 93

8.6. Tipos de Sistemas de Inferência Fuzzy 95 


\section{Lista de Figuras}

Figura 1 - Principais variáveis incertas da curva de produção de petróleo de acordo com as fases de um projeto de E\&P.

Figura 2 - Hierarquia da análise de risco aplicada a poços de petróleo. 22

Figura 3 - Distribuições de probabilidade das variáveis de entrada do modelo para Oil in Place.

Figura 4 - Análise de sensibilidade do modelo e distribuição de probabilidade da variável de saída Oil in Place.

Figura 5 - Extrapolação linear do Potencial Produtivo Instalado de um sistema de produção de petróleo com as visões otimista, pessimista e mais provável.

Figura 6 - Diferenças entre a curva de Potencial e a Produção Realizada devido aos eventos de perdas não programadas.

Figura 7 - Modelo conceitual da metodologia de previsão da produção de petróleo.

Figura 8 - Estrutura do sistema de inferência fuzzy para modelagem da Data de Entrada em produção de poços.

Figura 9 - Conjuntos fuzzy da dimensão Empresarial: entradas (a) Potencial, (b) Ganho Econômico e (c) saída Defasagem.

Figura 10 - (a) Esquema de poço perfurado, completado e interligado

(b) estrutura submarina de um conjunto de poços.

Figura 11 - Conjuntos fuzzy do subsistema de inferência Construção (a) Estrutura Submarina e (b) Construção do poço.

Figura 12 - Conjuntos fuzzy do subsistema de inferência Interligação (a) Distância da Costa, (b) Lâmina d'água e (c) Operação com PLSV.

Figura 13 - Variáveis intermediárias (a) Construção e (b) Interligação e (c) conjunto fuzzy da saída Defasagem Técnica.

Figura 14 - (a) Conjunto fuzzy de saída considerando apenas a dimensão Empresarial, (b) conjunto fuzzy de saída considerando apenas os subsistemas de inferência Construção e Interligação e (c) conjunto fuzzy de saída considerando todos os sistemas de inferência

fuzzy.

Figura 15 - Interface gráfica do software fuzzyTECH®: (a) parametrização das variáveis linguísticas; (b) criação do bloco de regras; (c) parametrização da variável de saída e (d) visão geral do sistema de inferência fuzzy.

Figura 16 - Comparativo entre a DEFASAGEM_PLAN_PROJ dos poços de 2015 e 2016 
Figura 17 - Resultados da previsão de 2015 (a) DATA_PLAN_PROJ com defasagem estocástica, (b) DATA_PLAN_PROJ sem defasagem estocástica, (c) DATA_PREV_SIF sem defasagem estocástica e (d)

DATA_PREV_SIF com defasagem estocástica.

Figura 18 - Resultados da previsão de 2016 (a) DATA_PLAN_PROJ com defasagem estocástica, (b) DATA_PLAN_PROJ sem defasagem estocástica, (c) DATA_PREV_SIF sem defasagem estocástica e (d)

DATA_PREV_SIF com defasagem estocástica.

Figura 19 - Comparação das médias das distribuições das previsões com a produção realizada no ano de 2015.

Figura 20 - Comparação das médias das distribuições das previsões com a produção realizada no ano de 2016.

Figura 21 - Contribuições da dissertação.

Figura 22 - Representação gráfica da variável linguística lâmina d'água.

Figura 23 - Estrutura do geral de um SIF.

Figura 24 - Estrutura de um sistema de Inferência Fuzzy do tipo Mamdani.

Figura 25 - Estrutura de um sistema de Inferência Fuzzy do tipo Takagi-Sugeno. 


\section{Lista de Tabelas}

Tabela 1 - Exemplo de previsão de produção utilizando a equação (6) .54

Tabela 2 - Exemplo de previsão de produção utilizando a equação

(6). considerando a revisão nas Datas de Entrada dos poços 1 e 2

Tabela 3 - Limites dos termos linguísticos e os universos de discurso das entradas Potencial e Ganho Econômico.

Tabela 4 - Bloco de regras do subsistema de inferência Construção. 62

Tabela 5 - Limites dos termos linguísticos e os universos de discurso das entradas Estrutura Submarina e Construção do poço

Tabela 6 - Limites dos termos linguísticos e os universos de discurso das entradas Distância da Costa, Lâmina d'água e Operação com PLSV.

Tabela 7 - Bloco de regras do agrupamento dos subsistemas Construção e Interligação.

Tabela 8 - Dados e resultados do processo de sintonia.

Tabela 9 - Estatísticas do processo de sintonia utilizando poços de 2015.

Tabela 10 - Estatísticas do processo de sintonia utilizando poços de 2015 excluindo os poços 20 e 27.

Tabela 11 - Dados e resultados do processo de validação

Tabela 12 - Estatísticas do processo de sintonia utilizando poços de 2016. 
"Conforme a complexidade de um sistema aumenta, a habilidade humana de fazer declarações precisas e significativas sobre o seu comportamento diminui, até alcançar um limite além do qual precisão e relevância tornam-se características mutuamente exclusivas"

Princípio da Incompatibilidade - Lotfali AskarZadeh 


\section{1 \\ Introdução}

\section{1.}

\section{Considerações Iniciais}

A previsão de produção é uma das etapas mais críticas do processo de planejamento de curto prazo das empresas de exploração e produção de petróleo (E\&P). O volume de petróleo que será produzido, denominado meta de produção, influencia diretamente todas as ações das empresas e tem crítico impacto em relação ao mercado.

A qualidade do processo de previsão de produção mostra-se relevante sob diversos aspectos. Inicialmente, pela necessidade de planejamento de curto prazo dos recursos físicos das empresas que dão suporte às atividades do $\mathrm{E} \& \mathrm{P}$, como navios de offloading, sondas, embarcações de suporte, e na programação de carga das refinarias para embasar as negociações de importação e exportação de petróleo. Em segundo lugar, as previsões de produção são utilizadas no planejamento de curto e médio prazo das companhias como uma variável de extremo impacto nos resultados e, consequentemente, financiabilidade. Com isso, ressalta-se a necessidade de se conhecer os riscos da previsão de produção (CASTRO, et al., 2010).

Sabe-se que, no curto prazo, além das incertezas geológicas de reservatório, a previsão de produção é influenciada fortemente por incertezas gerenciáveis, relacionadas à capacidade operacional da empresa.

O conceito de incerteza e risco varia um pouco nas diversas publicações especializadas e, por isso, torna-se necessário definir como estes conceitos são utilizados neste trabalho. Adota-se a definição de COSTA (2003) onde: incerteza é a grandeza associada à falta de conhecimento de atributos cujos valores não se pode obter de maneira precisa ou para o qual exista dúvida; e risco está relacionado com a estimativa probabilística das previsões de produção com incerteza, sendo representado através de uma distribuição de probabilidade e estando diretamente associado a uma tomada de decisão. O risco está, portanto, associado às incertezas geológicas de reservatório e operacionais. 


\section{2. \\ Motivação}

Em condições de incerteza, uma alternativa para análise de risco é a utilização da simulação estocástica, que visa construir uma distribuição de probabilidade para a variável que se está analisando, possibilitando avaliar o risco (probabilidade) do valor assumido por esta ser inferior a um determinado limite estabelecido.

Com este objetivo, CASTRO, et al. (2010) propôs um simulador para avaliar o risco da previsão de produção considerando quatro dimensões de variáveis de entrada, a saber: Potencial Produtivo Instalado, Entrada de Novos Poços, Parada Programada para Manutenção e Eficiência Operacional. O objetivo do simulador é identificar, avaliar e quantificar de forma antecipada as incertezas presentes no ambiente para suportar o processo de determinação da meta de produção para o horizonte de doze meses.

Identificou-se que este simulador pode ser aprimorado no que tange à modelagem do comportamento das suas variáveis de entrada, dado que estas afetam diretamente a precisão e a interpretabilidade do modelo.

Neste contexto, este trabalho constitui um esforço para elevar a acurácia do resultado da simulação, sob a hipótese de que a melhoria na modelagem das variáveis de entrada resulta na elevação da precisão final da simulação. Foco não está apensas na precisão, mais também no encadeamento lógico para construção do resultado a fim garantir a sua interpretabilidade, dado que resultados interpretáveis dão aos decisores mais segurança na tomada de decisão.

Tal esforço é justificado pela busca por melhores e mais bem fundamentadas previsões de produção desencadeada em função do novo cenário de preços baixos de petróleo que tem tornado o processo de tomada de decisão cada vez mais crítico para as empresas de E\&P.

\section{3.}

\section{Objetivo}

Dentre as dimensões do modelo de simulação, a entrada de novos poços é uma das variáveis mais sensíveis ao resultado final da previsão de produção - 
especialmente quando os poços são altamente produtivos - por apresentar grande incerteza.

Desse modo, este trabalho tem por objetivo desenvolver um sistema de inferência fuzzy para aprimorar a modelagem da dimensão Entrada de Novos Poços. Especificamente, o sistema prevê a variável Data de Entrada em produção de poços de petróleo marítimos de alta produtividade. O sistema é concebido de forma que possa ser integrado ao modelo de simulação estocástica de análise de risco da previsão de produção de petróleo visando aumentar a precisão da previsão.

$\mathrm{Na}$ literatura existente o efeito da entrada de poços na previsão de produção ainda não foi tratado, conferindo assim a este trabalho um caráter inédito.

Além disto, complementarmente, este trabalho busca estabelecer uma metodologia para a previsão de produção visando a formalização do processo de análise de risco da previsão da produção de petróleo, sobretudo no que tange à modelagem das variáveis de entrada do modelo de simulação estocástica, garantindo a sua rastreabilidade, repetitividade e precisão.

\section{4 . \\ Descrição do Trabalho}

O desenvolvimento deste trabalho se inicia com uma vasta revisão bibliográfica acerca da análise de risco e decisão na atividade de E\&P, suas características e principais ferramentas utilizadas para o tratamento das incertezas. O entendimento do contexto, relacionamentos lógicos entre as variáveis de entrada e a previsão da produção do modelo de simulação estocástica a ser investigado foi o segundo passo da sequência metodológica empregada. A partir desta fase, os principais pontos passíveis de melhoria foram identificados e discutidos para que fosse possível a proposição de novas alternativas para modelagem das variáveis de entrada do modelo e estruturação do processo de previsão e análise de risco - nesta fase iniciou-se o desenvolvimento da metodologia para modelagem das variáveis de entrada do modelo.

Dada a sensibilidade da variável Data de Entrada da dimensão Entrada de Novos Poços no resultado final da previsão, passou-se a entender o mecanismo de previsão da data de entrada de poços novos em produção e a investigar as 
variáveis que impactam nesta previsão. Feito isto, iniciou-se a busca de ferramentas para estruturar o problema e prever matematicamente a data de entrada de poços novos em produção e assim se chegou à teoria fuzzy. Através de um estudo aprofundado sobre os conjuntos e a lógica fuzzy, concluiu-se que os sistemas de inferência fuzzy linguísticos seriam aplicáveis como uma nova alternativa metodológica para o problema.

De posse das variáveis e da ferramenta, iniciou-se um processo cíclico de construção de um sistema de inferência fuzzy: modelagem, testes, análise de resultados e ajustes na modelagem. Por fim, foi feito o acoplamento do sistema de inferência ao modelo de simulação estocástica e foi avaliado o seu impacto no resultado final da previsão.

\section{5 .}

\section{Organização da Dissertação}

Este trabalho está organizado em sete capítulos, iniciados por esta Introdução, que aborda as considerações iniciais, motivação, objetivo e descrição do trabalho.

O Capítulo 2 posiciona o leitor no contexto geral da análise de decisão e risco na atividade de E\&P no qual o modelo proposto neste estudo está inserido. É destacado como é feito o tratamento da estocasticidade em problemas típicos do setor para que através desta exposição seja possível avaliar e justificar a contribuição que o presente trabalho propõe. Em seguida, são apresentadas a lógica fuzzy e suas aplicações disponíveis na literatura, enfatizando modelos linguísticos e aplicações em E\&P.

A seguir, no Capítulo 3, o modelo de simulação estocástica utilizado para avaliação do risco da previsão de produção é descrito em detalhes, a fim de expor ao leitor a relevância e a aplicação do sistema de inferência fuzzy proposto neste trabalho. Neste capítulo, é concebida uma metodologia para a previsão de produção que incorpora as melhorias e recomendações identificadas ao longo do desenvolvimento deste trabalho visando a formalização do processo de análise de risco da previsão da produção de petróleo garantindo a sua rastreabilidade, repetitividade e precisão. 
No Capítulo 4 a modelagem do início da produção de poços de petróleo através de um sistema de inferência fuzzy é apresentada pontuando os conceitos aplicados e exemplificando a dinâmica do processo de inferência.

No Capítulo 5 é exposto o processo para sintonia e validação do sistema de inferência fuzzy e apresenta os resultados obtidos. Em seguida estes resultados são aplicados à metodologia de previsão de petróleo com o objetivo de avaliar o efeito da utilização do sistema de inferência fuzzy no resultado final da previsão. Por fim, é feita uma discussão sobre o valor do ganho de precisão na previsão de produção para o estabelecimento da meta de produção.

O Capítulo 6 é dedicado às considerações finais e perspectivas de continuação da pesquisa. Uma breve revisão do trabalho destaca as contribuições do mesmo.

Finalmente, são listadas as Referências Bibliográficas utilizadas, seguidas do Apêndice do trabalho. 


\section{2 \\ Revisão Bibliográfica}

Esta revisão bibliográfica tem como objetivo situar o leitor no contexto geral da análise de decisão e risco na atividade de E\&P ao qual o sistema de inferência fuzzy proposto neste estudo está associado. É abordado como é feito o tratamento da estocasticidade em problemas típicos do setor para que seja possível justificar a contribuição do presente trabalho. São apresentadas também a lógica fuzzy e suas aplicações disponíveis na literatura, enfatizando modelos linguísticos e aplicações em E\&P.

\section{1.}

\section{Análise de Decisão e Risco na Exploração e Produção de Petróleo}

Os reservatórios de petróleo são formações complexas resultantes de processos geológicos deposicionais ao longo de milhões de anos e, assim, qualquer descrição que se faça do reservatório terá uma boa dose de arbitrariedade. A despeito de todos os dados disponíveis, existem infinitas descrições possíveis do meio onde o petróleo está contido. Uma vez que é possível gerar infinitas realizações para um mesmo conjunto de dados, o problema deixa de ser determinístico para ser probabilístico. O enfoque probabilístico deve ser também aplicado na integração das diversas incertezas presentes e que devem ser consideradas: propriedades dos reservatórios e fluidos, características operacionais, econômicas e tecnológicas (COSTA, 2003). Neste enfoque probabilístico a estocasticidade das variáveis pode ser considerada um risco e a estimativa da realização destas variáveis caracteriza, portanto, análise de risco.

NEWENDORP \& SCHUYLER (2000) ponderam que o ganho da análise de decisão e risco não está relacionado à redução ou eliminação do risco, mas em possibilitar o conhecimento detalhado das incertezas envolvidas, a fim de possibilitar a construção de estratégias para minimizar a exposição ao risco. A compreensão desta vantagem competitiva tornou as aplicações de análise de risco, antes restritas à academia, ferramentas fundamentais para a indústria.

SUSLICK \& SCHIOZER (2004) vão além na aplicação da análise de risco na indústria e pontuam que a análise de risco provê: (1) meios para conduzir decisões altamente complexas em diversos estágios da exploração e produção de 
petróleo que possuem múltiplos objetivos e alto grau de incerteza; (2) uma abordagem para lidar com tradeoffs e preferência dos stakeholders no processo de tomada de decisão; (3) uma sistemática e uma maneira compreensiva para considerar todos os fatores relevantes para o processo decisório no upstream.

Um projeto típico de E\&P é composto de quatro fases: Exploração, Avaliação, Desenvolvimento e Produção. Estas fases são diferenciadas basicamente pela quantidade de informação disponível e o nível de risco associado a cada uma delas. Como as informações são restritas e insuficientes, o risco é máximo na fase de Exploração, mas à medida em que são feitos levantamentos sísmicos, poços são perfurados, e é desenvolvido o conhecimento sobre a área, o nível de risco é reduzido até que seja mínimo, nunca zero, na fase de Produção (Figura 1) (HIGGINS, 1993). A seguir as principais abordagens de análise de risco aplicadas em cada fase de um projeto de E\&P são detalhadas.

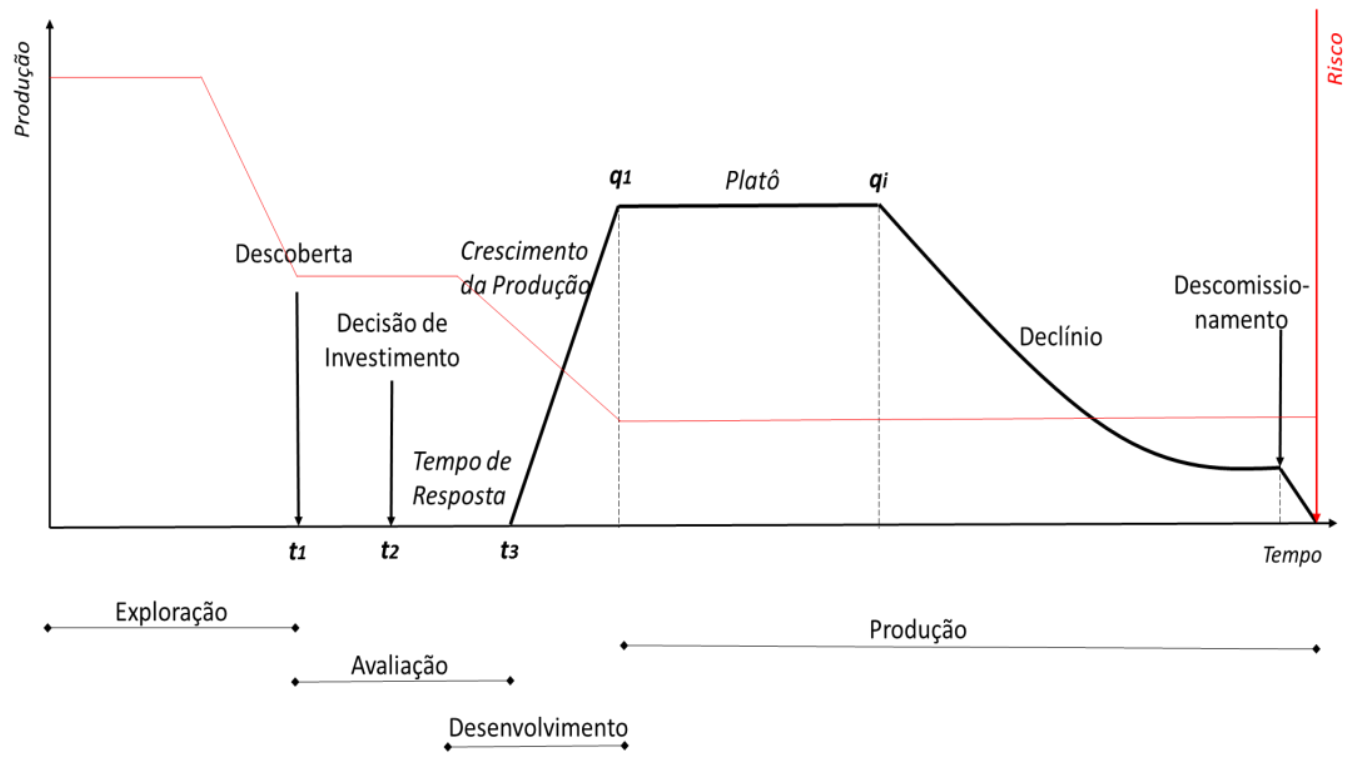

Figura 1 - Principais variáveis incertas da curva de produção de petróleo de acordo com as fases de um projeto de E\&P. Fonte: Adaptado de (JAKOBSSON, et al., 2014) e (HIGGINS, 1993).

A Exploração é a primeira fase de um projeto de E\&P e se caracteriza como um conjunto de pesquisas, operações e sondagem com o objetivo de identificar jazidas de petróleo (THOMAS, et al., 2001). Nesta fase, o conhecimento do prospecto que está sendo explorado é mínimo e as incertezas estão relacionadas à existência ou não de uma acumulação e à sua economicidade (LERCHE \& MACKAY, 1999). 
Segundo NEWENDORP \& SCHUYLER (2000), na fase de Exploração as análises de risco estão, preponderantemente, relacionadas às aplicações de geoestatística associadas aos estudos geológicos e geofísicos para quantificar se os requisitos para a acumulação de petróleo estão presentes, i.e., existência de rocha geradora, migração, selo ou trapa, rocha reservatório e sincronismo (THOMAS, et al., 2001).

NEWENDORP \& SCHUYLER (2000), nos capítulos 3 e 4, cobrem minuciosamente o conceito de valor monetário esperado (VME) utilizando o clássico exemplo do jogo da perfuração (wildcat drilling) estruturando as análises através de árvores de decisão.

ROSE (1992) estrutura a estimativa de sucesso geológico utilizando também os conceitos de VME e árvores de decisão e destaca que é necessário considerar o comportamento do tomador de decisão diante do risco. O tomador de decisão pode escolher uma alternativa de menor VME ou de VME negativo, estando assim "apostando contra a banca" (gambling). Desta forma, a Teoria da Preferência provê a base para construção de funções de utilidade aplicadas à preferência ao risco do tomador de decisão, a fim de permitir uma análise de decisão mais precisa por não apenas considerar o VME e árvores de decisão, mas também o perfil do decisor.

No contexto da Teoria da Preferência destacam-se (COZZOLINO, 1977), (LERCHE \& MACKAY, 1999) e a aplicação da Metodologia de Utilidade MultiAtributo (MAUT) integrando evolução tecnológica, restrições ambientais e performance financeira de projetos de E\&P em águas ultra profundas feita por NEPOMUCENO, et al. (1999). A Exploração se encerra com a Descoberta (ponto $\mathrm{t}_{1}$ na Figura 1) ou com venda/devolução do prospecto.

À medida em que o nível de informação aumenta com a evidenciação da Descoberta através da perfuração de um poço descobridor (wildcat well), as incertezas quanto ao sucesso geológico são mitigadas e, consequentemente, as incertezas relacionadas ao fator de recuperação aumentam (SUSLICK \& SCHIOZER, 2004).

Durante a fase de Avaliação, a complexidade da análise se intensifica devido ao número de variáveis que devem ser consideradas, numa fase onde o conhecimento do campo ainda é reduzido, e há forte dependência da estratégia de produção. Nesta fase é feita uma avaliação do reservatório visando responder se a 
acumulação é viável economicamente ou não, e então é tomada a Decisão de Investimento (tempo $t_{2}$ na Figura 1). Considerar-se-á a análise de risco desta fase sob dois aspectos: volume de produção e análise de investimento.

No aspecto volume de produção, a utilização da simulação numérica de fluxo de reservatório neste estágio é fundamental por permitir a integração entre dados relativos à caracterização rocha-fluido e fluxo de fluidos. A grande vantagem da utilização da simulação numérica de fluxo nesta fase é a incorporação da dependência entre as incertezas do volume in situ e sua distribuição, com incertezas relativas às heterogeneidades do reservatório e ao fluxo de fluidos, que estão intimamente associadas. A simulação numérica de fluxo torna possível a obtenção do risco de desempenho, em variáveis como volumes produzidos, vazões, etc., em qualquer período de tempo. Parâmetros de produção e operação do campo, como datas de aberturas e fechamentos de poços, restrições de produção, vazões limites e recompletações, podem ser incorporados tornando as previsões mais realistas (COSTA, 2003).

No aspecto análise de investimento, destaca-se o uso da abordagem de Opções Reais (ROA) em complemento aos conceitos tradicionais de Descounted Cash Flow (DCF) e VPL nas análises econômicas. A ROA permite considerar a flexibilidade gerencial (a “opção"), característica da atividade de E\&P, na análise de investimento. A ROA considera a realização ou não de um cenário no resultado da avaliação econômica de um ativo. Ver DIAS $(2004,2015)$ para exemplos dos ganhos da ROA em relação ao uso de DCF e VPL em projetos de E\&P.

Apesar da ROA estar sendo descrita na fase de Avaliação, esta abordagem é utilizada em todas as fases de um projeto de E\&P. Conforme detalhado por DIAS (2004, 2015) as opções são intrínsecas à atividade de E\&P. Durante a fase de Exploração os decisores lidam com a opção de perfurar ou não um poço exploratório (wildcat drilling). No caso de sucesso exploratório (descoberta de óleo/gás) a empresa tem a opção de investir na fase de Avaliação através de poços delimitadores e sísmicas 3D adicionais com o objetivo de obter informações a respeito do volume e qualidade da reserva e redução das incertezas técnicas. Quando a incerteza remanescente não justifica investimentos adicionais em informação, a empresa tem a opção decidir por investir em desenvolver a reserva (i.e. iniciar a fase de Desenvolvimento), devolver a concessão para a agência governamental ou esperar por melhores condições macroeconômicas. Finalmente, 
durante a fase de Produção, a empresa tem a opção de expandir a produção (e.g. perfuração de poços adicionais), a opção de suspensão temporária da produção ou até a opção de abandonar a concessão. Esta visão de opção torna valiosa a quantificação do Valor da Informação (VoI) e do Valor da Flexibilidade (VoF) para a concepção e avaliação dos projetos.

Para SUSLICK \& SCHIOZER (2004), à medida em que o número de projetos e a complexidade cresce na indústria de E\&P são utilizadas técnicas baseadas na Teoria dos Mercados e Eficiência de Portfólio propostas por Markowitz em 1952 a fim de obter um balanço ótimo entre valor e risco.

$\mathrm{Na}$ fase de Desenvolvimento o primeiro aspecto a ser considerado é o Tempo de Resposta ( $t_{2}-t_{3}$ na Figura 1$)$ da organização para o início do Crescimento da Produção (tempo $t_{3}$, na Figura 1) dado que a decisão de investimento foi tomada. Nesta fase, as análises de risco estão relacionadas ao gerenciamento do projeto e, sob a ótica da produção, aos programas de perfuração de poços como visto em NEWENDORP \& SCHUYLER (2000).

WILLIAMSON, et al. (2006) reúnem as aplicações de previsão de poços e as classifica de maneira hierárquica considerando como objetivos principais a previsão de fluxo de caixa, custo de projeto e, principalmente, produção (Figura 2). Destaca-se neste trabalho a influência do elevado grau de incerteza do cronograma dos poços na previsão de produção.

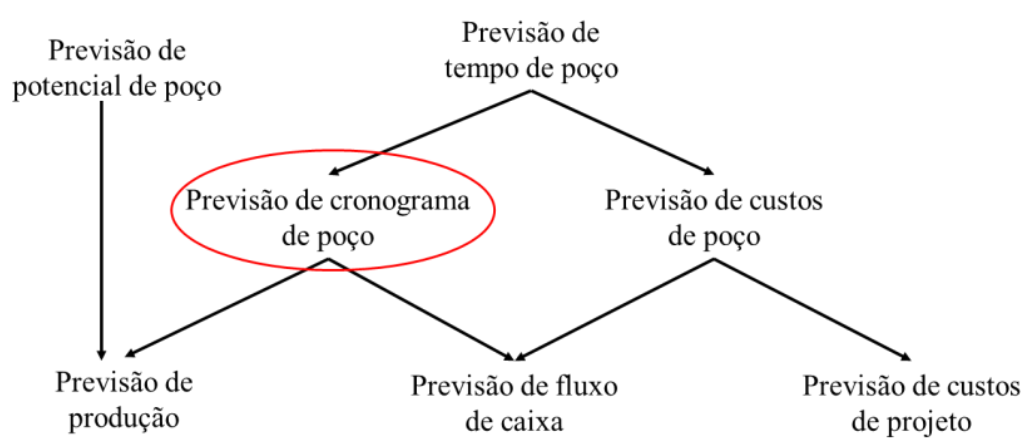

Figura 2 - Hierarquia da análise de risco aplicada a poços de petróleo. Fonte: Adaptado de (WILLIAMSON, et al., 2006).

$\mathrm{Na}$ fase final, Produção, a principal pergunta a ser respondida pelos modelos de análise de risco é o quanto de petróleo será produzido em um determinado período de tempo. As análises de risco de produção se diferenciam de acordo com 
o horizonte de previsão e estratégia de abordagem. Dentro deste contexto, JAKOBSSON, et al. (2014) diferenciam as modelagens de acordo com a sua abordagem, a saber:

a) Bottom-up - modelos estruturados para analisar as unidades básicas de um portfólio de produção (reservatório, poço ou campo, por exemplo) e obter a previsão da produção total geral a partir da soma destas unidades;

b) Top-down - modelos que realizam a previsão de maneira agregada através de alguma forma de extrapolação, análise de portfólio ou modelos macroeconômicos, como feito por FIÉVET, et al. (2015) em uma aplicação no Reino Unido e na Noruega.

De acordo com as etapas de um projeto de E\&P, JAKOBSSON, et al. (2014) e MURTHA (2015) estilizam o comportamento da produção de um campo e resumem que as principais variáveis incertas a serem obtidas pelos modelos são:

a) Tempo de Resposta $\left(t_{2}-t_{3}\right)$ - tempo entre a decisão de investimento e o início da produção (já discutida na fase de Desenvolvimento);

b) Crescimento da Produção $\left(\mathrm{t}_{3}\right)$ - período onde a produção parte de zero até o Platô à medida em que os poços previstos entram em produção. Forte influência da data de entrada dos poços;

c) Platô $\left(\mathrm{q}_{1}\right)$ - período onde a produção é máxima e constante, estando restrita à capacidade da instalação;

d) Declínio $\left(\mathrm{q}_{\mathrm{i}}\right)$ - período onde a produção decresce gradualmente ou devido à redução de pressão do reservatório e/ou ao aumento da produção de água/gás. $\mathrm{O}$ Declínio continua até o descomissionamento, conforme indicado na Figura 1. 
JENSEN (1998) trata a análise de risco da produção de maneira similar, porém ao prever a produção em campos maduros (i.e. campos em produção já há algum tempo) considera aspectos operacionais como a regularidade da produção e o tempo de vida de instalações de produção.

Outro ponto de destaque a ser considerado na etapa de produção e que vem sendo intensamente discutida na indústria e na academia é o descomissionamento dos projetos de $\mathrm{E} \& \mathrm{P}$, devido às incertezas técnicas e regulatórias para realização destas operações.

Nota-se, portanto, que em horizontes curtos de previsão em portfólios de $\mathrm{E} \& \mathrm{P}$, projetos em fase exploratória inicial - quando ainda não houve a decisão de investimento - dificilmente influenciarão a curva de produção, de forma que as variáveis aleatórias a serem consideradas prioritariamente são Tempo de Resposta, Crescimento da Produção, Platô, Declínio e Descomissionamento.

O escopo deste trabalho é avaliar o efeito das variações de cronograma da entrada de poços, Tempo de Resposta (primeiro poço a entrar em produção) e o Crescimento da Produção (entrada dos demais poços planejados) na previsão de produção de petróleo. Especificamente, o sistema de inferência fuzzy proposto tem como saída a previsão da data do início da produção dos poços (momento $t_{3}$ da Figura 1, caso seja o primeiro poço do projeto).

O efeito das variações de cronograma da entrada de poços na previsão de produção é um problema ainda não tratado na literatura, de forma que este trabalho apresenta um caráter inédito.

\section{2.}

\section{Tratamento das Incertezas}

A tentativa de modelagem de uma situação real recai na dificuldade de definir quais valores usar para as variáveis de entrada. Esta dificuldade advém do processo físico real em si, quando os seus parâmetros não são constantes, mas variam seguindo um determinado comportamento. A incerteza das variáveis de entrada é modelada tratando-as como variáveis estocásticas (MCKAY, et al., 1979).

As atividades de E\&P são, por definição, complexas, e podem ser caracterizadas por vários pontos de vista, com um grande número de parâmetros. 
Além da complexidade intrínseca dos reservatórios e das flutuações econômicas, os estudos sempre carregam um nível de incertezas, que podem ser consideradas como medidores desconhecidos para um imperfeito conhecimento do reservatório e da sua viabilidade econômica. Logo, o desconhecimento e a complexidade das incertezas geológicas e econômicas conduzem a uma abordagem estocástica.

Nos últimos anos, a indústria do petróleo tem demonstrado um notável interesse técnico e acadêmico em considerar as incertezas na avaliação de projetos de E\&P. Busca-se integrar, através de formulações variadas, as diversas informações oriundas das áreas de geofísica, geologia e engenharia de modo a compor um cenário esperado, ao invés de uma única visão determinística do projeto (COSTA, 2003).

A incorporação das incertezas se dá de diferentes formas na atividade de E\&P, dentre as quais destaca-se o uso sistemático da Teoria da Probabilidade, Simulação Estocástica e Planejamento de Experimentos.

\subsection{1. Uso Sistemático da Teoria da Probabilidade}

A abordagem estocástica voltada para análise de decisão e risco foi formalmente aplicada à indústria de petróleo pela primeira vez em 1956 através do estudo de viabilidade de campos de petróleo realizado pelo economista francês Maurice Allais. Em seu estudo, este analisou aspectos econômicos e geológicos de cada um dos estágios da exploração através da Teoria de Probabilidade (SUSLICK \& SCHIOZER, 2004).

Ainda segundo SUSLICK \& SCHIOZER (2004), durante este período, houve várias tentativas de definir a probabilidade nos diversos estágios da exploração (DREW, 1967; HARBAUGH, et al., 1977; HARBAUGH, 1984; HARRIS, 1984, 1990; KAUFMAN, 1963; KRUMBEIN, \& GRAYBILL, 1965) e o início da incorporação da análise de risco nas avaliações de reservas de óleo e gás feitas pelas agências governamentais (e.g. U.S. Geological Survey, Institut Francais du Petroles).

MEGILL (1977); NEWENDORP (1975); ROSE (1887 e 1992) abordam estas questões e também comentam extensivamente a análise de decisão considerando incertezas no processo. Conforme já citado na seção anterior, 
ferramentas como teoria da probabilidade e árvore de decisão são utilizadas. A integração com o modelo econômico foi introduzida na análise de decisão inicialmente na exploração e para casos onde a incerteza era caracterizada por distribuição de probabilidade dos parâmetros envolvidos. Tais autores apresentaram importantes conceitos mostrando que a análise de risco é um fundamental componente da análise de decisão.

\subsection{2.}

\section{Simulação Estocástica}

A simulação estocástica está baseada em um modelo, i.e., uma ou mais equações, suas premissas e as relações lógicas entre os parâmetros das equações (MURTHA, 1997). Como ilustração, considere o exemplo de MURTHA (1997) do modelo volumétrico para o Oil in Place, $N$, em termos de Área, A; Net Pay, $h$; Porosidade, $\varphi$, Saturação de Água $S_{w}$; Fator Volumétrico da Formação $B_{o}$ (equação 1).

$$
N=7,758 \operatorname{Ah} \varphi\left(1-S_{w}\right) / B_{0}
$$

Assuma $A, h, \varphi, S_{w}$ e $B_{o}$ como variáveis de entrada e $N$ como a variável de saída. Uma vez especificado os valores de cada uma das variáveis de entrada, é possível calcular o valor da variável de saída. Assumido cada parâmetro como uma variável aleatória, cada rodada da simulação estocástica consiste em selecionar um valor para cada variável de entrada de acordo com as funções densidade de probabilidade que as representam e calcular a variável de saída. Assim, considerando que os parâmetros da equação (1) sejam representados através das distribuições conforme a Figura 3, uma seleção aleatória de cada um dos parâmetros poderia resultar em $\mathrm{A}=3,127 ; \mathrm{h}=48 ; \varphi=18 \% ; S_{w}=43 \%$ e $B_{o}=$ 1,42. Esta combinação representa uma realização particular do prospecto e, considerando a equação (1), resultaria em um volume de Oil in Place de 63,5 milhões de barris. 


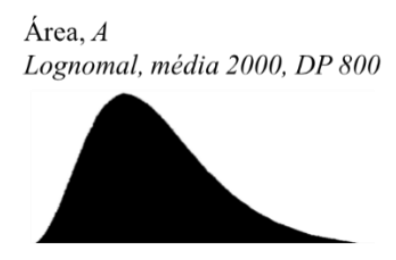

Fator volumétrico da formação $B_{o}$ Normal, média 1,34, DP 0,02

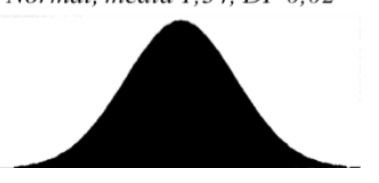

Net Pay, $h$

Normal, média 45, DP 3

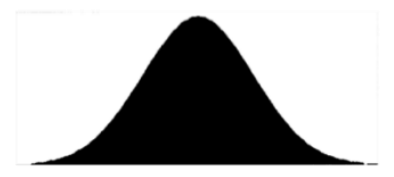

Saturação de Água $S_{w}$

Triangular $0,20,0,30,0,45$

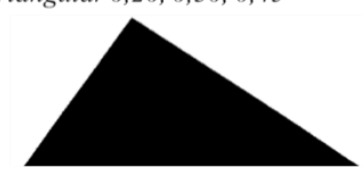

Porosidade, $\varphi$

Normal, média 0,14, DP 0,02

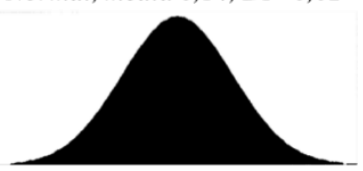

Figura 3 - Distribuições de probabilidade das variáveis de entrada do modelo para Oil in Place. Fonte: Adaptado de (MURTHA, 1997).

A simulação é uma sucessão de centenas ou milhares de repetidas rodadas, onde os valores possíveis da variável de entrada são sorteados. Ao final do processo todos os valores da variável de saída são agrupados em um histograma ou numa função de distribuição acumulada (MURTHA, 1997). A Figura 4 mostra a análise de sensibilidade e o histograma da variável de saída deste modelo.

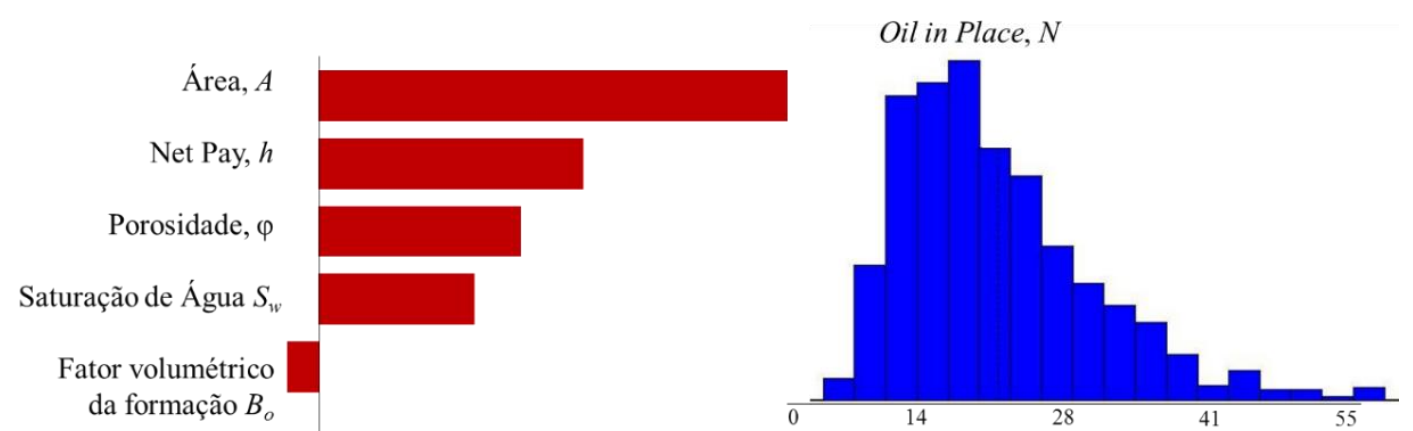

Figura 4 - Análise de sensibilidade do modelo e distribuição de probabilidade da variável de saída Oil in Place. Fonte: Adaptado de (MURTHA, 1997).

O resultado da simulação estocástica contém mais informações sobre os aspetos que podem influenciar a saída, quando comparado com as abordagens de geração de cenários e a determinística. O modelo e as suas premissas são destacadas na simulação, permitindo ao usuário uma análise quantitativa, a inclusão de dependências e incorporação de dados históricos.

O uso da simulação estocástica permite responder perguntas, tais como: (1) "Qual é o volume mais provável da acumulação?"; (2) "Qual alternativa é mais ariscada?"; (3) "Alguma alternativa domina as outras?" (4) "Qual a probabilidade 
de não atingir a taxa de produção esperada?"; (5) "Qual o resultado financeiro mais provável? ”

A análise de sensibilidade viabilizada pela simulação estocástica revela quais parâmetros são chave para o resultado, o que ajuda na quantificação do valor da informação adicional. No contexto do exemplo de (MURTHA, 1997) (Figura 4) poderia ser concluído que, como o resultado do modelo é muito sensível à área $A$, é necessário realizar mais estudos geológicos e geofísicos para melhor delimitar o reservatório e assim tornar possível a tomada de decisão.

Matematicamente a simulação estocástica está baseada na seleção aleatória de valores das variáveis de entrada. Dentre as técnicas de amostragem existentes destacam-se o método de Monte Carlo e o Hipercubo Latino, sendo esta segunda mais eficiente (MCKAY, et al., 1979).

Genericamente e para distribuições contínuas, o método de amostragem de Monte Carlo consiste em gerar uma variável aleatória $U$ uniformemente distribuída entre 0 e 1, aplicar $U$ à função inversa da função acumulada para encontrar o valor de $X$ (equação 2 ).

$$
X=F^{-1}(U) ; \quad U \sim \operatorname{unf}(0,1)
$$

Este algoritmo é conhecido como Transformação Inversa e é bastante eficiente na geração de variáveis aleatórias exponenciais. Ver ROSS (2013) para detalhes e outras técnicas aplicadas para outros tipos de variáveis aleatórias contínuas ou discretas.

As técnicas de amostragem de Monte Carlo são inteiramente aleatórias, i.e, qualquer valor amostrado de $U$ pode resultar em qualquer valor de $X$. As amostras, obviamente, têm maior probabilidade de serem amostradas em áreas da distribuição que tenham maior probabilidade de ocorrência. Cada amostra Monte Carlo usa um novo valor aleatório entre 0 e 1, com iterações suficientes, a amostragem de Monte Carlo recria as distribuições das variáveis de entrada através de amostragem. Um problema de agrupamento ocorre quando um número pequeno de iterações é usado, fazendo com que a distribuição de probabilidade dos dados amostrados não convirja para a distribuição teórica (MCKAY, et al., 1979; MURTHA, 1997). 
A amostragem Hipercubo Latino é uma técnica que requer um menor número de iterações para representar precisamente distribuições de probabilidade quando comparada com o método de Monte Carlo. O diferencial do Hipercubo Latino é a estratificação do espaço das distribuições das variáveis de entrada. A estratificação divide a curva cumulativa em intervalos iguais da escala de probabilidade cumulativa ( 0 a 1 ), e o número de intervalos é igual ao número de iterações. Uma amostra é então selecionada aleatoriamente de cada intervalo da distribuição. A amostragem é forçada a representar valores em cada intervalo e assim recria a distribuição de probabilidade. Segundo MCKAY, et al. (1979) quando algumas condições de monotonicidade são satisfeitas, o Hipercubo Latino melhora os métodos de amostragem simples e os autores recomendam o seu uso para seleção de valores de variáveis de entrada na simulação estocástica.

\subsubsection{1.}

\section{Simulação Estocástica de Reservatórios}

Métodos determinísticos tradicionalmente têm sido usados em estudos de simulação numérica. Os parâmetros do reservatório são calculados para obter valores representativos que permitam a avaliação do reservatório e a previsão de produção. Esta abordagem não é satisfatória para previsão de produção quando a incerteza é alta. O conceito de simulação estocástica de reservatório foi introduzido para lidar com este problema da incerteza.

A modelagem estocástica simula a performance do reservatório através do uso de distribuições de probabilidade para representar as variáveis de entrada. Funções de probabilidade são construídas a partir de todos os dados geológicos de reservatórios e, consequentemente, incorporam os efeitos das heterogeneidades do reservatório, erros de medição e incerteza de reservatório. As equações diferenciais parciais que representam o fluxo de calor e os balanços de massa são então integradas ao intervalo da distribuição de entrada para obter a distribuição da produção de fluido (DING, et al., 1992).

DING, et al. (1992) aplica a simulação estocástica associada à simulação numérica de reservatório para estimar o potencial de recuperação de petróleo da técnica de injeção cíclica de vapor e, através dos resultados obtidos, recomenda o uso da técnica pela possibilidade de estabelecer a performance mais provável do 
reservatório, a partir da medida de sua incerteza e análise de sensibilidade das variáveis de entrada no resultado.

Inicialmente em seu estudo, DING, et al. (1992) compara diferentes métodos de amostragem e chega à mesma conclusão de MCKAY, et al. (1979) para a aplicação em simulação de reservatórios, devido à capacidade da amostragem por Hipercubo Latino reduzir dramaticamente o número de simulação. O grande número de variáveis consideradas na simulação estocástica de reservatório torna o esforço computacional um aspecto fundamental para a viabilidade desta aplicação.

COSTA (2003) alerta que, dependendo do número de realizações, da complexidade do problema de fluxo e do número de células da malha, o processamento de todas as realizações através do simulador de fluxo pode consumir elevado tempo de processamento e a necessidade de maiores recursos computacionais. Dessa maneira, a necessidade de redução das simulações e simplificações no processo torna-se clara para a viabilidade das análises.

Cabe ressaltar a necessidade de técnicas que conduzam a este objetivo. Destacam-se: (1) a definição do melhor método de recuperação usando apenas três realizações geológicas (pessimista, provável e otimista) exemplificada por STRIPE, et al. (1993); (2) o uso de um simulador rápido na utilização de uma malha grosseira ou de apenas uma seção do reservatório para a simulação de um elevado número de modelos do reservatório seguido de simulação estocástica proposta por BALLIN, et al. (1993); (3) metodologia de CAMPOZANA \& BALLIN (1998) para a obtenção da incerteza na previsão de produção, que consiste em selecionar as principais variáveis incertas, através de conhecimento de especialista, levando em consideração os valores altos, baixos e prováveis das mesmas. Uma vez definido o intervalo para cada variável, define-se o caso base para a simulação de fluxo. A metodologia propõe a construção da distribuição de probabilidade do fator de recuperação. Por fim, conhecendo-se a distribuição de probabilidade do volume original de hidrocarbonetos, obtém-se o risco do volume produzido por Monte Carlo.

Segundo COSTA (2003), para reservatórios onde as heterogeneidades podem ser resumidas por um número único, simulação estocástica pode ser aplicada com algum método de otimização para modelar a incerteza e tomar decisões. Um exemplo é a representação da incerteza por distribuição de 
probabilidade pelo coeficiente Dykstra-Parson e uso da amostragem de Monte Carlo com o método de otimização de Newton-Greenstadt juntos ao modelo de fluxo analítico para selecionar o melhor parâmetro operacional para projetos com a utilização de surfactantes.

\subsection{3.}

\section{Planejamento de Experimentos}

Outro conceito que tem sido aplicado na avaliação de incerteza de parâmetros de reservatórios é o do planejamento estatístico de experimentos. Graças ao crescimento dos recursos computacionais, a simulação de reservatório está se tornando cada vez mais complexa. Assim, cada vez mais parâmetros incertos podem ser introduzidos em estudos de reservatórios e com isso a dificuldade recai em identificar as variáveis relevantes em estimar os seus impactos na previsão de produção de petróleo. Para realizar estas operações de forma eficiente, o Planejamento de Experimentos permite projetar as simulações adequadamente (DEJEAN \& BLANC, 1999).

O Planejamento de Experimentos é uma técnica para maximizar a informação obtida de um número mínimo de experimentos. Com uma configuração bem projetada, a mesma informação obtida quando um parâmetro é variado de cada vez pode ser obtida com significativamente menos rodadas de simulação. As interações entre os vários parâmetros de entrada podem ser identificadas e estimadas com um desenho mais elaborado (DAMSLETH, et al., 1992).

O Planejamento de Experimentos foi introduzido pela primeira vez na engenharia de reservatórios no início dos anos noventa para estimar incertezas, encontrar esquemas de produção ótimos e, recentemente, para gerenciar a incerteza estrutural. Nas aplicações de reservatório, o processo físico é substituído pelo simulador de reservatório de modo que os experimentos são numéricos. Esta é a única diferença em relação às aplicações clássicas de Planejamento de Experimentos e toda a teoria se aplica com pequenas adaptações (DEJEAN \& BLANC, 1999).

Nota-se que o Planejamento de Experimentos é aplicado de forma integrada às técnicas de Superfície de Resposta e simulação estocástica com o objetivo de 
transferir diferentes fontes de incerteza na resposta de produção. O resultado final é uma estimativa de densidade da resposta condicionada ao modelo de regressão e às funções aleatórias atribuídas aos parâmetros (COSTA, 2003; DEJEAN \& BLANC, 1999). Para detalhes da aplicação integrada destas técnicas ver DEJEAN \& BLANC (1999).

Com o aprimoramento das aplicações de ferramentas de inteligência artificial, estas passaram a ser incorporadas na atividade de E\&P (BRASWELL, 2013; MOHAGHEGH, 2000a, 2000b, 2000c). Destacam-se as aplicações de sistemas híbridos ou Soft Computing no tratamento da estocasticidade (AMINZADEH, 2005; NIKRAVESH, 2003, 2004). Os quatro constituintes da Soft Computing são a Lógica fuzzy, Algoritmos Genéticos, Raciocínio Probabilístico e Redes Neurais. O seu progressivo sucesso na solução de problemas tem atraído adeptos com diferentes formas de concatenação de técnicas que anteriormente só eram utilizadas em separado. CASTRO (2005) destaca algumas formas de combinação das técnicas básicas, a saber: Sistemas NeuroFuzzy, Fuzzy Evolucionário, Sistemas Genéticos-Fuzzy, Redes Neuro-Genéticas, Redes Bayesian Genéticas.

Devida à natureza imprecisa e à complexidade do problema tratado neste estudo, a ferramenta selecionada foi a lógica fuzzy dada a sua capacidade em tratar a imprecisão intrínseca demonstrada por ZADEH (1965).

\section{3.}

\section{A Teoria Fuzzy}

Seres humanos são capazes de lidar com processos bastante complexos, baseados em informações imprecisas ou aproximadas. A estratégia adotada pelos operadores humanos é também de natureza imprecisa e geralmente possível de ser expressa em termos linguísticos. Segundo GOMIDE, et al (1995) a teoria de conjuntos fuzzy e os conceitos de lógica fuzzy podem ser utilizados para traduzir em termos matemáticos a informação imprecisa expressa por um conjunto de regras linguísticas. Se um operador humano for capaz de articular sua estratégia de ação como um conjunto de regras da forma $S E-E N T A ̃ O$, um algoritmo passível de ser implementado em computador pode ser construído. O resultado é um sistema de inferência baseado em regras, no qual a teoria de conjuntos fuzzy e a 
lógica fuzzy fornecem o ferramental matemático para se lidar com as tais regras linguísticas.

A teoria de conjuntos fuzzy foi concebida por ZADEH (1965) com o objetivo de fornecer um ferramental matemático para o tratamento de informações de caráter impreciso ou vago. A lógica fuzzy, baseada nessa teoria, foi inicialmente construída a partir dos conceitos já estabelecidos de lógica clássica; operadores foram definidos à semelhança dos tradicionalmente utilizados e outros foram introduzidos ao longo do tempo, muitas vezes por necessidades de caráter eminentemente prático (OLIVEIRA JR, 1999).

Ver APÊNDICE A para detalhes dos conceitos e fundamentos matemáticos da teoria de conjuntos fuzzy, lógica fuzzy e sistemas de inferência fuzzy.

\subsection{1. Modelagem Fuzzy}

Os sistemas de inferência fuzzy são uma das aplicações mais famosas da lógica fuzzy e da teoria dos conjuntos fuzzy. Isto é devido à sua característica dual que, por um lado, é capaz de lidar com conceitos linguísticos e por outro lado, são aproximadores universais capazes de realizar mapeamentos não-lineares entre entradas e saídas (GUILLAUME, 2001). Ao lidar com o tradeoff entre interpretabilidade e precisão, a modelagem de um sistema de inferência fuzzy, segundo GACTO, et al. (2011) pode ser dividida em duas diferentes áreas dependendo de qual é o requisito principal perseguido:

a) Modelagem Fuzzy Linguística: O principal objetivo é obter modelos fuzzy com boa interpretabilidade. Desenvolvido principalmente por meio de sistema do tipo Mamdani clássico;

b) Modelagem Fuzzy Precisa: O principal objetivo é obter modelos fuzzy com boa precisão. Desenvolvido principalmente por meio de sistema do tipo Takagi-Sugeno ou através de aproximadores, i.e, conjuntos fuzzy sem um significado associado. 
Modelagem Fuzzy Linguística é focada na modelagem da linguagem natural e contém regras construídas a partir da opinião de especialistas. Antes do surgimento da lógica fuzzy, a opinião de especialistas já era usada para construir sistemas especialistas para fins de modelagem. Esses sistemas especialistas eram baseados na lógica booleana clássica e não eram adequados para gerenciar a progressividade nos fenômenos (GUILLAUME, 2001). A lógica fuzzy permite que regras graduais sejam introduzidas em simuladores baseados em conhecimentos especializados.

A Modelagem Fuzzy Linguística oferece um elevado nível semântico e uma boa capacidade de generalização, porém, como descrito em ZHOU \& GAN (2008) pode, em alguns contextos, se tornar impraticável por apresentar precisão insuficiente nos resultados. O que aponta para as limitações humanas, particularmente, em relação à dificuldade para formalizar as interações em processos complexos.

A Modelagem Fuzzy Precisa é baseada em aprendizagem a partir de dados. Sua principal vantagem é a precisão numérica, enquanto um grande inconveniente é o seu comportamento "caixa preta", i.e., fornecem um modelo numérico, cujos coeficientes não têm significado para os especialistas. As redes neurais e aplicações híbridas tornaram-se muito populares neste contexto.

SUGENO \& KANG (1986) foram um dos primeiros a propor autoaprendizagem de sistemas de inferência fuzzy e abrir caminho para a Modelagem Fuzzy Precisa, projetados a partir de dados. Mesmo que as regras difusas, que são geradas automaticamente a partir de dados, sejam expressas da mesma forma que as regras de especialistas, geralmente há uma grande perda de semântica.

Aderente às características do sistema de inferência fuzzy proposto neste trabalho, serão descritos a seguir Modelos Fuzzy Linguísticos aplicados a problemas estrutural ou conceitualmente similares ao problema de previsão da entrada de novos poços em produção, dado que não foram localizadas na literatura estudo que tratassem desta situação-problema. 


\subsection{2.}

\section{Aplicação de Modelos Fuzzy Linguísticos}

Os Modelos Fuzzy Linguísticos são aplicados de diferentes formas de acordo com a situação problema em questão. Este tipo de modelagem tem se tornado frequente para a avaliação de risco de acidentes e segurança de processos industriais (GUIMARÃES \& LAPA, 2007; KANG, et al., 2017; REZAEI, et al., 2011, ZAHEDI, et al., 2011), dado a complexidade e a quantidade de variáveis a serem consideradas.

Em seu trabalho, GUIMARÃES \& LAPA (2007) utilizam um sistema de inferência fuzzy para avaliar o risco em sistemas de engenharia nuclear. O estudo busca entender o processo de envelhecimento de uma planta de geração de energia nuclear e como isto afeta a segurança da planta. O sistema é concebido como uma alternativa ao método de estabelecimento de prioridades do tradicional Failure Mode and Effect Analysis (FMEA) e, segundo os autores, os resultados obtidos utilizando sistema de inferência fuzzy são mais precisos.

KANG, et al. (2017) utiliza um sistema de inferência fuzzy para diagnosticar a performance de um aquecedor de água de alimentação de uma planta de geração de energia nuclear. O modelo tem como variáveis de entrada sete indicadores de controle de processo do aquecedor e gera como saída um diagnóstico da degradação subdividido em "cuidado" e "aviso".

REZAEI, et al. (2011) propõem a aplicação de um sistema de inferência fuzzy que gera como saída a distância em metros que fragmentos de rocha podem percorrer em função da explosão de dinamite em uma mina de ferro. O vôo de pedaços de rochas é um dos maiores riscos das explosões de dinamite em uma mina subterrânea, sendo o principal fator de acidentes. A inexatidão dos métodos empíricos de previsão deste fenômeno tem conduzido à utilização de novos métodos, tais como Modelos Fuzzy Linguísticos. Os resultados obtidos são superiores ao modelo estatístico.

ZAHEDI, et al. (2011) aplicam um Modelo Fuzzy Linguístico para reconhecer o mal desempenho de uma planta de dessalinização de petróleo cru a partir de conhecimento especializado e do manual de operação da planta. A partir da comparação dos resultados do modelo proposto com os dados da planta, verificou-se que o sistema proposto é capaz de resolver problemas de descontrole 
operacional rápida e precisamente. Os autores destacam que a aplicação protege o processo das emoções humanas, como stress e cansaço e sugerem o seu uso também no treinamento de operadores.

Outro conjunto de aplicações de sistemas de inferência fuzzy do tipo Mamdani com regras obtidas por especialidades estão no contexto da indústria extrativista de mineração. MONJEZI, et al. (2009) propõem um sistema de inferência fuzzy para prever a fragmentação das rochas causada pela explosão de dinamites em uma mina de ferro. A fragmentação das rochas é influenciada por vários parâmetros, como propriedades da massa rochosa, geometria de explosão e propriedades explosivas. Apesar de várias técnicas empíricas terem sido desenvolvidas para prever a fragmentação da rocha, estas são baseadas nos dados adquiridos a partir de diferentes operações, numa certa gama de tipos de rochas e não podem ser generalizadas para várias condições de solo. Além disso, segundo os autores, a consideração simultânea de todos os parâmetros pertinentes não é possível, especialmente quando alguns deles não são claramente compreendidos ou de difícil quantificação. O sistema de inferência fuzzy foi concebido a partir das relações conhecidas entres as variáveis e com base na opinião de especialistas, resultando em mais de 300 regras linguísticas. A comparação com um modelo estatístico demonstra a superioridade do modelo fuzzy.

CARRANZA \& HALE (2001) descrevem uma aplicação de inferência fuzzy para mapear o potencial de mineração de ouro. O sistema de inferência fuzzy do tipo Mamdani hierárquico foi construído com base na teoria geológica, de forma que a proximidade com as características geológicas foi traduzida em funções de pertinência com base no conhecimento qualitativo e quantitativo de associações espaciais entre ocorrências de ouro conhecidas e características geológicas na área estudada. Os resultados obtidos foram comparados com o estudo geoquímico já feito na área estudada e os resultados se mostraram altamente comparáveis.

ACAROGLU, et al. (2008) propõem um sistema de inferência fuzzy para prever a energia requerida por um Tunnel Boring Machine (TBM) durante o processo de construção de túneis. A quantidade de energia necessária para escavar uma unidade de volume de rocha é um dos parâmetros mais importantes utilizados para a previsão de desempenho das TBMs. Segundo os autores, muitas pesquisas têm sido conduzidas para prever os parâmetros de corte dos cortadores de disco 
usando abordagens analíticas, empíricas e numéricas, mas dada a complexidade e a grande incerteza na determinação das variáveis independentes, é estabelecido um sistema de inferência fuzzy para prever a energia requerida. A comparação dos resultados obtidos pelo modelo são próximos dos reais, o que demonstra a aplicabilidade do sistema de inferência fuzzy.

SOUZA, et al. (2013) aplicam um Modelo Fuzzy Linguístico para calcular um índice que represente a capacidade de pagamento (payment capacity index, PCI) dos consumidores de energia elétrica. O PCI depende de um conjunto de variáveis, onde se destaca a proporção do valor da conta de eletricidade em relação à renda familiar total. Todavia, muitas delas não são conhecidas com precisão como, por exemplo, a renda familiar. Esta apenas pode ser inferida a partir do consumo mensal de energia elétrica, através de sentenças lógicas como: se o consumo de energia é baixo, então a renda é baixa; ou, se o consumo de energia é alto, então a receita é alta. Os autores consideram ainda que o histórico de atraso no pagamento dos consumidores também influencia o PCI. Assim, foi definido um sistema de inferência fuzzy hierárquico em duas etapas: um para inferir a renda familiar, permitindo assim a estimativa da proporção do valor da conta de energia elétrica em relação à renda familiar; e um segundo para calcular o PCI utilizando a proporção encontrada na etapa um e o histórico de atraso no pagamento. A lógica fuzzy foi utilizada como ferramenta neste trabalho pela sua capacidade de tratar variáveis imprecisas ou vagamente definidas.

VARGENS, et al. (2003), também utilizando a capacidade preditiva dos Modelos Fuzzy Linguísticos, propõem um modelo que permite aos fazendeiros fazer a previsão de sua produção de cacau com mais precisão quando comparado ao método estabelecido pela Comissão Executiva de Planejamento da Lavoura Cacaueira (CEPLAC). O sistema foi projetado para auxiliar no gerenciamento da fazenda sem, contudo, exigir do produtor conhecimentos técnicos específicos. O sistema do tipo Mamdani foi concebido a partir das recomendações técnicas da CEPLAC e suas regras foram obtidas a partir da opinião de especialistas.

Destaque para a estrutura do sistema de inferência fuzzy proposto por VARGENS, et al. (2003) que gera uma saída que ajusta o resultado da previsão de produção já existente. O modelo altera o resultado da previsão de produção gerada pelo método da CEPLAC, i.e., dado um determinado valor de previsão de produção o sistema gera como saída um fator que reduz, mantém ou aumenta a 
produção. Os valores linguísticos de saída são Negativo Grande (NG), Negativo Médio (NM), Zero (ZE), Positivo Pequeno (PP), Positivo Grande (PG).

Percebe-se que a lógica fuzzy é aplicada quando a matemática e a lógica clássicas não são suficientes para modelar a realidade dada a sua complexidade, imprecisão intrínseca ou má definição. Muitas destas aplicações são construídas com base em modelos já existentes que representavam a realidade, através de simplificações e abstrações. Assim, a lógica fuzzy vem complementar estes modelos permitindo resultados mais precisos por capturar melhor a realidade e não serem afetados por simplificações. Os fundamentos matemáticos da vantagem da lógica fuzzy em relação à lógica clássica estão disponíveis na seção 8.3 do APÊNDICE A.

\subsection{3.}

\section{Lógica Fuzzy na Exploração e Produção de Petróleo}

A lógica fuzzy tem ganhado relevância na modelagem de problemas na atividade de E\&P - especialmente devido à quantidade de variáveis e à complexidade das suas relações lógicas. Muitas análises somente podem ser feitas no sentido amplo e sem muita precisão, isto porque, conforme a complexidade de um sistema aumenta, a capacidade humana de fazer declarações precisas e significantes sobre o seu comportamento diminui, até alcançar um limite além do qual precisão e relevância tornam-se características mutuamente exclusivas Princípio da Incompatibilidade (ZADEH, 1965).

É possível identificar aplicações da lógica fuzzy em praticamente todas as áreas da exploração e produção de petróleo. ZHANGGUI, et al. (1998) acoplaram a lógica fuzzy à geoestatística para caracterizar a anisotropia e quantificar as correlações espaciais existentes entre as propriedades do reservatório para prever a distribuição da permeabilidade do reservatório de Shanlan na China Ocidental. Eles concluíram que, devido à falta de dados confiáveis nos estágios iniciais da exploração do reservatório, a lógica fuzzy é uma das melhores maneiras de compensar essa falta de informação, integrando-a ao método Kriging durante o processo de interpolação.

CHEN, et al. (1995) utilizaram uma regressão fuzzy para determinar os parâmetros de equação de Archie quando a falta de ajuste entre os valores 
observados e simulados não é apenas devido a erros de medição, mas também à natureza vaga das variáveis no modelo avaliado. Eles mostraram que a análise de regressão convencional não é precisa, especialmente se os dados disponíveis representam vagamente o fenômeno.

$\mathrm{Na}$ área de caracterização do reservatório há alguns trabalhos publicados, com destaque para ZHOU, et al. (1993), que mostrou que sistemas híbridos neurofuzzy são muito efetivos nesta área de estudo. Eles integraram a capacidade de aprendizagem das redes neurais à interpretabilidade da lógica fuzzy para prever as propriedades dos reservatórios a partir das informações provenientes de poços.

NIKRAVESH, et al. (1997) também trabalharam com redes neuro-fuzzy com o objetivo de gerenciar reservatórios de óleo fraturados de baixa permeabilidade durante a injeção de água. Utilizando este sistema híbrido, eles foram capazes de monitorar a trajetória da água injetada para evitar danos ao reservatório.

A avaliação de risco é um fator chave para a escolha de um projeto de Recuperação Avançada de Petróleo (EOR). Neste contexto, CHUNG \& CARROLL (1995) fizeram uma pesquisa sobre a implementação da lógica fuzzy durante esta análise de risco. Eles provaram que o uso do sistema de inferência fuzzy poderia reduzir a quantidade de variáveis de entrada das análises de risco realizadas com base em simulação convencional. O modelo proposto é uma ferramenta de suporte à tomada de decisão de investimento de um projeto de EOR.

RIVERA \& FARABEE (1994) projetaram um sistema de inferência fuzzy para controlar a pressão durante a operação de fraturamento hidráulico e resolver o problema de controle de fluidos na válvula de estrangulamento (choke valve).

FILHO \& CASTRO (2014) propõem um sistema de inferência fuzzy para selecionar os poços candidatos a operação de fraturamento hidráulico com o objetivo de reduzir o dano à formação e aumentar a produção do poço. O modelo foi concebido a partir das melhores práticas para seleção de poços disponíveis na literatura. Os autores utilizaram redes neurais e algoritmos genéticos para ajustar os parâmetros das variáveis linguísticas com conhecimento adquirido a partir de uma base de dados operacionais do Brasil. ZOVEIDAVIANPOOR, et al (2012) também aplicaram sistema fuzzy na seleção de poços candidatos para o fraturamento hidráulico em reservatórios no Irã. Eles demonstraram que este 
sistema poderia auxiliar na seleção e classificação dos poços de alta prioridade para serem fraturados.

Outros trabalhos foram realizados sobre este tema de seleção de alternativas. GARROUCH \& LABBABIDI (2003) aplicaram a lógica fuzzy para subsidiar a decisão de perfurar um poço no modo de controle de pressão underbalanced ou overbalanced.

GARROUCH, et al. (2004) desenvolveram um sistema fuzzy numa aplicação web, com o objetivo de fornecer um critério de seleção de poços multilaterais. Eles mostraram que este sistema especialista poderia ajudar engenheiros de perfuração a decidir sobre a opção de perfuração multilateral nos casos em que as condições operacionais são limitadas.

SAGGAF \& NEBRIJA (2003) utilizaram lógica fuzzy na identificação de litologia através de dados obtidos via wire-line. Eles aplicaram o modelo a um conjunto de poços e demostraram a sua capacidade de prever com exatidão aceitável em comparação com os métodos estatísticos atuais.

HAMIDI, et al. (2010) aplicaram a lógica fuzzy para a caracterização de tipos de rochas. Eles discutiram o problema dos métodos atuais e propuseram um sistema de inferência fuzzy do tipo Mamdani que pode lidar com a diferenciação entre massas de rochas de forma mais realista.

Destaca-se o trabalho de ROISENBERG, et al. (2009) devido à similaridade conceitual com a situação problema tratada neste trabalho. ROISENBERG, et al. (2009) propõem uma metodologia fuzzy-probabilística com o objetivo de sistematizar a argumentação e a mensuração da probabilidade de sucesso de descoberta de petróleo em um dado prospecto a partir da avaliação da variabilidade dos fatores geológicos necessários para que exista uma acumulação de petróleo (i.e. rocha geradora, rocha reservatório, rocha selante, armadilha, migração e sincronicidade).

As variáveis que permitem a confirmação da existência de um fator geológico nem sempre podem ser confirmadas ou obtidas diretamente, e assim a forma mais efetiva de modelá-las é a partir de variáveis aleatórias. A metodologia considera que a estocasticidade destas variáveis pode ser vista como risco e assim cada um dos fatores geológicos são modelados através de um sistema de inferência fuzzy do tipo Mamdani. A variável de saída de cada sistema de inferência fuzzy é interpretada como a favorabilidade do fator geológico e é 
composta pelos seguintes termos linguísticos: "favorável”, “encorajador", "neutro", "questionável” e "não favorável".

Sabendo que só existirá acumulação de petróleo se todos os fatores geológicos estiverem presentes, a metodologia propõe uma interpolação do resultado fuzzy utilizando uma função uniforme e a combinação deles através do método de Monte Carlo.

A metodologia, além de avaliar a probabilidade de sucesso de descoberta em um determinado prospecto, incorpora também informações complementares (e.g. dados históricos e indicadores diretos de hidrocarbonetos) ao resultado obtido pelos modelos fuzzy combinados por Monte Carlo, a fim de elevar a precisão do resultado.

Um dos destaque do trabalho de ROISENBERG, et al. (2009) é a importância dada ao processo de modelagem e à necessidade de que as variáveis consideradas em cada um dos sistemas de inferência fuzzy, os conjuntos fuzzy e os blocos de regras devam ser ajustados pelo especialista antes da análise de cada prospecto. Isto reforça o apelo à interpretabilidade deste tipo de aplicação fuzzy onde, diferentemente das aplicações de controle, o foco não está apenas na precisão, mas no processo de construção do resultado.

Por fim, a partir desta revisão nota-se que sistemas de inferência fuzzy linguísticos podem ser utilizados para modelar variáveis de entradas em problemas complexos evitando simplificações na sua modelagem com o objetivo de aprimorar a precisão e interpretabilidade do modelo como um todo. Não foi identificada abordagens similares à proposta neste estudo na literatura, de forma que este trabalho pode contribuir para novas aplicações, sendo aplicado ao mesmo contexto ou extrapolado para problemas diversos. 


\section{3 Metodologia de Previsão de Produção de Petróleo}

Este capítulo tem como objetivo descrever o modelo de simulação estocástica utilizado para previsão e análise de risco da produção e conceber uma metodologia para aplicação deste modelo incorporando as melhorias e recomendações identificadas ao longo do desenvolvimento deste trabalho. Obtémse, assim, a formalização do processo e estabelecem-se diretrizes para a modelagem das variáveis de entrada do modelo, garantindo interpretabilidade, repetitividade e precisão da previsão e análise de risco da produção. A partir da exposição feita, é possível posicionar o leitor quanto à relevância e à aplicação do sistema de inferência fuzzy proposto neste trabalho.

\section{1.}

\section{Risco da Previsão de Produção de Petróleo}

O quanto de petróleo será produzido em um determinado período de tempo é uma informação crítica para as companhias de E\&P. A previsão de produção é o principal vetor de planejamento, de forma que, a partir deste número, todos os demais planos são desenvolvidos (e.g. custos e investimentos). Além do impacto interno, a previsão de produção representa um parâmetro fundamental de desempenho da empresa diante do mercado, de modo que o seu não cumprimento pode implicar diretamente em grandes perdas nas bolsas de valores.

Neste contexto, o modelo de simulação desenvolvido por CASTRO, et al. (2010) propõe uma ferramenta para avaliar o nível de risco da previsão de produção de petróleo de portfólios de E\&P (produção média superior a 1 milhão de barris por dia) em curtos horizontes de planejamento, em geral de um ano. Segundo CASTRO, et al. (2010), modelos de risco para avaliação de portfólio de E\&P tornam-se relevantes quando a complexidade é elevada. Por considerar que as previsões de produção de petróleo de projetos de E\&P sofrem influência psicológica (pessimismo ou conservadorismo) dos gestores responsáveis pelos projetos de desenvolvimento da produção, o autor afirma que as projeções de produção de petróleo tendem a ser distorcidas, sendo preciso então quantificar o risco das previsões. Desta forma, o modelo busca confrontar as previsões individuais dos projetos através de uma análise de risco agregada, considerando 
todo o portfólio e utilizando fontes de informações diferentes das utilizadas pelos projetos.

Além da visão agregada, que possibilita avaliar as inter-relações entre os projetos, uma das principais características do modelo é a consideração de aspectos operacionais gerenciáveis conjuntamente com as incertezas geológicas de reservatório. Ao incorporar a visão operacional, o modelo permite avaliar não somente o risco associado aos reservatórios, mas também a capacidade de gestão e de execução da empresa, possibilitando assim uma previsão de produção mais precisa no curto prazo.

Para permitir o entendimento da dinâmica do modelo, as variáveis de entradas são descritas agrupadas em quatro dimensões: (1) Potencial Produtivo Instalado, (2) Entrada de Novos Poços, (3) Parada Programada para Manutenção e (4) Eficiência Operacional. Em seguida são apresentados o modelo matemático e um exemplo numérico para demonstrar a obtenção da principal saída do modelo média anual de produção diária - destacando o efeito da variável Data de Entrada da dimensão Entrada de Novos Poços, objeto de estudo este trabalho.

\section{2. \\ Potencial Produtivo Instalado}

Sistema de produção de petróleo é definido como um conjunto de poços e instalações industriais capaz de produzir petróleo. Um sistema de produção de petróleo é uma parte da estrutura de E\&P que pode ser, desde uma plataforma marítima, uma instalação terrestre, até um grupo de instalações terrestres ou de plataformas. Os sistemas de produção de petróleo são definidos pela sua relevância estratégica, que em geral estão relacionados à sua capacidade de produção de petróleo.

A capacidade de produção de um sistema é definida pela soma do potencial de produção de cada um dos seus poços, considerando as restrições das instalações, se existirem. Assim, define-se Potencial Produtivo Instalado de um sistema como o somatório dos potenciais de produção dos poços que já entraram em operação em um determinado instante de tempo, ou seja, este é um volume conhecido, que já está sendo produzido pelo sistema. Este volume é tratado como “óleo velho" dentro do portfólio. 
É intuitiva a conclusão de que a dimensão Potencial Produtivo Instalado é mais relevante em sistemas maduros, que por já estarem na fase de Produção há algum tempo tendem a apresentar menor variabilidade nos seus valores futuros, especialmente no curto prazo, que é o campo de aplicação desta metodologia.

O Potencial Produtivo Instalado varia ao longo da vida produtiva dos poços. À medida em que os poços produzem, o Potencial Produtivo Instalado se reduz a uma determinada taxa que varia de acordo com as características do reservatório onde o petróleo está contido. Sendo assim, o Potencial Produtivo Instalado é descrito por uma curva de declínio.

Ressalta-se que a curva de declínio aqui definida não é, necessariamente, igual ao declínio dos reservatórios produtores, dado que a unidade básica do modelo é sistema de produção de petróleo e este pode produzir de diversos reservatórios diferentes simultaneamente. A metodologia neste aspecto é agregada, o declínio é de todo o sistema.

O valor inicial da curva, a taxa de declínio e o modelo de declínio devem ser os aspectos a serem considerados na modelagem do Potencial Produtivo Instalado.

A valor inicial da curva deve ser definido de maneira que este seja um ponto representativo para declínio histórico do sistema de forma que não apresente influência de fatores espúrios transientes ou deixe de capturar uma eventual mudança de tendência real do declínio. A má definição do valor inicial pode influenciar significativamente o resultado da análise, tornando-a não representativa.

A definição da taxa de declínio deve ser feita buscando, primordialmente, a coerência com as análises de reservatório (e.g. ajuste de histórico e simulação numérica de fluxo), especialmente em sistemas homogêneos onde existe a preponderância de um único reservatório. Porém, em caso de ausência de análises atualizadas, ou em sistemas heterogêneos que não dispõem de resultados agregados, deve ser feita uma análise do histórico do Potencial Produtivo Instalado observando a tendência para definição da taxa de declínio.

Se nenhuma alteração ocorrer em um determinado sistema no curto prazo, não há justificativa para que o mesmo apresente um comportamento diferente, logo existe previsibilidade a partir do histórico do Potencial Produtivo Instalado. Desta forma, a análise consiste em avaliar o histórico de potencial do sistema e a partir dele extrapolar linearmente o comportamento do declínio, um com uma 
visão otimista e outro com uma visão pessimista. Um terceiro padrão de comportamento é traçado como uma visão intermediária (mais provável) na bissetriz do ângulo formado pelas extrapolações anteriores (Figura 5). O uso de uma extrapolação linear é uma simplificação do modelo que não resulta em grandes perdas de precisão, dado que o horizonte de planejamento é curto. Esta análise é feita para todos os sistemas em operação. Durante a análise da série histórica de potencial deve-se retirar o efeito do aumento de potencial decorrente de novos poços.

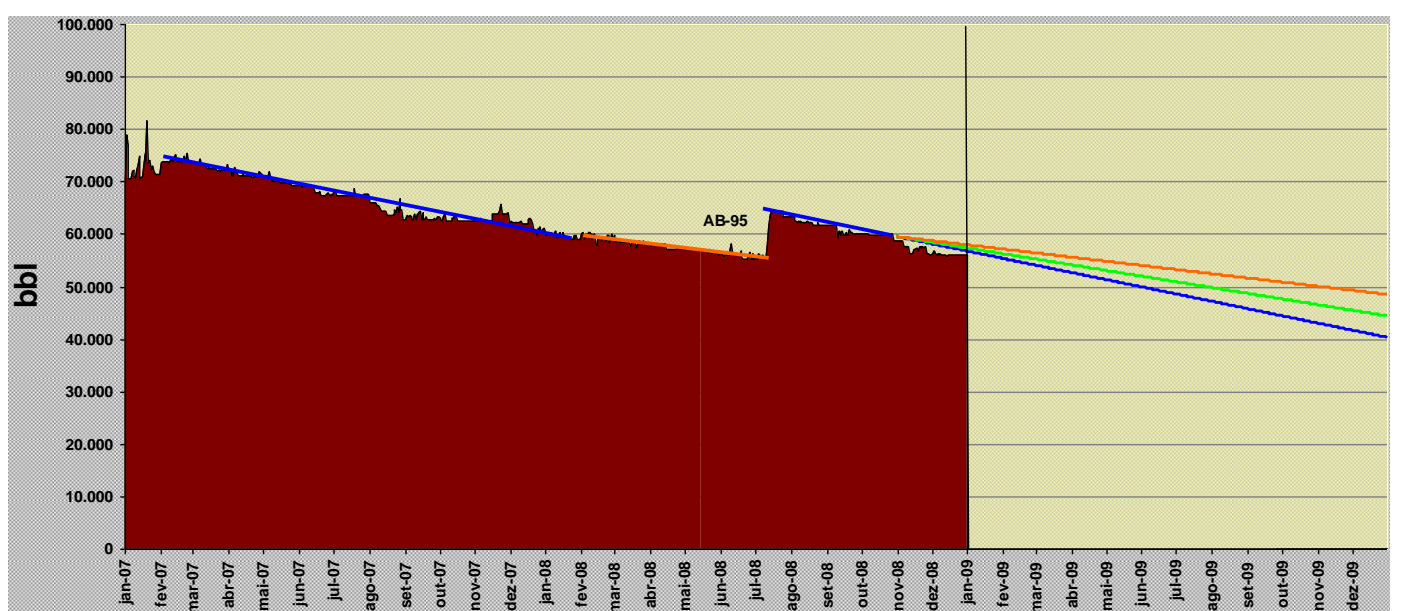

Figura 5 - Extrapolação linear do Potencial Produtivo Instalado de um sistema de produção de petróleo com as visões otimista (vermelho), pessimista (azul) e mais provável (verde). Fonte: Adaptado de (CASTRO, et al., 2010).

Para cada um dos cenários das curvas de declínio de potencial é atribuída uma probabilidade de ocorrência através de uma função discreta que admite apenas três valores (similar a uma árvore de decisão), como representado a seguir.

Taxa de Declínio Potencial $\leftarrow \operatorname{Disc}\left(P_{C_{1}}, P_{C_{2}}, P_{C_{3}}\right) \Rightarrow$ TDpotencial $k_{k t}$

Onde:

TDpotencial $_{k t}$ - taxa de declínio do sistema $k$ no momento $t$;

Disc - distribuição discreta;

$\mathrm{P}_{C_{1,2} e_{3}}$ - probabilidade de ocorrência de cada cenário da TDpotencial ${ }_{k t}$;

$k$ - indicador de número de sistemas;

$t$ - momento (dia).

Caso não existam informações que influenciem a ocorrência dos cenários, é considerado como padrão a Lei de Swanson, $\mathrm{P}_{C_{1}}=0,3, \mathrm{P}_{C_{2}}=0,4, \mathrm{P}_{C_{3}}=0,3$ 
(HURST, et al., 2000) - simplificação fortemente utilizada na indústria de petróleo e gás para aproximar as distribuições de probabilidade contínuas, como o log-normal na estimativa de reservas. Para detalhes sobre as limitações da Lei de Swanson ver BICKEL, et al. (2011).

\section{3.}

\section{Entrada de Novos Poços}

A dimensão Entrada de Novos Poços é uma variável de reservatório que representa o quanto de potencial de produção será adicionado ao Potencial Produtivo Instalado devido ao início de operação de novos poços produtores de óleo. Trata-se, portanto, de "óleo novo", um volume de produção a ser adicionado à curva de produção do portfólio.

Quando um poço novo entra em operação, o seu potencial passa a ser considerado como Potencial Produtivo Instalado do sistema ao qual o poço novo foi interligado. Por exemplo, o início da produção do poço AB-95 em destaque na Figura 5.

Considera-se, nesta metodologia, que a entrada de novos poços está sujeita a três variáveis estocásticas: (1) Potencial Inicial - o volume de Potencial que o novo poço irá adicionar ao Potencial Produtivo Instalado do sistema ao qual ele será interligado; (2) Taxa de Declínio do Poço Novo - como e de quanto será o declínio do potencial do novo poço; (3) Data de Entrada - quando o Potencial Inicial do poço novo será adicionado ao Potencial Produtivo Instalado do sistema ao qual ele será interligado, desloca o Potencial Inicial no tempo.

Potencial Inicial é uma variável que representa o volume que o poço pode produzir, considerando: as características físicas do poço e do reservatório em si (e.g. pressão de fundo, coluna de óleo, interconectividade); a estrutura de elevação e escoamento (e.g. manifold, método de elevação e linhas de produção); e as características da instalação de produção (e.g. capacidade de processamento de líquidos e compressão de gás) para a qual o poço estará interligado. Pelo menos um destes três aspectos é o gargalo, o limitador, para o estabelecimento do Potencial Inicial.

Em algumas situações, devido à falta de integração entre as áreas responsáveis, pode-se estimar um volume para o Potencial Inicial maior do que 
pode ser processado pela instalação de produção considerando os poços já em produção e os poços que entrarão em produção. Isto pode ocorrer em dois momentos distintos: nas fases iniciais de produção de um sistema, quando este está próximo ao seu platô, i.e., quando os sistemas que estão produzindo próximo à sua capacidade de processamento (Figura 1); ou na fase final da produção quando, apesar do declínio acentuado na produção de óleo, ocorre aumento significativo da produção de gás associado (aumento da razão gás óleo, RGO) ou da água (aumento da porcentagem de água e sedimentos, BSW), fazendo com que a instalação atinja a sua capacidade de líquido (óleo + água) ou de compressão/processamento de gás. Sendo assim, buscando estabelecer valores efetivos para Potencial Inicial dos novos poços, deve-se incluir na modelagem limites superiores para o Potencial Produtivo Instalado de cada sistema, considerando a sua capacidade nominal de processamento de líquidos, tratamento e descarte de água, processamento, compressão, injeção e queima de gás. Deve-se ainda considerar que algumas unidades podem alterar sua capacidade por opções operacionais temporárias ou por melhorias nos seus equipamentos.

A Taxa de Declínio do Poço Novo deve ser compatível com a taxa considerada para o reservatório do qual este poço produzirá. Pondera-se, porém, que o declínio nas fases iniciais de produção tende a ser mais acentuado, apresentando um comportamento exponencial. Portanto, as previsões e simulação das séries de potencial dos novos poços devem ser feitas de maneira individualizada, considerando esta especificidade, mesmo trabalhando com um horizonte curto. Caso o poço novo esteja localizado em uma nova fronteira que não possui outros poços em produção, deve-se fazer uma correlação com os poços do mesmo campo ou bacia que apresentem características similares.

Importante destacar que, além das variáveis Potencial Inicial e Taxa de Declínio do Poço Novo do tipo reservatório como já definido acima, a dimensão Entrada de Novos Poços considera também uma variável operacional relacionada ao cronograma do projeto dos novos poços, que representa a possibilidade de atraso ou antecipação em relação à data esperada para o início da produção dos poços. A Data de Entrada está relacionada com a capacidade da empresa em cumprir as atividades necessárias para o início da produção de um poço novo (i.e., perfuração, completação e interligação) dentro do cronograma previsto. 
Tratar a Data de Entrada dos novos poços de alta produtividade como uma variável aleatória nesta dimensão é fundamental e muitas vezes mais relevante do que buscar precisão no Potencial Inicial e na Taxa de Declínio do Poço Novo. Isto porque um atraso significativo pode, por exemplo, fazer com que o poço previsto não entre em produção dentro do período de planejamento, impactando fortemente a curva de produção. Em províncias em expansão que possuem poços com alta produtividade, como é o caso do Pré-Sal brasileiro, a data de início da produção dos poços se destaca como a variável mais sensível para as previsões de produção de curto prazo.

O Potencial Inicial e a Data de Entrada dos poços são modelados através de funções triangulares com parâmetros (a) pessimista, (b) otimista e (c) mais provável, obtidos a partir da opinião de especialistas. A Taxa de Declínio do Poço Novo é modelada por uma distribuição discreta com os mesmos três parâmetros. Estes parâmetros representam os valores possíveis do Potencial Inicial e da Taxa de Declínio do Poço Novo e, para a Data de Entrada, representam atraso ou antecipação em relação à data planejada pelo projeto responsável pelo início da operação do poço, índice $t$ do termo $P o c ̧ O_{i t}$.

As variáveis da dimensão Entrada de Novos Poços são definidas como representado a seguir.

Potencial Inicial $\leftarrow$ Tri $($ min, maisprov, $\max ) \Rightarrow P_{\text {oco }}$ it;

Taxa de Declínio do Poço Novo $\leftarrow \operatorname{Disc}\left(P_{C_{1}}, P_{C_{2}}, P_{C_{3}}\right) \Rightarrow$ TDpoço $i t$;

Data de Entrada $\leftarrow$ DATA_PLAN_PROJ + Tri(min, maisprov, max $) \Rightarrow t$;

Onde:

Poço $o_{i t}$ - potencial de produção do poço novo i no momento t;

TDpoço $o_{i t}$ - taxa de declínio da produção do poço i em cada momento $t$;

Disc - distribuição discreta;

Tri - distribuição triangular;

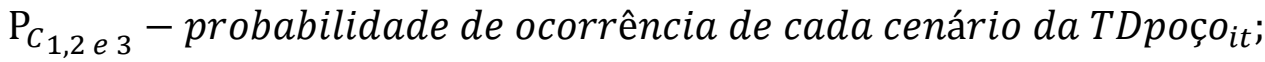

$i$ - indicador do número de poços;

$t$ - momento (dia).

Prever o índice $t$ do termo $P o c ̧ o_{i t}$ é o principal objetivo do sistema de inferência fuzzy proposto neste trabalho. 


\section{4. Parada Programada para Manutenção}

Esta dimensão de risco representa o volume total de perdas de produção decorrentes de paradas programadas para manutenção. Estas são eventos temporários de interrupção ou redução da produção dos sistemas. Estes eventos são inerentes à operação das instalações e dos poços e possuem uma natureza previsível, de forma que são planejados antecipadamente.

As paradas programadas são grandes projetos, que reúnem em um mesmo período diversos serviços de manutenção que não podem ser feitos durante a operação normal do sistema. Devido à dinâmica operacional, o escopo dos projetos das paradas programadas pode variar significativamente desde o início do planejamento até a execução.

Em geral, os sistemas necessitam de uma grande parada a cada três anos de operação, porém essa frequência pode ser modificada por diversos motivos: requisitos contratuais, oportunidades de parar, tempo total em operação, falha de projeto ou na construção da instalação, obrigações legais e interesses empresariais.

Com o objetivo de obter o volume total de perdas de produção gerado devido às paradas programadas para manutenção, considerar-se-á nesta metodologia que esta dimensão de risco está submetida a três variáveis estocásticas: (1) Impacto da Parada - percentual do Potencial Produtivo Instalado do sistema que não será realizado devido à parada; (2) Data de Início da Parada quando iniciará o Impacto da Parada, desloca a parada tempo; (3) Duração da Parada - por quanto tempo o sistema estará submetido ao Impacto da Parada.

A equação (3) define o volume total de perdas de produção gerado devido às paradas programadas para manutenção.

Parada $_{k t}=\left(\right.$ Potencial $_{k t} *$ Impacto $\left._{k t}\right) *$ Duração $_{k}$

Onde:

Parada $k_{t}-$ volume de perdas devido à parada do sistema $k$ no momento $t$; Potencial $_{k t}$ - potencial de produção do sistema $k$ no momento $t$; Impacto $_{k t}$ - percentual do Potencial $k$ não realizado devido à parada;

Duração $o_{k}$ - duração em dias da parada do sistema $k$;

$k$ - indicador do número de sistemas;

$t$ - momento (dia); 
O Impacto da Parada está relacionado aos serviços de manutenção que serão feitos no sistema durante a parada. Uma parada do separador de produção de uma plataforma por um requisito legal (e.g. Norma Regulamentadora $\mathrm{n}^{\circ} 13$, por exemplo, pode requer que $100 \%$ da produção do sistema seja interrompida, porém uma parada por tempo de operação dos compressores de gás para injeção de Gás Lift de uma instalação terrestre somente influenciará a produção dos poços equipados com este método de elevação, impactando assim somente $40 \%$ da produção do sistema durante o período da parada, por exemplo. O Impacto da Parada pode variar também durante a Parada Programada de forma que tal variação deve ser considerada durante a análise (geralmente o Impacto da Parada é menor no início e no final da parada).

Devido à variabilidade do escopo dos projetos das paradas programadas e aos usuais problemas operacionais durante a sua execução, o Impacto da Parada torna-se uma variável estocástica que deve ser considerada para modelar o volume total de perdas que a parada programada gerará efetivamente.

Data de Início da Parada representa quando a perda de produção iniciará. Assim como na dimensão Entrada de Novos Poços, um atraso ou uma antecipação significativa pode fazer com que a perda impacte ou não a curva de produção no período de planejamento. A estocasticidade desta variável pode ser resumida pela capacidade da empresa de cumprir o cronograma do projeto devido a fatores gerenciáveis ou não, tais como: condição de mar (no caso de paradas de sistemas marítimos) e mudanças nas estratégias empresariais que resultam diretamente em postergação/antecipação do início das paradas.

A variável Duração da Parada indica por quanto tempo o Impacto da Parada influenciará a produção do sistema. A Duração da Parada é influenciada por variados fatores que levam a uma parada mais curta ou mais longa. Por exemplo, uma parada prevista para durar 30 dias pode ser otimizada e durar apenas 22 dias devido a um bônus existente no contrato feito com a empresa que realizará a parada ou a mesma parada pode exceder o número de dias previsto e durar 35 dias, por uma mudança de escopo decorrente de uma nova necessidade identificada durante a execução da parada.

As variáveis desta dimensão são definidas como representado a seguir. 
Impacto da Parada $\leftarrow$ Tri(min, maisprov, max $) \Rightarrow$ Impacto $_{k t}$;

Duração da Parada $\leftarrow$ Tri(min, maisprov, max $) \Rightarrow$ Duração $o_{k}$;

Data de Início $\leftarrow$ DATA_PLAN_PROJ + Tri (min, maisprov, max $) \Rightarrow t$;

Onde:

Impacto $_{k t}$ - impacto da parada do sistema $k$ no momento $t$;

Duração $o_{k}$ - duração em dias de parada do sistema $k$;

Tri - distribuição triangular;

$k$ - indicador do número de sistemas;

$t$-momento (dia).

\section{5.}

\section{Eficiência Operacional}

Assim como a Parada Programada para Manutenção, esta dimensão tem caráter operacional e contribui negativamente para a realização do volume de produção. A Eficiência Operacional refere-se aos eventos de perdas não programados relacionados às falhas dos equipamentos e componentes de um sistema que impedem que a sua Produção Realizada seja igual ao seu Potencial Produtivo Instalado. Sendo assim, esta dimensão de risco representa uma medida do desempenho operacional dos sistemas.

A Figura 6 ilustra o comportamento da Produção Realizada, destacando as diferenças em relação ao Potencial Produtivo Instalado devido aos eventos de perdas.

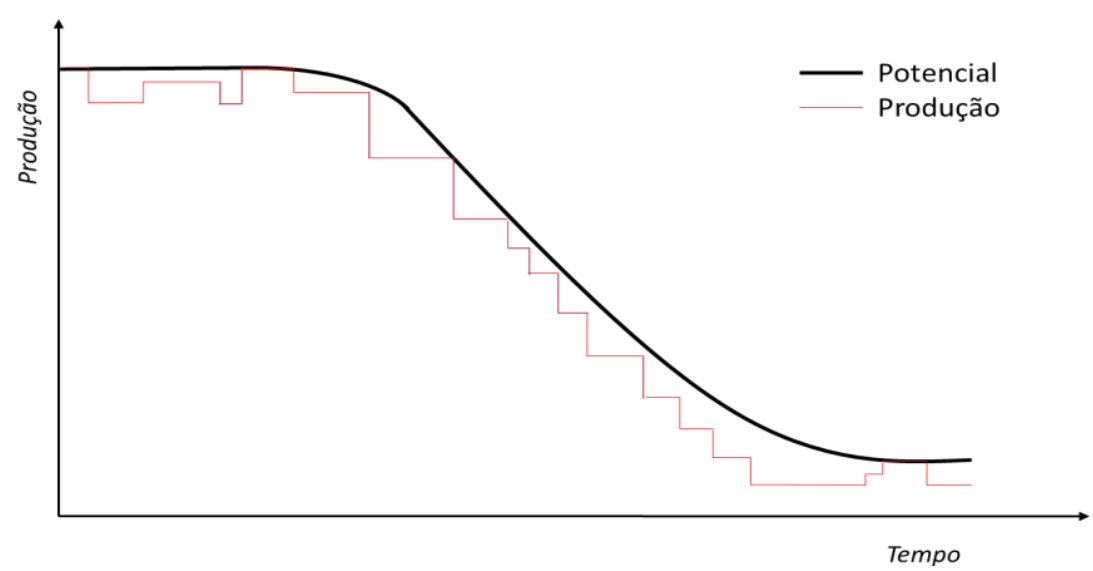

Figura 6 - Diferenças entre a curva de Potencial e a Produção Realizada devido aos eventos de perdas não programadas. 
Destaca-se que as Perdas de Produção consideradas na Eficiência Operacional são interrupções ou reduções na produção resultantes de eventos inesperados e não previstos antecipadamente, de forma que as perdas de produção que resultam das paradas programadas não são contabilizadas. Matematicamente a Eficiência Operacional é definida pela equação (4).

Eficiência $_{k t}=\left(\right.$ Produção Realizada $_{k t} /$ Potencial $\left._{k t}\right) * 100$

Tal que,

Produção Realizada $_{k t}=$ Potencial $_{k t}-$ Perdas $_{k t}$

Onde:

Potencial $_{k t}$ - potencial de produção do sistema $k$ no momento $t$; Eficiência $k-$ eficiência do sistema $k$ no momento $t$;

Perdas $_{k t}$ - volume de perdas de produção do sistema $k$ no momento $t$; $k$ - indicador do número de sistemas;

$t$ - momento (dia).

A eficiência é considerada uma variável aleatória e é modelada por instalação através de uma função normal com média igual à média histórica das eficiências e desvio padrão igual ao desvio padrão histórico das eficiências. A modelagem da eficiência pode ser representada por:

Eficiência Operacional $\leftarrow \operatorname{Normal}(\mu, \sigma) \Rightarrow$ Eficiência $_{k t}$

Onde:

$\operatorname{Normal}(\mu, \sigma)$ - distribuição normal com média $\mu$ e desvio padrão $\sigma$.

O uso de distribuição normal é uma simplificação do modelo que resulta em diversas dificuldades técnicas que devem ser consideradas na modelagem e no resultado final da previsão como, por exemplo, a necessidade de truncar limites para eficiência resultante simulada.

\section{6.}

\section{Modelo Conceitual e Analítico}

A principal saída do modelo é a média anual de produção diária de petróleo. A relação entre as variáveis de entrada e a saída do modelo é resumida na Figura 7 e detalhada através de um modelo analítico (equação 6). 


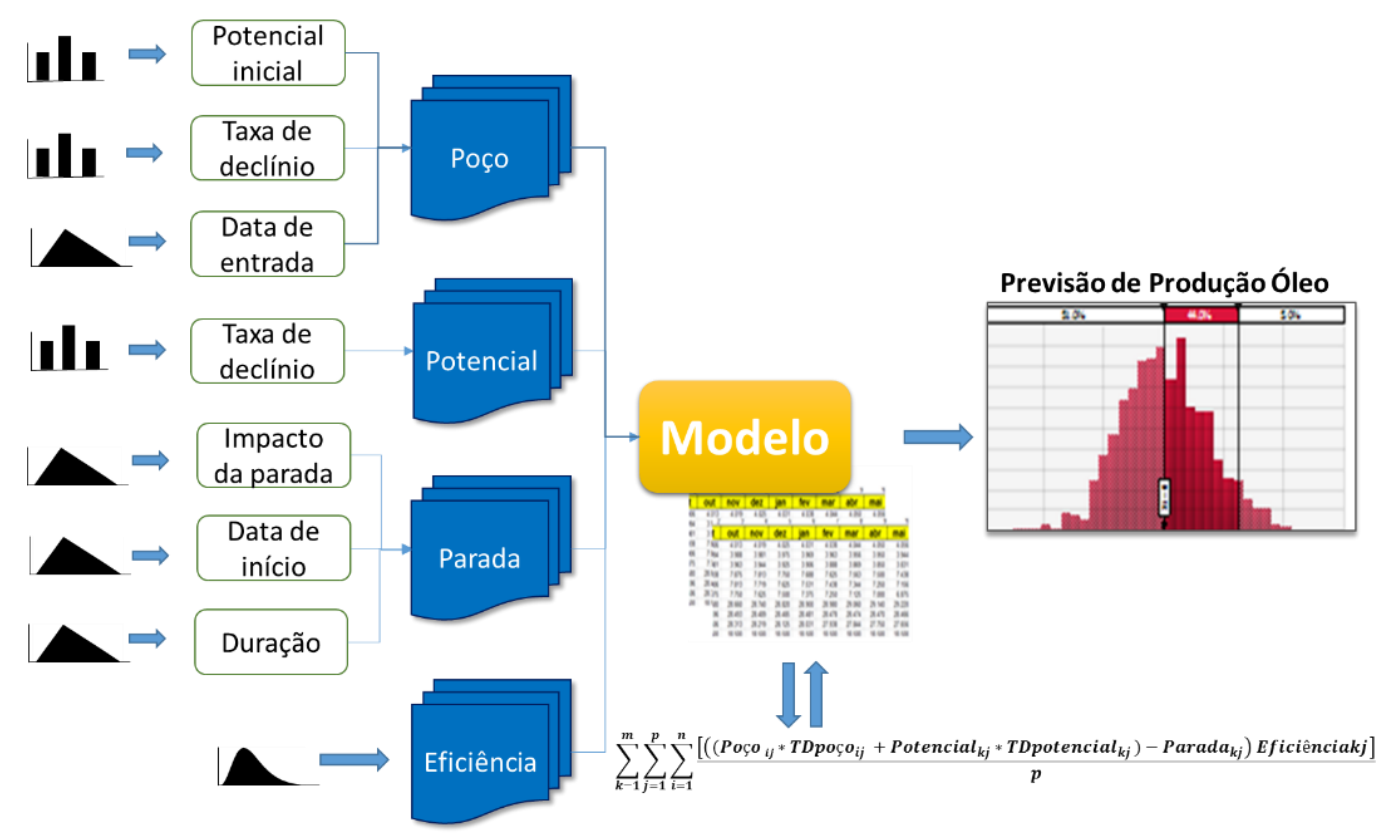

Figura 7 - Modelo conceitual da metodologia de previsão da produção de petróleo.

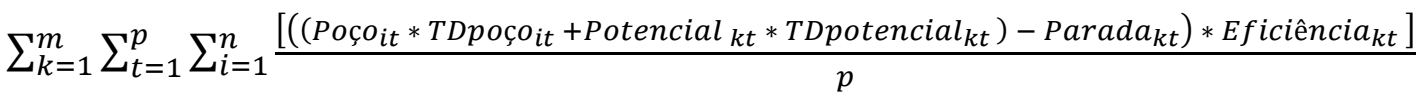

(6)

Tal que,

$0<$ Eficiência $_{k j} \leq 1$, Poço $_{i t}$, Potencial $_{k t}$ e Paradas $_{k t} \in \mathbb{R}$ e $p \neq 0$

Onde:

Poço ${ }_{i t}$ - potencial de produção do poço novo i no momento $t$;

TDpoço $o_{i t}$ - taxa de declínio da produção do poço i em cada momento $t$

Potencial $_{k t}$ - potencial de produção do sistema $k$ no momento $t$;

TDpotencial $_{k t}$ - taxa de declínio do sistema $k$ no momento $t ;$

Parada $_{k t}$ - volume de perdas devido à parada do sistema $k$ no momento $t$;

Eficiência $k_{t}{ }^{-}$eficiência do sistema $k$ no momento $t$;

$i$ - indicador de número de poços;

$k$ - indicador do número de sistemas;

$t$ - momento (dia);

$n$ - número total de Novos Poços;

$m$ - número total de sistemas;

$p$ - total de dias do período de planejamento. 
O resultado da equação (6) é a média anual de produção diária de petróleo de todos os sistemas em um determinado período de tempo $p$. O método de amostragem utilizado no modelo é o Hipercubo Latino.

\section{7. \\ Exemplo de Previsão de Produção de Petróleo}

A fim de demonstrar a dinâmica do modelo analítico considere como exemplo a previsão de produção para o ano de 2017 de um sistema genérico A com as seguintes características:

i. Potencial Produtivo Instalado

a. Potencial: $70.000 \mathrm{bpd}$;

b. TDpotencial: $10 \%$ a.a.

ii. Entrada de Novos Poços

a. Poço1 - Potencial Inicial: 15.000 bdp; TDpoço1: 10\% a.a.; Data de Entrada: 01/09/2017;

b. Poço2 - Potencial Inicial: 25.000 bdp; TDpoço2: 10\% a.a.; Data de Entrada: 01/03/2017.

iii. Parada Programada para Manutenção

a. Impacto da Parada: 100\%;

b. Duração da Parada: 31 dias;

c. Data de Início: 01/05/2017.

iv. Eficiência Operacional: $83 \%$

Aplicando a equação (6) ao sistema genérico A, obtém-se uma previsão de produção média de 69.503 bpd para 2017. As etapas do cálculo da previsão de produção considerando o Potencial Produtivo Instalado, as Entradas de Novos Poços planejados para iniciarem produção, a Parada Programa para Manutenção e a Eficiência Operacional são apresentadas na Tabela 1.

Tabela 1 - Exemplo de previsão de produção utilizando a equação (6).

\begin{tabular}{rcccccccccccc} 
Sistema A & jan & fev & mar & abr & mai & jun & jul & ago & set & out & nov & dez \\
\hline Poço 1 & - & - & - & - & - & - & - & - & 15000 & 14862 & 14725 & 14587 \\
Poço 2 & - & - & 25000 & 24771 & 24541 & 24312 & 24083 & 23853 & 23624 & 23394 & 23165 & 22936 \\
\hline Potencial & 70000 & 69364 & 93727 & 92862 & 91996 & 91130 & 90264 & 89399 & 103533 & 102530 & 101526 & 100523 \\
\hline Parada & - & - & - & - & $(91.996)$ & - & - & - & - & - & - & - \\
\hline Eficiência & $83 \%$ & $83 \%$ & $83 \%$ & $83 \%$ & $83 \%$ & $83 \%$ & $83 \%$ & $83 \%$ & $83 \%$ & $83 \%$ & $83 \%$ & $83 \%$ \\
\hline \hline Produção & 58100 & 57572 & 77794 & 77075 & 0 & 75638 & 74919 & 74201 & 85932 & 85100 & 84267 & 83434 \\
\hline \hline
\end{tabular}


Suponha que as Datas de Entrada dos poços 1 e 2 foram revistas e alteradas de 01/09/2017 para 01/11/2017 e de 01/03/2017 para 01/04/2017, respectivamente. Refazendo a previsão de produção, ceteris paribus, a média de produção de 2017 cai para 65.868 bpd. Os resultados da nova previsão são apresentados na Tabela 2 .

Devido ao alto Potencial Inicial relativo dos poços 1 e 2, variações na Data de Entrada, mesmo que pequenas, geram um impacto significativo no resultado da previsão de produção. Analisando apenas os impactos na média de produção, considerando a cotação internacional do barril de petróleo a 50 U\$/bbl, a variação de 3.635 bpd, reduz a geração de receita do sistema genérico A em aproximadamente 66 milhões de dólares no ano.

Tabela 2 - Exemplo de previsão de produção utilizando a equação (6) considerando a revisão nas Datas de Entrada dos poços 1 e 2.

\begin{tabular}{rcccccccccccc} 
Sistema A & jan & fev & mar & abr & mai & jun & jul & ago & set & out & nov & dez \\
\hline Poço 1 & - & - & - & - & - & - & - & - & - & - & 15000 & 14860 \\
Poço 2 & - & - & - & 25000 & 24769 & 24537 & 24306 & 24074 & 23843 & 23611 & 23380 & 23148 \\
\hline Potencial & 70000 & 69364 & 68727 & 93091 & 92223 & 91355 & 90487 & 89620 & 88752 & 87884 & 102016 & 101008 \\
\hline Parada & - & - & - & - & $(92.223)$ & - & - & - & - & - & - & - \\
\hline Eficiência & $83 \%$ & $83 \%$ & $83 \%$ & $83 \%$ & $83 \%$ & $83 \%$ & $83 \%$ & $83 \%$ & $83 \%$ & $83 \%$ & $83 \%$ & $83 \%$ \\
\hline \hline Produção & 58100 & 57572 & 57044 & 77265 & 0 & 75825 & 75105 & 74384 & 73664 & 72944 & 84673 & 83837 \\
\hline \hline
\end{tabular}

Conforme exemplificado, a solução da equação (6) é trivial se considerarmos as dimensões de risco determinísticas, porém este resultado não permite conclusões a respeito da variabilidade, o que é fundamental para as tomadas de decisão em um ambiente de risco.

A modelagem das dimensões de risco apresentada nas seções anteriores permite que a solução da equação (6) não apenas resulte em uma estimativa pontual da previsão de produção, mas sim em um conjunto de valores possíveis e as suas respectivas probabilidades de ocorrência. 


\section{4 \\ Modelagem da Data de Entrada em Produção de Poços}

Este capítulo tem como objetivo detalhar a modelagem da Data de Entrada em produção de poços de petróleo através de um sistema de inferência fuzzy destacando os conceitos aplicados e exemplificando a dinâmica do processo de inferência.

\section{1. Data de Entrada em Produção de Poços}

A Data de Entrada em produção de um poço depende de uma série de variáveis, dentre as quais é possível destacar: (1) o interesse empresarial devido ao potencial de produção e/ou ao ganho econômico-estratégico gerado pelo poço; e (2) a complexidade das características técnicas da construção e da interligação do poço à plataforma. Assim, a previsão do início da produção dos poços estará relacionada a uma composição de variáveis dos aspectos mencionados acima.

Todavia, algumas destas variáveis, tais como as características técnicas da construção e interligação do poço à plataforma, não são precisas ou completamente conhecidas, especialmente devido à quantidade e à complexidade das atividades envolvidas. Consequentemente, análises destas variáveis com o objetivo de prever a data de início da produção do poço somente podem ser feitas no sentido amplo e sem muita precisão.

Porém, como prever a data efetiva de início da produção de um poço de petróleo com base em sentenças como "este poço é estratégico para a empresa devido à alta lucratividade do projeto, mas a sua construção requer atividades de alta complexidade"? ZADEH (1999) demonstra como a lógica fuzzy tem sido eficiente em tratar situações onde a imprecisão é intrínseca ao problema.

Sendo assim, devido à natureza imprecisa do problema, neste trabalho é proposto um sistema de inferência fuzzy para prever a data efetiva de início de produção de um poço de petróleo. A Figura 8 ilustra a estrutura do sistema proposto. 


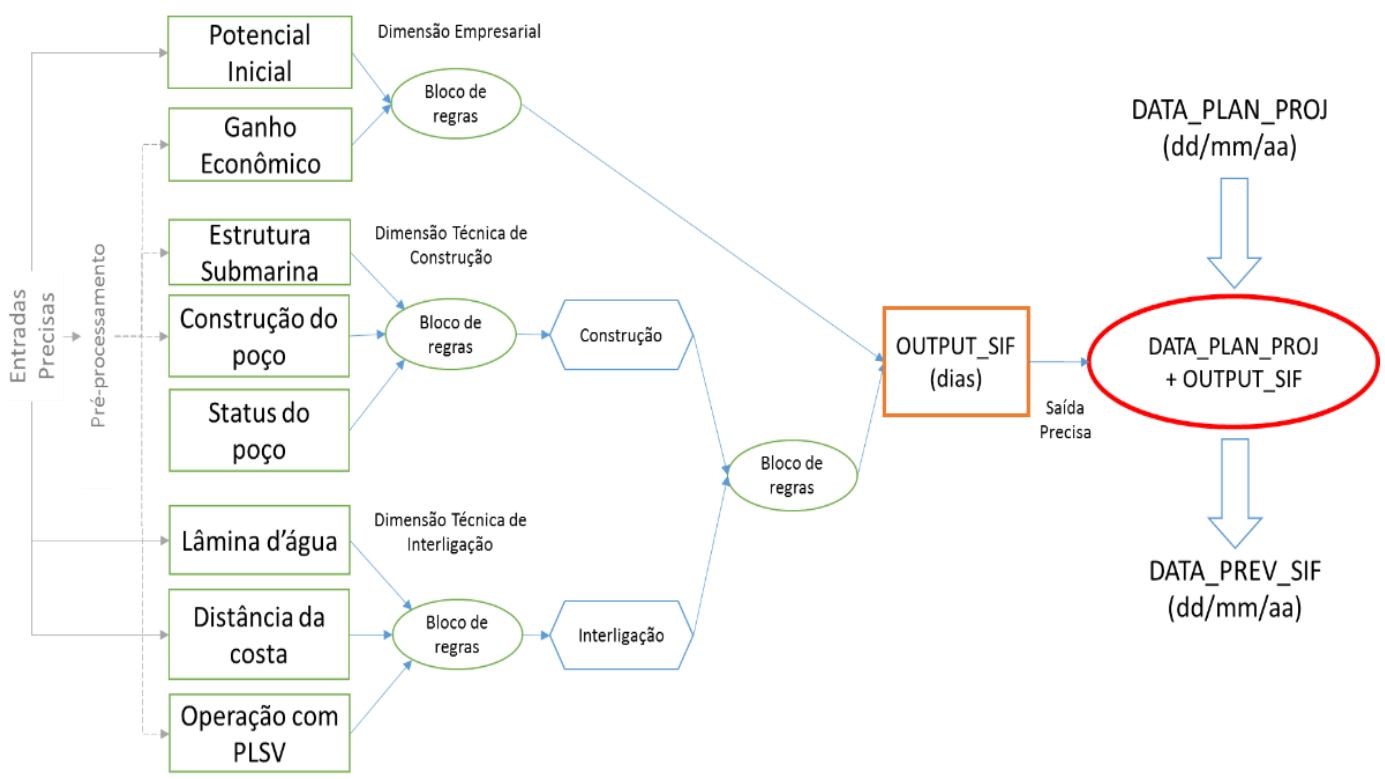

Figura 8 - Estrutura do sistema de inferência fuzzy para modelagem da Data de Entrada em produção de poços.

O objetivo do sistema de inferência fuzzy é avaliar e ajustar a data planejada pelo projeto (DATA_PLAN_PROJ, na Figura 8), gerando uma nova data para o início da produção dos poços que minimiza os desvios em relação à data que efetivamente os poços iniciarão a sua produção.

A saída do sistema de inferência fuzzy (OUTPUT_SIF) representa o ajuste em dias a ser realizado na data previamente planejada. Ou seja, a nova data de início, denominada DATA_PREV_SIF, é calculada pela soma do OUTPUT_SIF com a DATA_PLAN_PROJ, conforme indicado na Figura 8.

A DATA_PREV_SIF será utilizada como a nova referência da modelagem do índice $t$ da variável $P o c ̧ o_{i t}$ na metodologia de previsão da produção de petróleo descrito no Capítulo 3. Sendo a DATA_PREV_SIF uma data mais próxima à data em que o poço irá iniciar a sua produção efetivamente, quando comparada à DATA_PLAN_PROJ, a sua utilização deve tornar o resultado da simulação estocástica mais preciso.

As variáveis de entrada do sistema são as características dos poços que estão planejados para entrar em produção no horizonte de planejamento: potencial de produção inicial esperado, ganho econômico do projeto no qual o poço está inserido, lâmina d'água, distância do poço para a costa, complexidade da operação de interligação do poço à plataforma (operação com embarcação do tipo Pipe Line 
Suporte Vessel, PLSV) e complexidade da estrutura submarina necessária para produção do poço.

Como ilustrado na Figura 8, o sistema completo é composto de três subsistemas fuzzy e avalia as dimensões Empresarial e Técnica que influenciam um eventual atraso ou antecipação da entrada em produção de um poço de petróleo em relação à data inicialmente planejada pelo projeto. $\mathrm{O}$ primeiro subsistema de inferência representa a dimensão Empresarial e os demais subsistemas de inferência representam a dimensão Técnica subdividida em aspectos da Construção e da Interligação do poço.

\section{2.}

\section{Dimensão Empresarial}

A dimensão Empresarial do sistema de inferência fuzzy modela a influência dos interesses estratégicos da empresa na postergação ou antecipação da data de início da produção de um poço. Como os recursos (e.g. árvores de natal molhada, linhas, sondas e embarcações de apoio) necessários para iniciar a produção dos poços planejados para entrarem em produção são compartilhados, um poço que gera um alto retorno financeiro pode influenciar a mobilização de esforços para a sua antecipação. Caso o poço gere baixo retorno financeiro, este pode perder prioridade, não ter recursos alocados e, consequentemente, ser postergado.

O retorno financeiro de um poço está diretamente relacionado ao seu potencial de produção, porém esta não é a única variável a ser considerada, pois os poços podem estar inseridos em projeto de desenvolvimento da produção com diferentes rentabilidades por conta de custos operacionais, investimentos e, especialmente, contratos de parceria. Sendo assim, a dimensão Empresarial relaciona o Potencial Inicial dos poços com o Ganho Econômico gerado pelo projeto como um todo para definir o interesse empresarial. $\mathrm{O}$ seguinte conjunto de regras é definido com o objetivo de representar o interesse empresarial em alterar a data de início de produção de um poço.

\footnotetext{
SE Potencial ALTO e Ganho Econômico ALTO, ENTÃO Defasagem NEG_FORTE

SE Potencial ALTO e Ganho Econômico MÉDIO, ENTÃO Defasagem NEG_LEVE
} 
SE Potencial MÉDIO e Ganho Econômico ALTO, ENTÃO Defasagem NEG_LEVE

SE Potencial MÉDIO e Ganho Econômico MÉDIO, ENTÃO Defasagem INDIFERENTE

SE Potencial ALTO e Ganho Econômico BAIXO, ENTÃO Defasagem INDIFERENTE

SE Potencial BAIXO e Ganho Econômico ALTO, ENTÃO Defasagem INDIFERENTE

SE Potencial BAIXO e Ganho Econômico MÉDIO, ENTÃO Defasagem POS_LEVE

SE Potencial MÉDIO e Ganho Econômico BAIXO, ENTÃO Defasagem POS_LEVE

SE Potencial BAIXO e Ganho Econômico BAIXO, ENTÃO Defasagem POS_FORTE

As Figuras 9 a, b e c apresentam os conjuntos fuzzy dos antecedentes e consequente das regras que caracterizam as entradas Potencial Inicial e o Ganho Econômico e a saída Defasagem, ilustrando as entradas e saída precisas. Os limites dos termos linguísticos e o universo de discurso são apresentados na Tabela 3. Estes limites foram definidos a partir de entrevistas com especialistas tanto das áreas técnicas quanto das equipes de gestão e controle da produção e ajustados por um processo de sintonia que será detalhado no Capítulo 5.

Ganho Econômico é uma medida adimensional indireta que representa a lucratividade de um projeto de desenvolvimento da produção considerando o seu valor presente líquido normalizado, a avaliação das opções e a existência de parceria com outras empresas (Working Interests). Sendo assim, conforme indicado na Figura 8, as entradas precisas dos projetos de desenvolvimento da produção, inicialmente são pré-processadas para obtenção do critério Ganho Econômico variando entre 0 e 10, para que assim seja possível avaliar o grau de compatibilidade em relação aos conceitos estabelecidos para variável linguística.
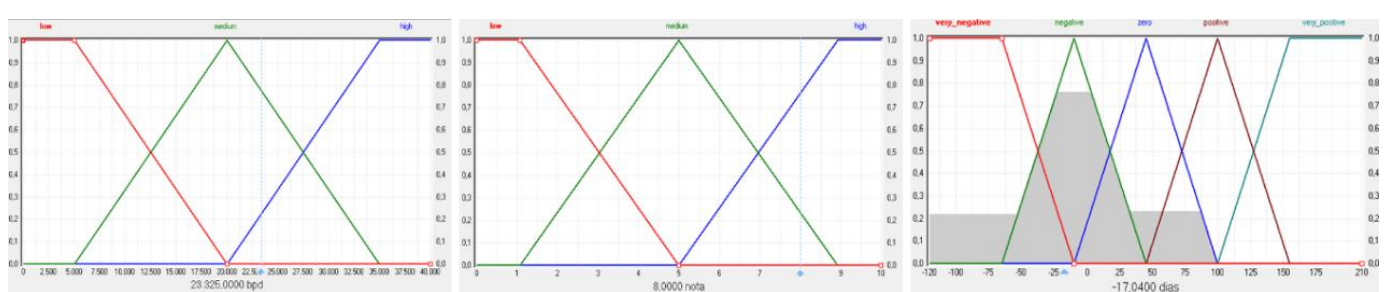

Figura 9 - Conjuntos fuzzy da dimensão Empresarial: entradas (a) Potencial, (b) Ganho Econômico e (c) saída Defasagem. 
Tabela 3 - Limites dos termos linguísticos e os universos de discurso das entradas Potencial e Ganho Econômico.

\begin{tabular}{clc} 
Variáveis de entrada & \multicolumn{1}{c}{ Descrição } & Termos linguísticos \\
\hline Potencial Inicial & Volume de produção inicial de petróleo & Baixo $(0-20.000)$ \\
(bpd) $(0-40.000)$ & esperado para o poço em barris por dia (bpd) & Médio $(5.000-35.000)$ \\
& & Alto $(20.00-40.000)$ \\
Ganho Econômico & Ganho Econômico do projeto de & Baixo (0-5) \\
(ad) $(0-10)$ & desenvolvimento da produção do qual o poço & Médio (1-9) \\
& faz parte & Alto (5- 10) \\
\hline
\end{tabular}

Assumindo que os valores das entradas são $23.325 \mathrm{bpd}$ para o potencial e 8,0 para o ganho econômico conforme indicado nas Figuras 9 a e b, teremos: grau de compatibilidade diferente de zeros nos conjuntos médio e alto de ambos antecedentes, ativação das regras de defasagem Negativo_Forte, Negativo_Leve e Indiferente e, portanto, alteração do conjunto do consequente conforme a região em destaque na Figura 9 c. Utilizando o método de defuzzificação centro de área, a inferência resulta em uma defasagem de -17 dias, coerente com o interesse empresarial de antecipação de um poço de Potencial Inicial e Ganho Econômico altos. Pondera-se, todavia, que neste momento o resultado da defuzzificação não tem sentido completo, pois o conjunto fuzzy resultante ainda não está considerando o efeito da dimensão Técnica.

\section{3. \\ Dimensão Técnica}

A Dimensão Técnica modela a influência das características dos poços nas operações de Construção e Interligação do poço à plataforma. Características mais severas ou novas implicam em operações de maior complexidade que tendem a durar mais tempo, impactando diretamente na postergação do início da operação dos poços. Em poços que apresentam caraterísticas mais simples ou usuais, as operações são mais previsíveis, podendo durar menos do que o esperado, gerando assim uma antecipação no início da produção.

Como apresentado na Figura 8, as variáveis de entrada da dimensão Técnica foram agrupadas em dois subsistemas fuzzy: Construção e Interligação. Foram criados subsistemas buscando reduzir o número de possíveis regras e permitir a avaliação conjunta de aspectos similares relevantes para o problema. Isto visando facilitar a validação do modelo através de uma estrutura com maior capacidade explicativa. 
A Construção do poço engloba as operações de perfuração, completação e estrutura submarina (e.g. linhas, manifolds, árvores de natal) necessárias para a produção do poço. A Interligação representa as operações de instalação das linhas flexíveis, rígidas, umbilicais eletro-hidráulicos e risers que conectam a árvore de natal à plataforma. As Figuras $10 \mathrm{a}$ e b ilustram um poço perfurado, completado e interligado e destacam a estrutura submarina de um conjunto de poços.
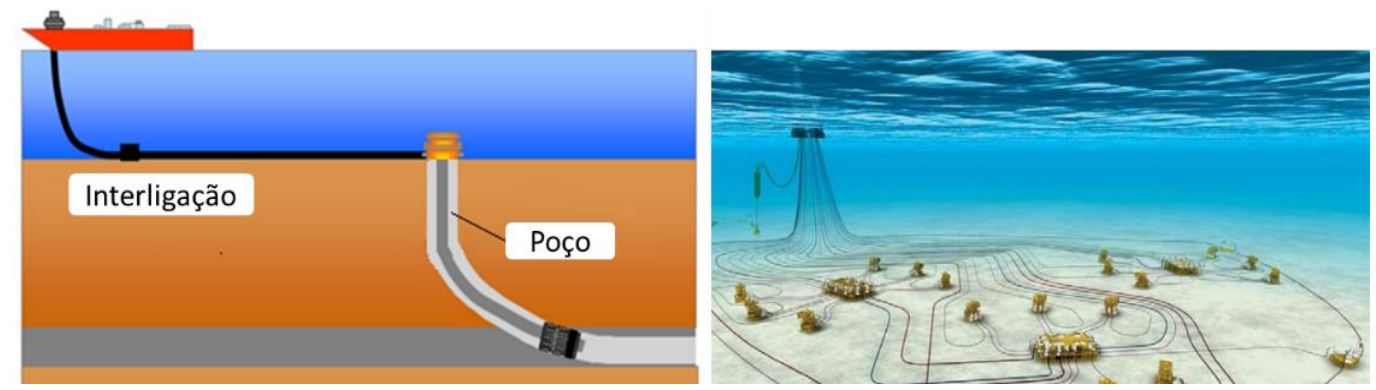

Figura 10 - (a) Esquema de poço perfurado, completado e interligado (b) estrutura submarina de um conjunto de poços.

\subsection{1. \\ Dimensão Técnica de Construção}

O subsistema de inferência Construção da dimensão Técnica avalia as características da construção que podem resultar na antecipação ou no atraso das atividades de interligação do poço à plataforma. As atividades de construção e interligação são sequenciais e, portanto, um atraso na construção resulta, por exemplo, em um início mais tarde da interligação. As variáveis consideradas neste subsistema são: a estrutura de equipamentos submarinos necessários para a operação do poço, a complexidades da construção do poço que engloba a perfuração e completação do poço e o status da construção.

O sistema adota uma importante regra considerando a variável singleton Status do Poço que assume O, se o poço não está disponível e 1 se o poço está disponível:

SE Poço DISPONÍVEL e Construção do poço QUALQUER e Estrutura Submarina QUALQUER ENTÃO defasagem INDIFERENTE

Como as atividades de Construção e Interligação do poço são sequenciais, esta regra indica que se o poço já está disponível, i.e., os equipamentos 
submarinos estão disponíveis e a perfuração e completação já foram finalizadas no momento em que a previsão é feita, a Construção não pode ser considerada e assim a Dimensão Técnica se reduz ao subsistema Interligação.

As nove regras resultantes dos termos linguísticos das demais variáveis são resumidas na Tabela 4. As Figuras 11 a e b apresentam os conjuntos fuzzy dos antecedentes e ilustram entradas precisas. Os limites dos termos linguísticos e o universo de discurso são apresentados na Tabela 5.

Assim como a variável linguística Ganho Econômico da dimensão Empresarial as variáveis Estrutura Submarina e Construção do Poço são adimensionais, portanto a suas entradas precisas são obtidas indiretamente no préprocessamento. A entrada da variável Estrutura Submarina é definida através da normalização da distância do poço à plataforma e pela definição de pesos para os tipos e tecnologia das linhas (serviço, produção, umbilicais), manifolds e árvores de natal necessárias para produção do poço. A entrada da variável Construção do Poço é definida da normalização da profundidade final dos poços pela definição de pesos para geometria dos poços (vertical, direcional e horizontal) e método de elevação (surgente, gás lift, bombeio centrifugo submerso).

Tabela 4 - Bloco de regras do subsistema de inferência Construção.

\begin{tabular}{|c|c|c|c|}
\hline \multirow{2}{*}{ Estrutura } & \multicolumn{3}{|c|}{ Construção do poço } \\
\cline { 2 - 4 } Submarina & Alto & Médio & Baixo \\
\hline Alto & Positivo & Positivo & Indiferente \\
\hline Médio & Positivo & Indiferente & Negativo \\
\hline Baixo & Indiferente & Negativo & Negativo \\
\hline
\end{tabular}

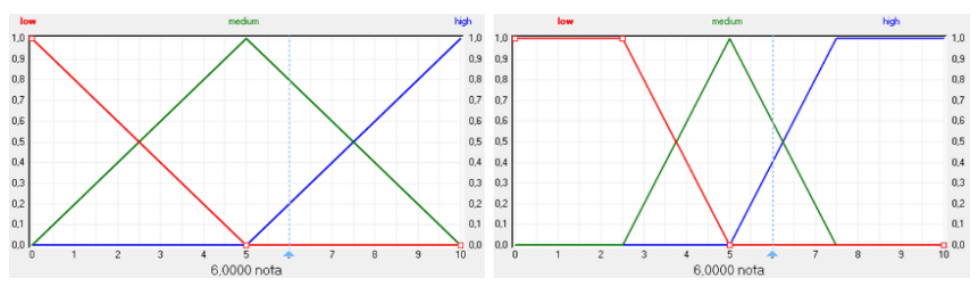

Figura 11 - Conjuntos fuzzy do subsistema de inferência Construção (a) Estrutura Submarina e (b) Construção do poço. 
Tabela 5 - Limites dos termos linguísticos e os universos de discurso das entradas Estrutura Submarina e Construção do poço

\begin{tabular}{|c|c|c|}
\hline Variáveis de entrada & Descrição & Termos linguísticos \\
\hline $\begin{array}{l}\text { Estrutura Submarina } \\
\quad \text { (ad) }(0-10)\end{array}$ & $\begin{array}{l}\text { Complexidade da estrutura submarina (e.g. linhas, } \\
\text { manifolds, árvores de natal) necessária para a } \\
\text { produção do poço avaliada entre } 0 \text { e } 10\end{array}$ & $\begin{array}{c}\text { Simples }(0-5) \\
\text { Média }(0-10) \\
\text { Complexa }(5-10)\end{array}$ \\
\hline $\begin{array}{l}\text { Construção do poço } \\
\text { (ad) }(0-10)\end{array}$ & $\begin{array}{l}\text { Complexidade da perfuração e completação do } \\
\text { poço avaliada entre } 0 \text { e } 10\end{array}$ & $\begin{array}{c}\text { Simples }(0-5) \\
\text { Média }(2,5-7,5) \\
\text { Complexa }(5-10)\end{array}$ \\
\hline Status do Poço (O/1) & $\begin{array}{l}\text { Status disponibilidade do poço para sua } \\
\text { interligação à plataforma }\end{array}$ & $\begin{array}{l}\text { Não Disponível, } \\
\text { Disponível }\end{array}$ \\
\hline
\end{tabular}

\subsection{2.}

\section{Dimensão Técnica de Interligação}

O subsistema de inferência Interligação da dimensão Técnica relaciona as características técnicas do poço que são relevantes à sua interligação à plataforma. As variáveis consideradas estão resumidas na Tabela 6 e as Figuras 12 a, b e c apresentam os conjuntos fuzzy da cada uma delas e ilustram entradas precisas.

A variável linguística Operação com PLSV também é adimensional, logo a sua entrada precisa é obtido no pré-processamento considerando a capacidade do navio do tipo PLSV, o número de conexões a serem realizadas e a quantidade de trechos rígidos e flexíveis.

Tabela 6 - Limites dos termos linguísticos e os universos de discurso das entradas Distância da Costa, Lâmina d'água e Operação com PLSV.

\begin{tabular}{|c|c|c|}
\hline $\begin{array}{l}\text { Variáveis de } \\
\text { entrada }\end{array}$ & Descrição & Termos linguísticos \\
\hline $\begin{array}{c}\text { Lâmina d'água }(\mathrm{m}) \\
(0-3000)\end{array}$ & $\begin{array}{l}\text { Profundidade em metros da cabeça do } \\
\text { poço ao nível médio do mar }\end{array}$ & $\begin{array}{c}\text { Rasa }(0-1500) \\
\text { Profunda }(0-3000) \\
\text { Ultra-profunda }(1500-3000)\end{array}$ \\
\hline $\begin{array}{l}\text { Distância da Costa } \\
\qquad(\mathrm{km})(0-400)\end{array}$ & $\begin{array}{l}\text { Distância em quilômetros do poço } \\
\text { marítimo à costa }\end{array}$ & $\begin{array}{c}\text { Curta }(0-200) \\
\text { Média }(45-350) \\
\text { Grande }(200-400)\end{array}$ \\
\hline $\begin{array}{l}\text { Operação com PLSV } \\
\text { (ad) }(0-10)\end{array}$ & $\begin{array}{l}\text { Complexidade da operação de } \\
\text { interligação dos poços às plataformas } \\
\text { através de um navio do tipo PLSV }\end{array}$ & $\begin{array}{c}\text { Simples }(0-5) \\
\text { Média }(2,5-7,5) \\
\text { Complexa }(5-10)\end{array}$ \\
\hline
\end{tabular}




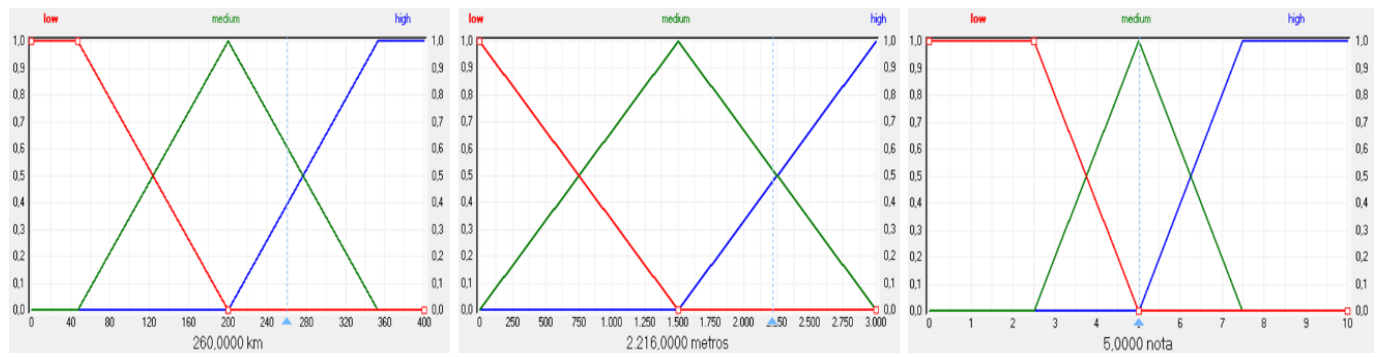

Figura 12 - Conjuntos fuzzy do subsistema de inferência Interligação (a) Distância da Costa, (b) Lâmina d'água e (c) Operação com PLSV.

Como apresentado na Figura 12, as variáveis são compostas por três termos linguísticos de forma que podem gerar até 27 regras. As regras consideram que o nível de complexidade da operação impacta na duração da atividade. As regras geradas são listadas e seus respectivos pesos são exemplificados abaixo.

(PESO 100) SE Distância da Costa GRANDE e Lâmina d'agua ULTRAPROFUNDA e Operação PLSVs COMPLEXA, ENTÃO POSITIVO

(PESO 60) SE Distância da Costa GRANDE e Lâmina d'agua ULTRAPROFUNDA e Operação PLSVs MÉDIA, ENTÃO POSITIVO

(PESO 60) SE Distância da Costa MÉDIA e Lâmina d'agua ULTRAPROFUNDA e Operação PLSVs COMPLEXA, ENTÃO POSITIVO

(PESO 60) SE Distância da Costa GRANDE e Lâmina d'agua PROFUNDA e Operação PLSVs COMPLEXA, ENTÃO POSITIVO

(PESO 40) SE Distância da Costa CURTA e Lâmina d'agua ULTRAPROFUNDA e Operação PLSVs COMPLEXA, ENTÃO POSITIVO

(PESO 40) SE Distância da Costa GRANDE e Lâmina d'agua ULTRAPROFUNDA e Operação PLSVs SIMPLES, ENTÃO POSITIVO

(PESO 40) SE Distância da Costa GRANDE e Lâmina d'agua RASA e Operação PLSVs COMPLEXA, ENTÃO POSITIVO

(PESO 100) SE Distância da Costa CURTA e Lâmina d'agua RASA e Operação PLSVs SIMPLES, ENTÃO NEGATIVO

(PESO 60) SE Distância da Costa MÉDIA e Lâmina d'agua RASA e Operação PLSVS SIMPLES, ENTÃO NEGATIVO

(PESO 60) SE Distância da Costa CURTA e Lâmina d'agua RASA e Operação PLSVs MÉDIA, ENTÃO NEGATIVO

(PESO 60) SE Distância da Costa CURTA e Lâmina d'agua PROFUNDA e Operação PLSVs SIMPLES, ENTÃO NEGATIVO

(PESO 40) SE Distância da Costa CURTA e Lâmina d'agua RASA e Operação PLSVs COMPLEXA, ENTÃO NEGATIVO

(PESO 40) SE Distância da Costa GRANDE e Lâmina d'agua RASA e Operação PLSVs SIMPLES, ENTÃO NEGATIVO 
(PESO 40) SE Distância da Costa CURTA e Lâmina d'agua ULTRAPROFUNDA e Operação PLSVs SIMPLES, ENTÃO NEGATIVO

(PESO 100) SE Lâmina d'agua RASA e Distância da Costa MÉDIA e Operação PLSVS MÉDIA, ENTÃO INDIFERENTE

(PESO 100) SE Lâmina d'agua PROFUNDA e Distância da Costa CURTA e Operação PLSVS MÉDIA, ENTÃO INDIFERENTE

(PESO 100) SE Lâmina d'agua PROFUNDA e Distância da Costa MÉDIA e Operação PLSVS SIMPLES, ENTÃO INDIFERENTE

Conforme a Figura 8, os sistemas de inferência Construção e Interligação têm como saída variáveis intermediárias que são novamente combinadas através de um novo bloco de regras para obtenção da defasagem. As variáveis intermediárias passam a informação no formato fuzzy de um bloco de regras para o outro, não estando submetidas nem à fuzzificação nem à defuzzificação, ou seja, as variáveis intermediárias são somente linguísticas, valores fuzzy. As regras estão apresentadas na Tabela 7.

Tabela 7 - Bloco de regras do agrupamento dos subsistemas Construção e Interligação.

\begin{tabular}{|c|c|c|c|}
\hline \multirow{2}{*}{ Construção } & \multicolumn{3}{|c|}{ Interligação } \\
\cline { 2 - 4 } & Positivo & Indiferente & Negativo \\
\hline Positivo & Positivo_Forte & Positivo & Indiferente \\
\hline Indiferente & Positivo & Indiferente & Negativo \\
\hline Negativo & Indiferente & Negativo & Negativo_Forte \\
\hline
\end{tabular}

Para exemplificar a dinâmica dos sistemas de inferência Construção e Interligação, considere que um determinado poço não está disponível (i.e. Status = ZERO), a construção e a estrutura submarina foram avaliadas como 6 , o poço está localizado a $260 \mathrm{~km}$ da costa, em uma lâmina d'água de $2.216 \mathrm{~m}$ e a operação de PLSV foi avaliada como 5, conforme ilustrado nas Figuras 11 a e b e 12 a, b e c.

Neste caso, teremos para variável intermediária Construção, Indiferente (Zero) com 0,6 e Positivo com 0,4 de grau de pertinência e para a variável intermediária Interligação Positivo 0,23 com grau de pertinência o que resulta por fim em uma previsão de defasagem de +140 dias (indicado nas Figuras 13 a, b e c). 


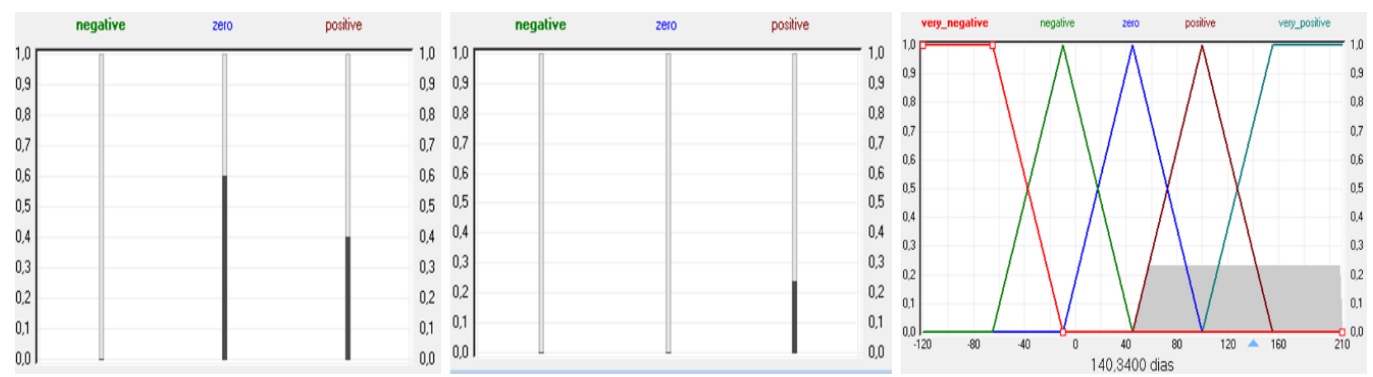

Figura 13 - Variáveis intermediárias (a) Construção e (b) Interligação e (c) conjunto fuzzy da saída Defasagem Técnica.

Seguindo o exemplo do poço considerado nas seções anteriores e associando conjuntos fuzzy gerados pela dimensão Empresarial (Figura 9 a) e pelo subsistema Construção e Interligação da dimensão Técnica (Figura 13 c), adotando o conectivo "ou”, obtém-se o conjunto fuzzy resultante final apresentado na Figura 14 c. Utilizando o método de defuzzificação centro de área encontra-se o resultado final crisp de +31 dias. O método de defuzzificação centro de área foi utilizado para considerar relevante qualquer ativação de um dos conjuntos de saída no resultado final da inferência.

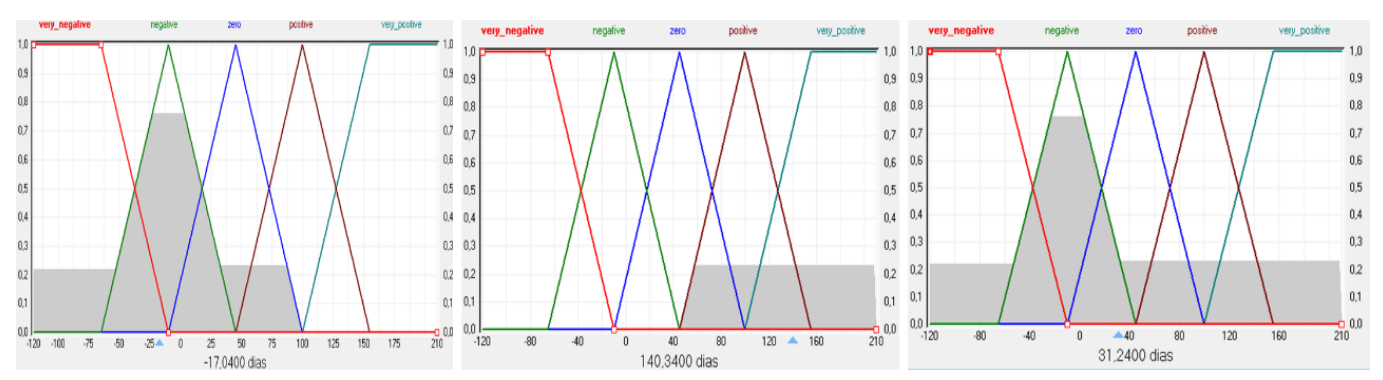

Figura 14 - (a) Conjunto fuzzy de saída considerando apenas a dimensão Empresarial, (b) conjunto fuzzy de saída considerando apenas os subsistemas de inferência Construção e Interligação e (c) conjunto fuzzy de saída considerando todos os sistemas de inferência fuzzy.

\section{4 .}

\section{Implementação do Sistema de Inferência Fuzzy}

Para implementação do protótipo foi utilizado o software fuzzyTECH ${ }^{\circledR}$ comercial desenvolvido por Inform Software Corporation que possui uma estrutura específica para lógica fuzzy (INFORM, 2001). Esta escolha agilizou o desenvolvimento do protótipo necessário à sintonia e validação do modelo de inferência fuzzy. A interface do fuzzyTECH ${ }^{\circledR}$ possui um editor de funções de pertinência para as variáveis de entrada e saída onde, através de uma interface 
gráfica, é possível inserir de forma amigável os conjuntos fuzzy de cada variável linguística utilizada.

O fuzzyTECH ${ }^{\circledR}$ possui uma estrutura de depuração capaz de ler um arquivo texto com as informações relacionadas aos poços utilizados para teste do modelo, e submetê-lo ao sistema de inferência fuzzy implementado no fuzzyTECH ${ }^{\circledR}$, gerando assim as saídas do modelo. Isso permitiu que os dados dos poços selecionados fossem agrupados e tratados em uma planilha Excel ${ }^{\circledR}$ para calcular a saída final do modelo.

As Figuras 15 a, b, c e d ilustram a interface gráfica do sistema fuzzyTECH ${ }^{\circledR}$ para parametrização das variáveis linguísticas, criação do bloco de regras, parametrização da variável de saída e visão geral do sistema de inferência fuzzy.

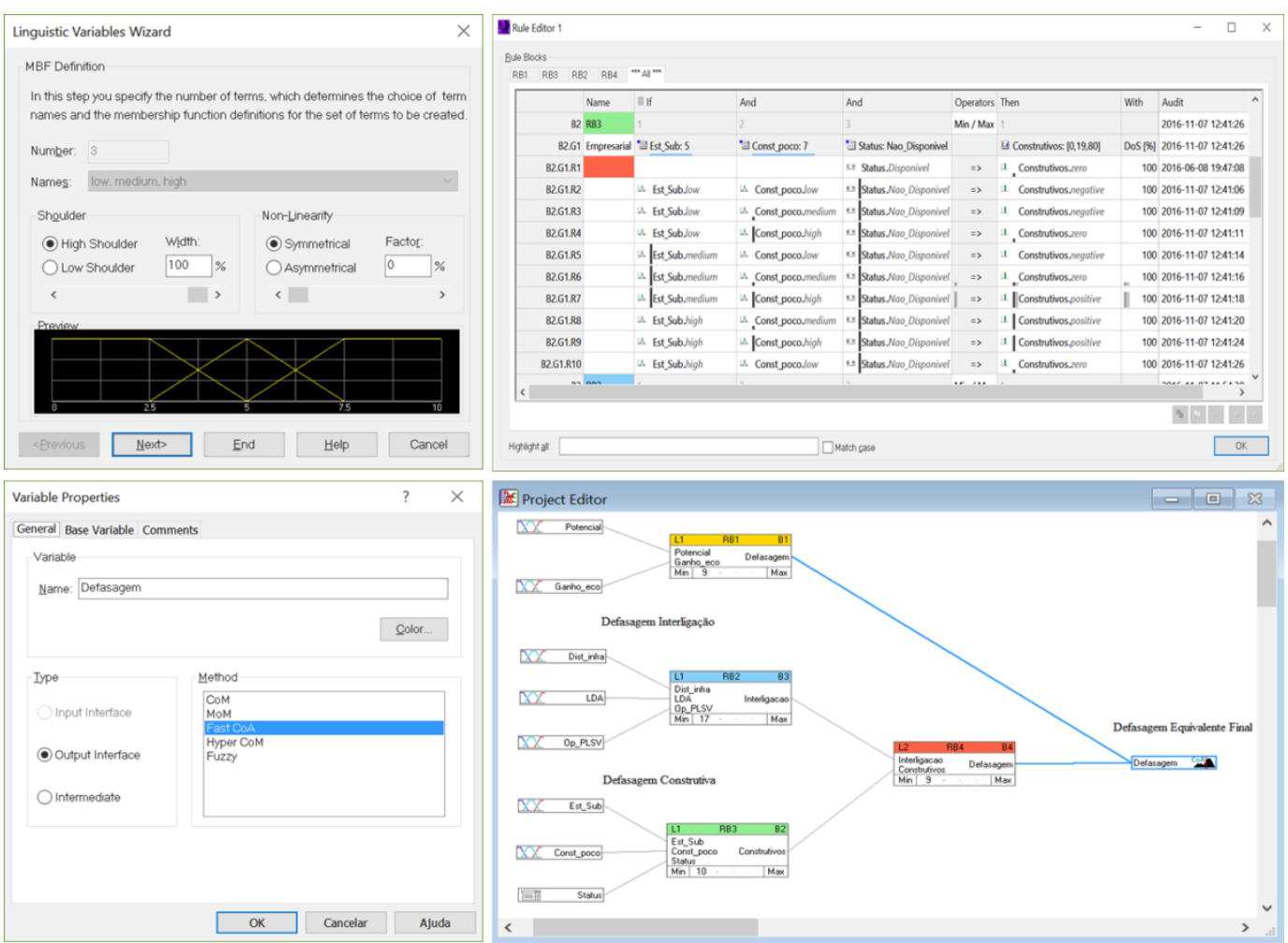

Figura 15 - Interface gráfica do software fuzzyTECH ${ }^{\circledR}$ : (a) parametrização das variáveis linguísticas; (b) criação do bloco de regras; (c) parametrização da variável de saída e (d) visão geral do sistema de inferência fuzzy. 


\section{5}

\section{Resultados}

Este capítulo expõe o processo para sintonia e validação do sistema de inferência fuzzy e apresenta os resultados obtidos. Em seguida, estes resultados são aplicados à metodologia de previsão e análise de risco de produção de petróleo com o objetivo de avaliar o efeito da utilização do sistema de inferência fuzzy no resultado final da previsão. Por fim, é feita uma discussão sobre o valor do ganho de precisão na previsão de produção para o estabelecimento da meta de produção.

\section{1.}

\section{Sintonia do Sistema de Inferência Fuzzy}

Os sistemas de inferência fuzzy inicialmente concebidos foram submetidos às informações de poços com resultados já conhecidos para sintonizar sua capacidade de previsão da data de início da produção dos poços. Assim, poços que foram planejados e já entraram em produção devem apresentar resultados coerentes quando seus dados forem submetidos à análise dos sistemas de inferência fuzzy. Esses devem ser robustos o suficiente para gerar uma nova data para o início da produção dos poços (DATA_PREV_SIF) mais próxima à data que efetivamente os poços iniciaram a sua produção (DATA_REALIZADA) quando comparada à data planejada pelo projeto (DATA_PLAN_PROJ).

A medida que foi definida para avaliar o desempenho do modelo foi: quanto menor a defasagem da nova data obtida com o resultado final da inferência fuzzy em relação à data realizada, melhor. As estatísticas utilizadas como medidas de desempenho foram média, desvio padrão e coeficiente de variação conforme definido abaixo:

$\bar{X}_{\text {|DEFASAGEM_PREV_SIF } \mid}<\bar{X}_{\text {|DEFASAGEM_PLAN_PROJ } \mid}$

$S_{\mid \text {DEFASAGEM_PREV_SIF } \mid}<S_{\mid \text {DEFASAGEM_PLAN_PROJ } \mid}$

$C o V_{\mid \text {DEFASAGEM_PREV_SIF } \mid}<\operatorname{CoV}_{\mid \text {DEFASAGEM_PLAN_PROJ } \mid}$

Onde:

DEFASAGEM_PREV_SIF $=$ DATA_REALIZADA - DATA_PREV_SIF

DEFASAGEM_PLAN_PROJ = DATA_REALIZADA - DATA_PLAN_PROJ 
O processo de sintonia consistiu na apresentação das características empresariais e técnicas de 35 poços planejados e realizados no ano de 2015 e posterior ajuste no suporte, formato e universo de discurso das variáveis linguísticas de entrada e saída, mudança do método de defuzzificação e atribuição de pesos para algumas regras. Os ajustes no sistema de inferência fuzzy foram feitos mantendo as relações conceituais estabelecidas inicialmente e buscando gerar uma DATA_PREV_SIF mais próxima à DATA_REALIZADA. O processo de sintonia seguiu a seguinte rotina:

a) Calcular DEFASAGEM_PLAN_PROJ = DATA_REALIZADA DATA_PLAN_PROJ;

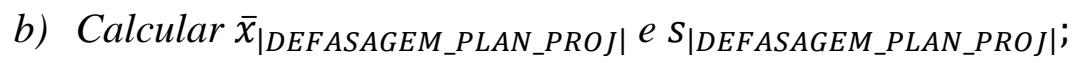

c) Ajustar os parâmetros do sistema de inferência fuzzy no fuzzyTECH ${ }^{\circledR}$;

d) Executar o sistema de inferência fuzzy no fuzzyTECH ${ }^{\circledR}$ e obter OUTPUT_SIF;

e) Calcular DATA_PREV_SIF = DATA_PLAN_PROJ + OUTPUT_SIF;

f) Calcular DEFASAGEM_PREV_SIF =DATA_REALIZADA DATA_PREV_SIF;

g) Calcular $\bar{x}_{\left|D E F A S A G E M_{-} P R E V_{-} S I F\right|}$ e $S_{\left|D E F A S A G E M_{-} P R E V_{-} S I F\right|}$;

h) Se $\bar{x}_{\left|D E F A S A G E M_{2} P R E V_{-} S I F\right|}>\bar{x}_{\left|D E F A S A G E M_{-} P L A N_{-} P R O J\right|}$ elou $S_{\left|D E F A S A G E M_{-} P R E V_{-} S I F\right|}>S_{\left|D E F A S A G E M_{-} P L A N_{-} P R O J\right|}$ volte ao passo $c$;

i) Se $\bar{x}_{\left|D E F A S A G E M_{-} P R E V_{-} S I F\right|}<\bar{x}_{\mid \text {DEFASAGEM_PLAN_PROJ| }} e$ $S_{\left|D E F A S A G E M_{-} P R E V_{-} S I F\right|}<s_{\left|D E F A S A G E M_{-} P L A N_{-} P R O J\right|}$ então pare.

Os dados utilizados no processo de sintonia e os resultados encontrados são apresentados na Tabela 8 . 
Tabela 8 - Dados e resultados do processo de sintonia.

\begin{tabular}{|c|c|c|c|c|c|c|c|c|c|c|c|c|c|c|}
\hline Poço & $\begin{array}{c}\text { Ganho } \\
\text { Eco. }\end{array}$ & Potencial & $\begin{array}{l}\text { Est. } \\
\text { l Sub. }\end{array}$ & $\begin{array}{l}\text { Const. } \\
\text { Poço }\end{array}$ & Status & $\begin{array}{l}\text { Lâmina } \\
\text { d'água }\end{array}$ & $\begin{array}{l}\text { Dist } \\
\text { costa }\end{array}$ & $\begin{array}{c}\text { Op. } \\
\text { PLSV }\end{array}$ & $\begin{array}{c}\text { DATA } \\
\text { PLAN_PROJ }\end{array}$ & $\begin{array}{c}\text { DATA } \\
\text { REALIZ. }\end{array}$ & $\begin{array}{c}\text { DEF. } \\
\text { PLAN_PROJ }\end{array}$ & $\begin{array}{c}\text { OUTPUT } \\
\text { SIF }\end{array}$ & $\begin{array}{c}\text { DATA } \\
\text { PREV_SIF }\end{array}$ & $\begin{array}{c}\text { DEF. } \\
\text { PREV_SIF }\end{array}$ \\
\hline P1 & 7 & 4.571 & 3 & 5 & 0 & 1.358 & 160 & 3 & 15-jan-15 & 31-jan-15 & 16 & 22 & 06-fev-15 & -6 \\
\hline P2 & 8 & 5.340 & 4 & 8 & 0 & 1.180 & 110 & 4 & 24-jan- 15 & 15 -mar-15 & 50 & 54 & 19-mar-15 & -4 \\
\hline P3 & 10 & 17.152 & 6 & 4 & 0 & 1.401 & 85 & 4 & 04-fev- 15 & 18 -fev- 15 & 14 & 17 & 21 -fev- 15 & -3 \\
\hline P4 & 8 & 12.002 & 5 & 8 & 0 & 1.894 & 193 & 5 & 08-fev- 15 & $10-m a r-15$ & 30 & 37 & 17 -mar-15 & -7 \\
\hline P5 & 10 & 11.981 & 5 & 6 & 0 & 1.267 & 120 & 4 & 08-fev-15 & $09-$ fev- 15 & 1 & 38 & 18 -mar-15 & -37 \\
\hline P6 & 10 & 6.829 & 5 & 5 & 0 & 1.514 & 200 & 4 & $10-$ fev- 15 & 01-fev- 15 & -9 & 26 & 08-mar-15 & -35 \\
\hline P7 & 8 & 22.080 & 5 & 7 & 1 & 2.110 & 280 & 5 & $11-$ fev- 15 & 13 -fev- 15 & 2 & 29 & 12 -mar-15 & -27 \\
\hline P8 & 10 & 256 & 5 & 5 & 0 & 1.361 & 160 & 3 & 15 -fev- 15 & 27 -abr- 15 & 71 & 34 & 21-mar-15 & 37 \\
\hline P9 & 8 & 23.753 & 6 & 7 & 0 & 2.143 & 310 & 7 & 18 -fev- 15 & $16-m a r-15$ & 26 & 67 & 26-abr- 15 & -41 \\
\hline P10 & 8 & 35.057 & 6 & 7 & 0 & 2.154 & 310 & 7 & 01-mar-15 & 26-mar- 15 & 25 & 40 & 10 -abr- 15 & -15 \\
\hline P11 & 10 & 20.553 & 9 & 8 & 0 & 1.433 & 85 & 7 & 02 -mar- 15 & 21-mai- 15 & 80 & 33 & 04-abr-15 & 47 \\
\hline P12 & 8 & 23.325 & 6 & 7 & 0 & 2.216 & 260 & 5 & 03-mar-15 & 17-mar- 15 & 14 & 51 & 23-abr- 15 & -37 \\
\hline P13 & 10 & 4.205 & 5 & 6 & 0 & 1.238 & 85 & 6 & $05-\operatorname{mar}-15$ & 18 -abr- 15 & 44 & 52 & 26-abr- 15 & -8 \\
\hline P14 & 8 & 13.404 & 5 & 8 & 0 & 2.251 & 226 & 5 & 22-mar- 15 & 05 -mai- 15 & 44 & 53 & 14-mai- 15 & -9 \\
\hline P15 & 8 & 27.248 & 6 & 7 & 0 & 2.182 & 310 & 7 & 23-mar-15 & 29-mai-15 & 67 & 53 & 15 -mai-15 & 14 \\
\hline P16 & 10 & 16.609 & 7 & 7 & 0 & 1.340 & 85 & 6 & 25 -mar- 15 & 22-jun-15 & 89 & 40 & 04-mai- 15 & 49 \\
\hline P17 & 10 & 1.232 & 5 & 7 & 0 & 478 & 138 & 3 & $30-m a r-15$ & 03-mai- 15 & 34 & 51 & 20-mai-15 & -17 \\
\hline P18 & 8 & 23.752 & 6 & 7 & 0 & 2.143 & 310 & 7 & 02 -abr- 15 & 30 -jun- 15 & 89 & 67 & 08-jun- 15 & 22 \\
\hline P19 & 10 & 13.249 & 5 & 6 & 0 & 1.597 & 74 & 3 & $30-a b r-15$ & 01-mai-15 & 1 & 33 & 02-jun- 15 & -32 \\
\hline P20 & 10 & 1.924 & 4 & 5 & 0 & 108 & 50 & 3 & 01-mai-15 & 22 -nov- 15 & 205 & -5 & 26-abr- 15 & 210 \\
\hline P21 & 10 & 5.675 & 4 & 3 & 0 & 1.729 & 136 & 4 & 24-mai-15 & 21-mar-15 & -64 & 3 & 27-mai-15 & -67 \\
\hline P22 & 10 & 6.483 & 5 & 5 & 0 & 1.684 & 136 & 6 & 04-jun- 15 & 18 -jun- 15 & 14 & 36 & 10-jul-15 & -22 \\
\hline P23 & 10 & 12.786 & 4 & 4 & 1 & 1.356 & 85 & 6 & 22-jun- 15 & 02-jun- 15 & -20 & 5 & 27 -jun- 15 & -25 \\
\hline P24 & 10 & 6.868 & 6 & 2 & 0 & 4.340 & 120 & 5 & 07-jul-15 & 04 -set- 15 & 59 & 26 & 02-ago-15 & 33 \\
\hline P25 & 8 & 24.305 & 5 & 7 & 1 & 2.217 & 260 & 5 & 03-ago-15 & 01-jul-15 & -33 & 57 & 29 -set- 15 & -90 \\
\hline P26 & 10 & 6.247 & 5 & 5 & 0 & 1.098 & 200 & 5 & 24-ago-15 & 01-out-15 & 38 & 27 & 20 -set- 15 & 11 \\
\hline P27 & 4 & 1.260 & 5 & 6 & 0 & 1.081 & 175 & 6 & 28-ago-15 & 26 -set- 16 & 395 & 85 & 21-nov-15 & 310 \\
\hline P28 & 8 & 34.809 & 6 & 7 & 1 & 2.129 & 310 & 7 & 14 -set- 15 & 25 -set- 15 & 11 & 41 & 25 -out-15 & -30 \\
\hline P29 & 10 & 6.900 & 5 & 4 & 0 & 1.824 & 126 & 5 & 30 -set- 15 & 24-out- 15 & 24 & 24 & 24-out-15 & 0 \\
\hline P30 & 8 & 13.032 & 7 & 8 & 0 & 2.024 & 210 & 7 & 21-out-15 & 16-jan-16 & 87 & 43 & 03 -dez- 15 & 44 \\
\hline P31 & 10 & 8.421 & 5 & 4 & 0 & 1.484 & 85 & 5 & 01-nov-15 & 28-nov-15 & 27 & 20 & 21-nov-15 & 7 \\
\hline P32 & 10 & 27.982 & 4 & 8 & 1 & 2.239 & 260 & 4 & 04-nov-15 & 31-jul-15 & -96 & 1 & 05-nov-15 & -97 \\
\hline P33 & 10 & 2.312 & 5 & 4 & 0 & 730 & 110 & 5 & 23-nov-15 & 23-nov-15 & 0 & -6 & 17-nov-15 & 6 \\
\hline P34 & 10 & 9.177 & 5 & 6 & 0 & 1.356 & 85 & 6 & 13-dez- 15 & 26 -fev- 16 & 75 & 42 & 24-jan- 16 & 33 \\
\hline P35 & 8 & 5.515 & 5 & 7 & 0 & 2.137 & 250 & 5 & $22-\mathrm{dez}-15$ & 24 -fev- 16 & 64 & 81 & 12 -mar-16 & -17 \\
\hline
\end{tabular}

A Tabela 9 compara as estatísticas dos resultados da DEFASAGEM_PLAN_PROJ e DEFASAGEM_PREV_SIF obtidas ao final do processo de sintonia do sistema de inferência fuzzy.

Tabela 9 - Estatísticas do processo de sintonia utilizando poços de 2015.

\begin{tabular}{ccc}
$\begin{array}{c}\text { Poços } \\
\mathbf{2 0 1 5}\end{array}$ & DEF. & DEF. \\
\hline Média & 54,80 & 41,40 \\
Desv.P & 78,71 & 59,44 \\
CoV & 143,64 & 143,57 \\
\hline
\end{tabular}

Observando a Tabela 8, nota-se que os poços 20 e 27 apresentam DEFASAGEM_PLAN_PROJ muito distinta dos demais poços, 205 e 395 dias respectivamente. Este comportamento dificilmente seria capturado pelo sistema de inferência fuzzy dado que o universo de discurso da variável de saída considerado adequado é de -120 até +210 dias. Sendo assim, e considerando que o sistema não prevê a ocorrência de eventos catastróficos, estes poços foram considerados 
outliers e removidos do processo de sintonia. Não prever eventos raros é uma limitação deste sistema de inferência fuzzy.

A Tabela 10 apresenta as estatísticas comparativas não considerando os poços 20 e 27.

Tabela 10 - Estatísticas do processo de sintonia utilizando poços de 2015 excluindo os poços $20 \mathrm{e}$ 27.

\begin{tabular}{rcc}
$\begin{array}{c}\text { Poços } \\
\mathbf{2 0 1 5}\end{array}$ & DEF. & DEF. \\
\hline Média & 39,94 & 28,15 \\
Desv.P & 41,82 & 22,89 \\
CoV & 104,72 & 81,30 \\
\hline
\end{tabular}

A retirada dos outliers melhora significativamente os resultados, reduzindo em $30 \%$ a média, $45 \%$ o desvio padrão e em $22 \%$ o coeficiente de variação da DEFASAGEM_PREV_SIF em relação à DEFASAGEM_PLAN_PROJ.

\section{2. \\ Validação do Sistema de Inferência Fuzzy}

A fim de validar a efetividade do modelo de inferência fuzzy sintonizado, este foi submetido a um novo conjunto de poços. Foram submetidos ao sistema 28 poços planejados e realizados até outubro de 2016. Os dados utilizados no processo de validação e os resultados encontrados são apresentados na Tabela 11. 
Tabela 11 - Dados e resultados do processo de validação

\begin{tabular}{|c|c|c|c|c|c|c|c|c|c|c|c|c|c|c|}
\hline Poço & $\begin{array}{c}\text { Ganho } \\
\text { Eco. }\end{array}$ & Potencial & $\begin{array}{l}\text { Est. } \\
\text { Sub. }\end{array}$ & $\begin{array}{c}\text { Const. } \\
\text { Poço }\end{array}$ & Status & $\begin{array}{c}\text { Lâmina } \\
\text { d'água }\end{array}$ & $\begin{array}{l}\text { Dist } \\
\text { costa }\end{array}$ & $\begin{array}{l}\text { Op. } \\
\text { PLSV }\end{array}$ & $\begin{array}{c}\text { DATA } \\
\text { PLAN_PROJ }\end{array}$ & $\begin{array}{c}\text { DATA } \\
\text { REALZZ. }\end{array}$ & $\begin{array}{c}\text { DEF. } \\
\text { PLAN_PROJ }\end{array}$ & $\begin{array}{c}\text { OUTPUT } \\
\text { SIF }\end{array}$ & $\begin{array}{c}\text { DATA } \\
\text { PREV_SIF }\end{array}$ & $\begin{array}{c}\text { DEF. } \\
\text { PREV_SIF }\end{array}$ \\
\hline P36 & 10 & 5.588 & 5 & 5 & 0 & 1.331 & 120 & 5 & 06-jan-16 & 06-fev-16 & 31 & 30 & 05 -fev-16 & 1 \\
\hline P37 & 10 & 3.055 & 5 & 4 & 1 & 1.705 & 136 & 5 & 10-jan-16 & 10-jan-16 & 0 & 27 & 06 -fev-16 & -27 \\
\hline P38 & 10 & 18.479 & 5 & 8 & 1 & 2.024 & 280 & 5 & 15-jan- 16 & 16-jan-16 & 1 & 68 & 23 -mar- 16 & -67 \\
\hline P39 & 8 & 17.438 & 5 & 7 & 0 & 2.137 & 280 & 5 & 14-fev-16 & 24 -fev- 16 & 10 & 79 & 03-mai-16 & -69 \\
\hline P40 & 8 & 17.398 & 9 & 7 & 0 & 2.179 & 310 & 10 & 17-fev-16 & 26-ago-16 & 191 & 79 & 06-mai-16 & 112 \\
\hline P41 & 8 & 29.029 & 5 & 7 & 1 & 2.121 & 270 & 5 & 25 -fev- 16 & 06 -fev-16 & -19 & 34 & 30 -mar-16 & -53 \\
\hline P42 & 8 & 5.031 & 5 & 3 & 1 & 667 & 110 & 5 & 31-mar-16 & 07-mar-16 & -24 & 1 & 01-abr-16 & -25 \\
\hline P43 & 10 & 9.629 & 5 & 5 & 1 & 1.469 & 85 & 4 & 01-abr-16 & 21-mar-16 & -11 & 26 & 27-abr- 16 & -37 \\
\hline P44 & 4 & 12.579 & 5 & 7 & 0 & 1.526 & 74 & 3 & 20 -abr- 16 & 11-ago-16 & 113 & 75 & 04-jul-16 & 38 \\
\hline P45 & 10 & 3.951 & 5 & 4 & 1 & 1.065 & 175 & 5 & 25 -abr- 16 & 13-abr-16 & -12 & 10 & 05-mai-16 & -22 \\
\hline P46 & 8 & 13.057 & 5 & 7 & 0 & 2.139 & 270 & 7 & 30 -abr-16 & 27 -set-16 & 150 & 90 & 29-jul-16 & 60 \\
\hline P47 & 10 & 5.899 & 5 & 7 & 0 & 1.100 & 175 & 6 & 15 -mai-16 & 24 -set-16 & 132 & 54 & 08-jul-16 & 78 \\
\hline P48 & 8 & 29.029 & 5 & 7 & 1 & 2.133 & 280 & 5 & 18-mai-16 & 19-abr-16 & -29 & 4 & 22-mai-16 & -33 \\
\hline P49 & 8 & 2.876 & 5 & 5 & 0 & 1.081 & 175 & 5 & 20-mai-16 & 19 -set-16 & 122 & 36 & 25-jun- 16 & 86 \\
\hline P50 & 10 & 19.999 & 5 & 7 & 1 & 2.222 & 270 & 5 & 30-mai-16 & 24-mar-16 & -67 & 22 & 21-jun-16 & -89 \\
\hline P51 & 10 & 18.719 & 2 & 5 & 1 & 948 & 175 & 3 & 30-mai-16 & 13 -abr- 16 & -47 & 14 & 13-jun-16 & -61 \\
\hline P52 & 2 & 163 & 5 & 3 & 0 & 68 & 52 & 4 & 05 -jun-16 & 16-out-16 & 133 & 66 & 10-ago-16 & 67 \\
\hline P53 & 8 & 4.999 & 5 & 5 & 0 & 1.660 & 136 & 6 & 25 -jun-16 & 03 -set-16 & 70 & 39 & 03-ago-16 & 31 \\
\hline P54 & 10 & 7.999 & 5 & 6 & 1 & 1.190 & 175 & 5 & 02-jul-16 & 17 -jun-16 & -15 & 23 & 25-jul-16 & -38 \\
\hline P55 & 10 & 7.302 & 6 & 7 & 0 & 982 & 120 & 5 & 06-jul-16 & 16-set-16 & 72 & 43 & 18-ago-16 & 29 \\
\hline P56 & 10 & 14.781 & 5 & 8 & 1 & 1.912 & 310 & 5 & 14-jul-16 & 24-jul-16 & 10 & 28 & 11-ago-16 & -18 \\
\hline P57 & 10 & 9.995 & 5 & 6 & 1 & 1.230 & 175 & 5 & 02-ago-16 & 21-jul-16 & -12 & 17 & 19-ago-16 & -29 \\
\hline P58 & 10 & 10.101 & 5 & 5 & 1 & 964 & 120 & 5 & 23-ago-16 & 02 -out-16 & 40 & 73 & 04-nov-16 & -33 \\
\hline P59 & 8 & 18.146 & 5 & 8 & 0 & 2.153 & 270 & 5 & 30-ago-16 & 18 -set-16 & 19 & 1 & 31-ago-16 & 18 \\
\hline P60 & 10 & 29.029 & 4 & 7 & 1 & 2.119 & 270 & 0 & 10 -set-16 & 06-jun-16 & -96 & -13 & 28-ago-16 & -83 \\
\hline P61 & 10 & 12.057 & 5 & 4 & 1 & 1.850 & 136 & 3 & 12 -set- 16 & 27 -set-16 & 15 & 78 & 29-nov-16 & -63 \\
\hline P62 & 8 & 13.250 & 6 & 5 & 0 & 2.147 & 310 & 7 & 19 -set-16 & 02 -out-16 & 13 & 35 & 24-out-16 & -22 \\
\hline P63 & 8 & 28.898 & 4 & 7 & 1 & 2.231 & 270 & 0 & 20 -set- 16 & 16-jun-16 & -96 & 1 & 21 -set-16 & -97 \\
\hline
\end{tabular}

A Tabela 12 compara as estatísticas dos resultados da DEFASAGEM_PLAN_PROJ e DEFASAGEM_PREV_SIF obtidas após a validação do sistema de inferência fuzzy. Nenhum poço de 2016 foi considerado como outlier.

Tabela 12 - Estatísticas do processo de sintonia utilizando poços de 2016.

\begin{tabular}{rcc}
$\begin{array}{c}\text { Poços } \\
\mathbf{2 0 1 6}\end{array}$ & $\begin{array}{c}\text { DEF. } \\
\text { PLAN_PROJ }\end{array}$ & $\begin{array}{c}\text { DEF. } \\
\text { PREV_SIF }\end{array}$ \\
\hline Média & 55,36 & 49,50 \\
Desv.P & 52,47 & 27,73 \\
CoV & 94,78 & 56,01 \\
\hline
\end{tabular}

A validação do modelo com os poços de 2016 reduziu em 11\% a média, $47 \%$ o desvio padrão e em $41 \%$ o coeficiente de variação da DEFASAGEM_PREV_SIF em relação à DEFASAGEM_PLAN_PROJ, resultados similares aos obtidos no processo de sintonia, com exceção da média.

Examinando os dados utilizados na sintonia e validação, nota-se que a menor redução na média pode estar relacionada a uma mudança do comportamento empresarial no que tange à entrada de poços em produção de 
2015 para 2016. Considerando o comparativo entre a DEFASAGEM_PLAN_PROJ dos poços de 2015 e 2016 apresentado na Figura 16, observa-se que em 2015 as antecipações foram pontuais e os atrasos se limitaram a, no máximo, 89 dias, ao passo que, em 2016, as antecipações foram mais frequentes e os atrasos mais significativos.

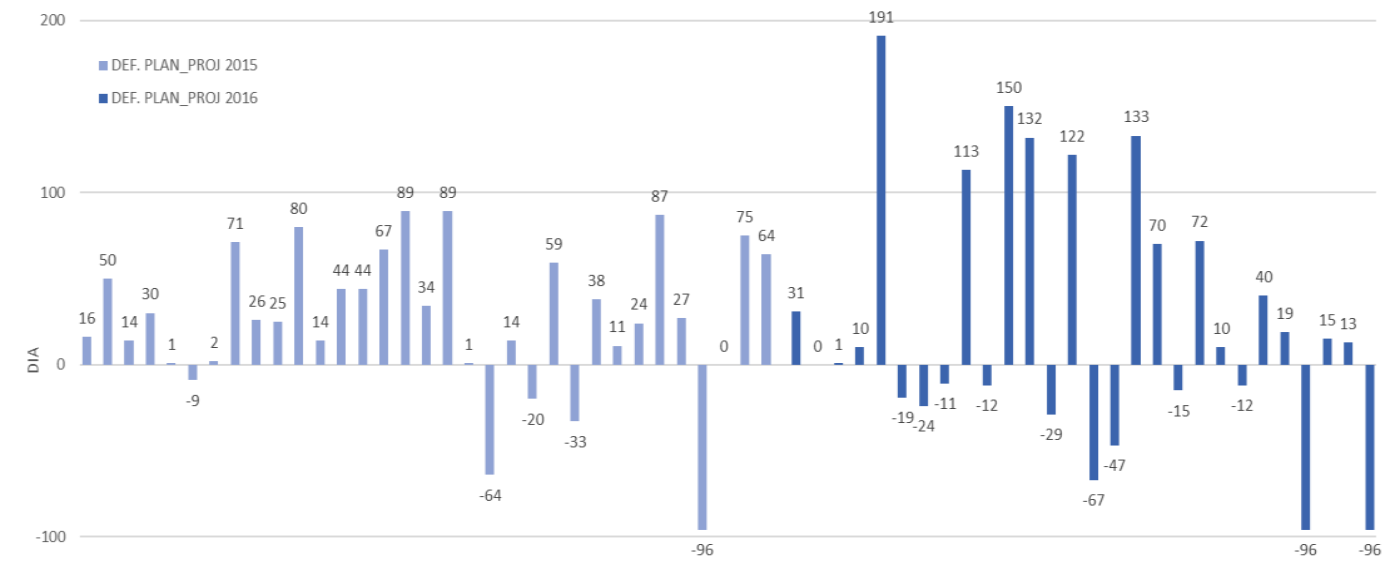

Figura 16 - Comparativo entre a DEFASAGEM_PLAN_PROJ dos poços de 2015 e 2016

\section{3. \\ Previsão de Produção de Petróleo}

Nesta seção é feita a integração do sistema de inferência fuzzy com a metodologia de previsão de produção de petróleo apresentada no Capítulo 3, com o objetivo de demonstrar o efeito do uso do modelo fuzzy para estabelecimento da Data de Entrada em produção dos poços nas previsões feitas para os anos de 2015 e 2016, ceteris paribus.

Para avaliar os resultados do sistema de inferência fuzzy no modelo de análise de risco, inicialmente optou-se por remover as funções triangulares que haviam sido estabelecidas para modelagem da defasagem do índice $t$ dos poços do termo $P o c ̧ o_{i t}$, de forma que o modelo pudesse ser avaliado somente com a DATA_PLAN_PROJ dos poços sem nenhuma estocasticidade (i.e. $t=$ DATA_PLAN_PROJ).

Em seguida, as datas planejadas pelo projeto foram substituídas pelo resultado final da inferência fuzzy (i.e. $t=$ DATA_PREV_SIF) e, por fim a estocasticidade foi novamente incorporada ao modelo (i.e. $t=$ DATA_PREV_SIF 
+ Trng(min, maisprov, max)). Desta forma, foi possível avaliar o efeito da cada informação isoladamente.
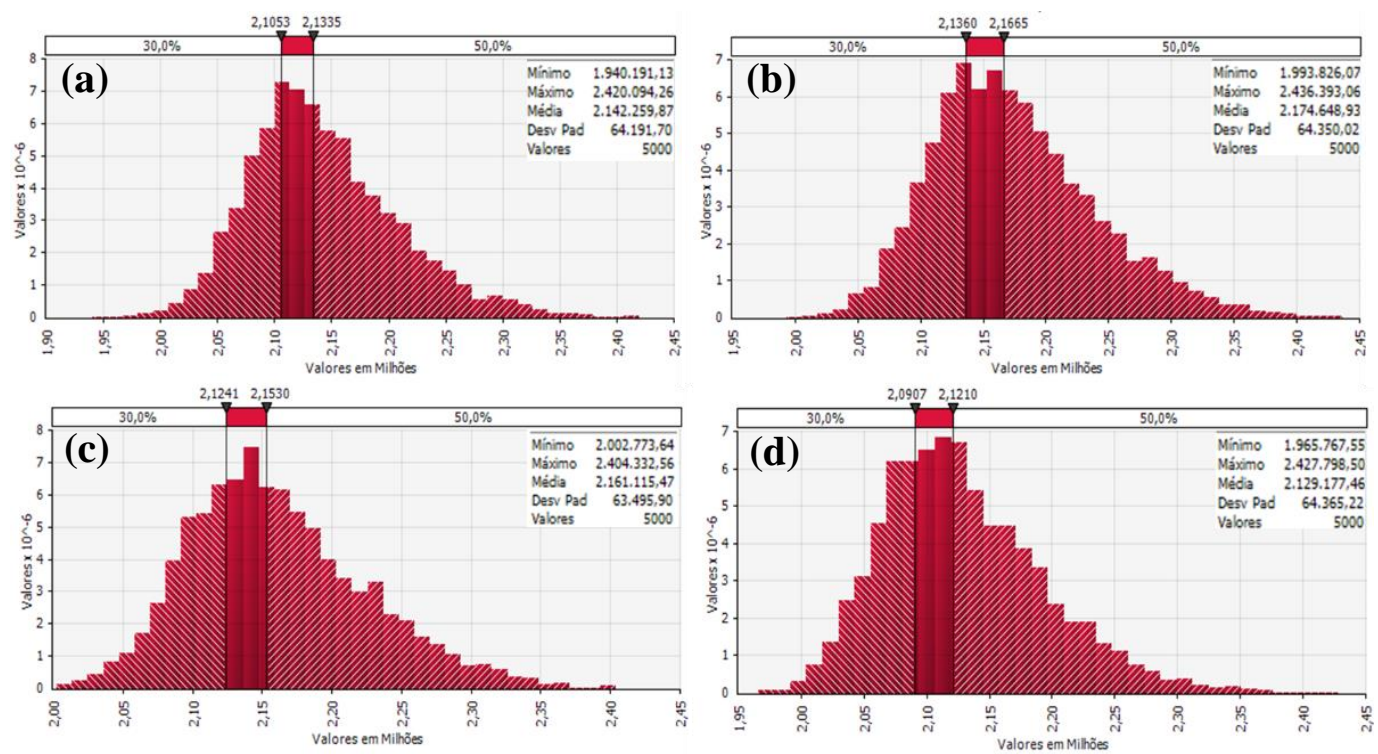

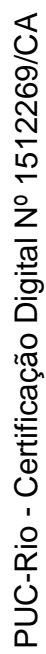

Figura 17 - Resultados da previsão de 2015 (a) DATA_PLAN_PROJ com defasagem estocástica, (b) DATA_PLAN_PROJ sem defasagem estocástica, (c) DATA_PREV_SIF sem defasagem estocástica e (d) DATA_PREV_SIF com defasagem estocástica.
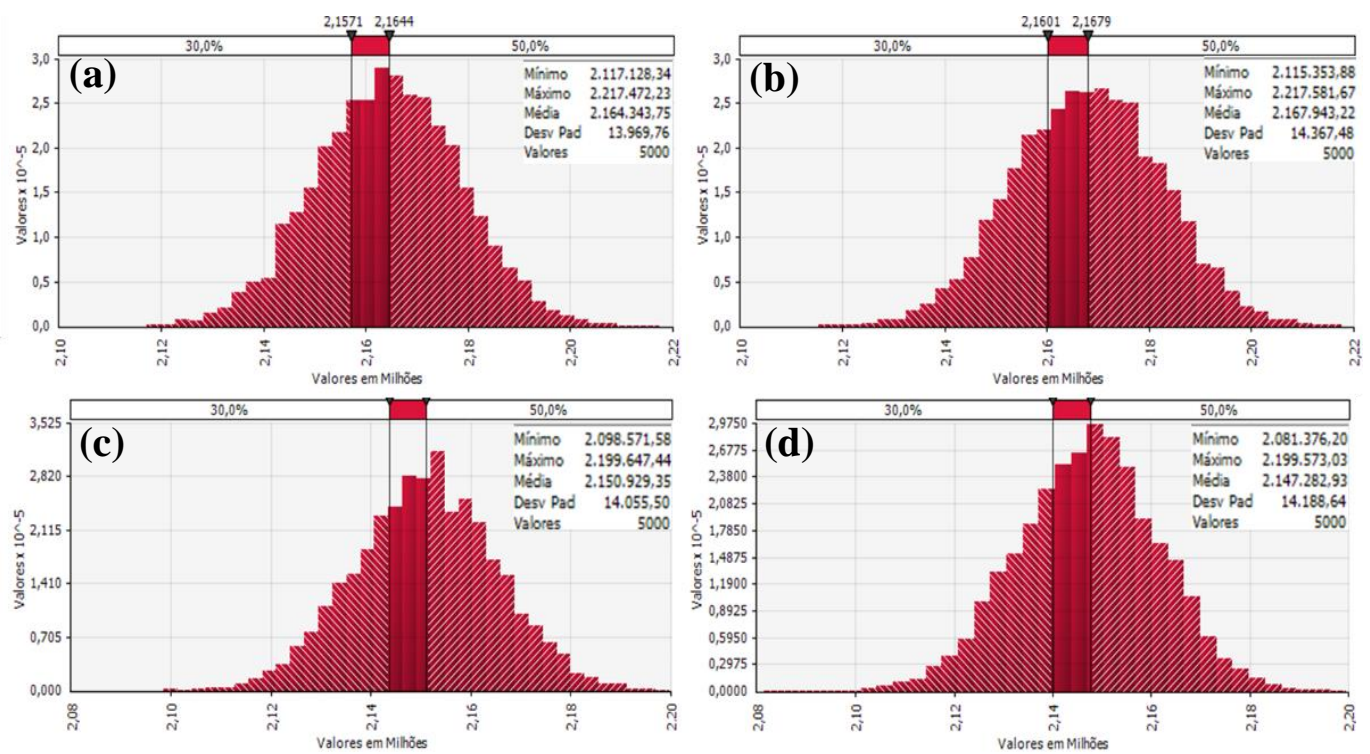

Figura 18 - Resultados da previsão de 2016 (a) DATA_PLAN_PROJ com defasagem estocástica, (b) DATA_PLAN_PROJ sem defasagem estocástica, (c) DATA_PREV_SIF sem defasagem estocástica e (d) DATA_PREV_SIF com defasagem estocástica.

As distribuições finais resultantes das previsões dos anos de 2015 e 2016 original (DATA_PLAN_PROJ com defasagem estocástica), DATA_PLAN_PROJ sem defasagem estocástica, DATA_PREV_SIF pelo sistema de inferência fuzzy 
sem defasagem estocástica e DATA_PREV_SIF pelo sistema de inferência fuzzy com defasagem estocástica do modelo original são apresentadas respectivamente nas Figuras 17 a, b, c e d e Figuras 18 a, b, c e d.

Avaliando o valor do ganho de precisão na previsão de produção para o processo de estabelecimento da meta de produção, considerou-se que o tomador de decisão é indiferente ao risco e busca definir uma meta de produção o mais realista possível. Sendo assim, estabelece como diretriz que a meta de produção para o ano seguinte deve ser igual ao valor equivalente à média da distribuição de probabilidade resultante da análise de risco da previsão de produção. Assim, a média será utilizada como base de comparação entre as análises.

As Figuras 19 e 20 comparam as médias das distribuições resultantes das previsões feitas com a produção realizada nos anos de 2015 e 2016.

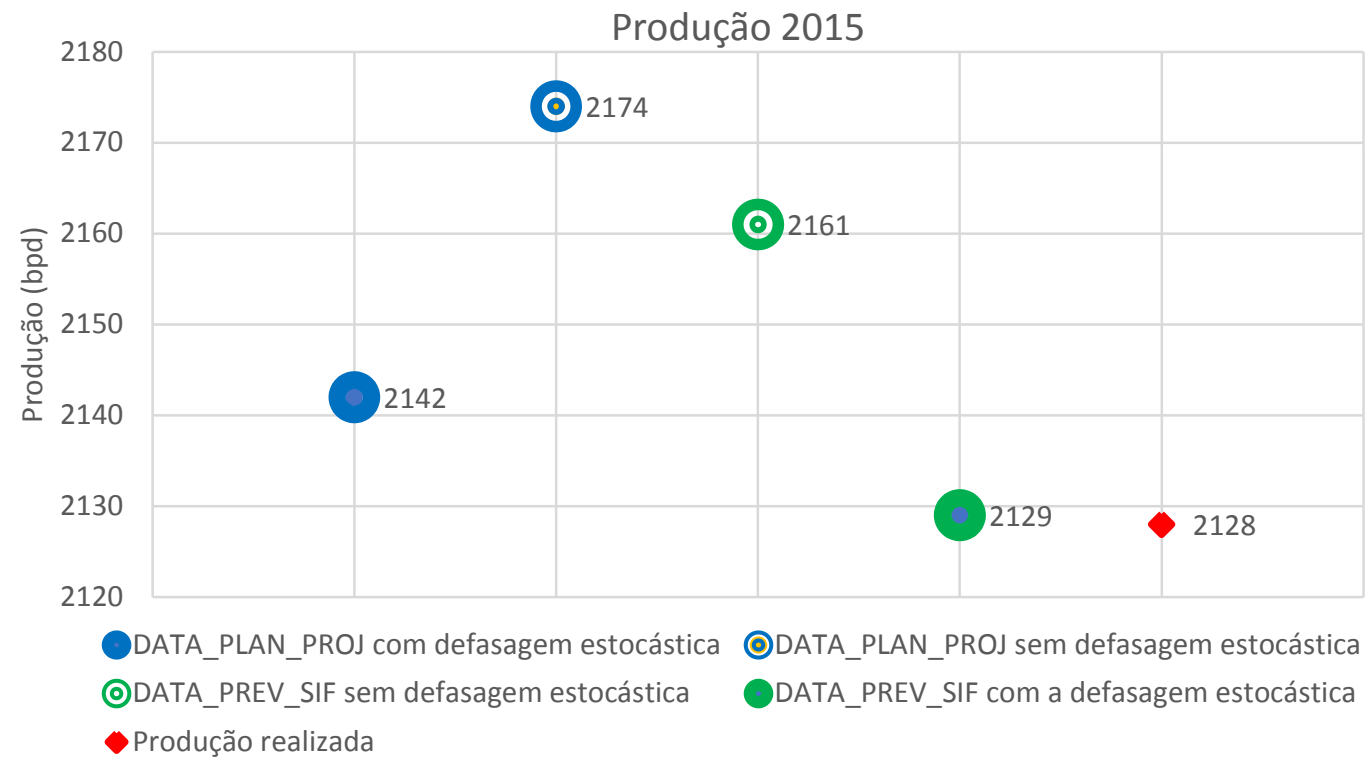

Figura 19 - Comparação das médias das distribuições das previsões com a produção realizada no ano de 2015. 


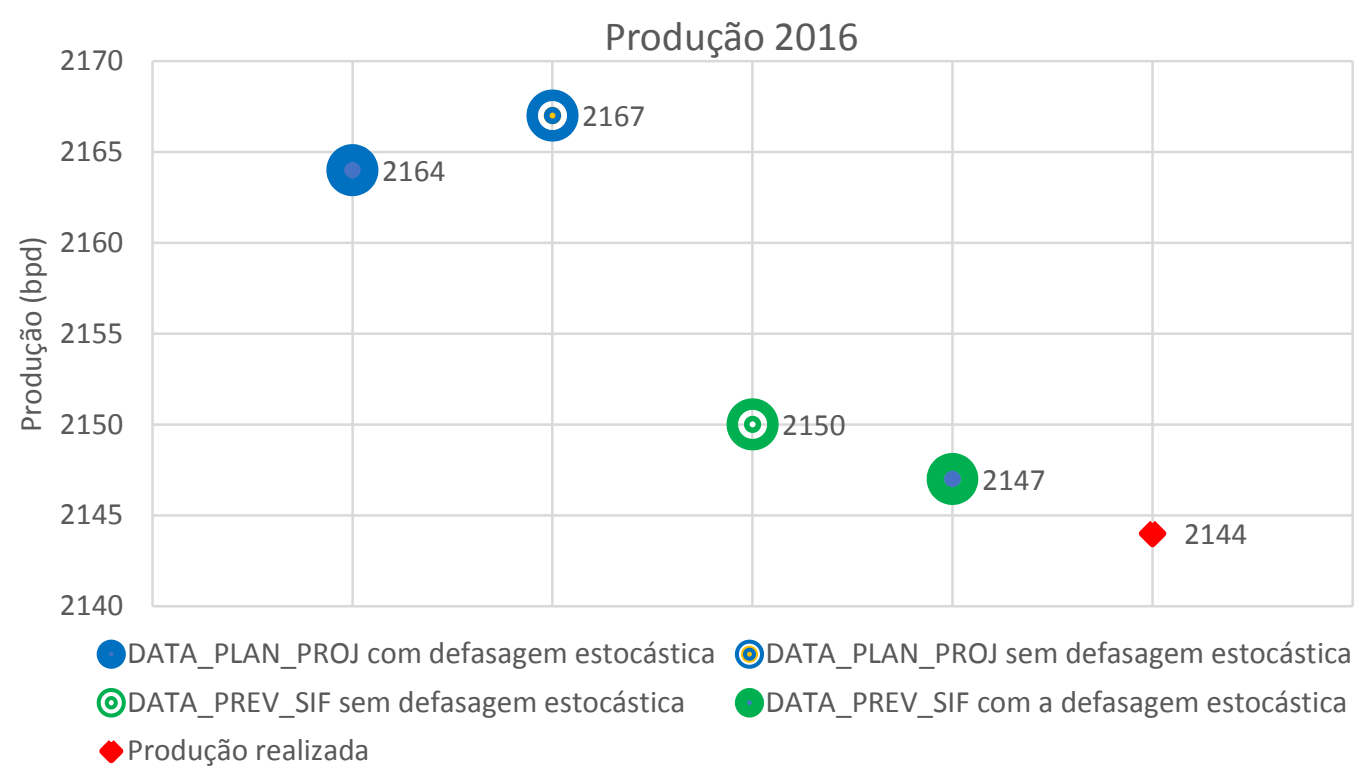

Figura 20 - Comparação das médias das distribuições das previsões com a produção realizada no ano de 2016.

Nota-se que a remoção da estocasticidade gera previsões altas, de forma que se conclui que as distribuições triangulares associadas às datas de entradas de poços no modelo original pressupõem, em média, atrasos. Em 2015 o efeito da estocasticidade na média final da distribuição da previsão de produção foi de +32 mil bpd (i.e. $2.174-2.142=2.161-2.129$ ) e em 2016 o efeito foi de +3 mil bpd (i.e. $2.167-2.164=2.150-2.147$ ). Dado que os resultados considerando a variabilidade geram melhores previsões, a análise se resume à comparação do modelo original (DATA_PLAN_PROJ com estocasticidade) com a DATA_PREV_SIF com estocasticidade.

Desta forma, para o ano de 2015, sabendo que o valor efetivamente realizado durante o ano foi de $2.128 \mathrm{mil} \mathrm{bpd,} \mathrm{observa-se} \mathrm{que} \mathrm{o} \mathrm{uso} \mathrm{do} \mathrm{modelo}$ original apresenta uma média de $2.142 \mathrm{mil}$ bpd, 14 mil bpd acima da produção realizada, e utilizando a DATA_PREV_SIF com estocasticidade a meta seria de 2.129 mil bpd, muito próximo à produção efetivamente realizada.

Em 2016, quando a vazão média anual realizada foi de 2.144 mil bpd, o uso do modelo original resultaria no estabelecimento de uma meta também muito arriscada, 2.164 mil bpd - 20 mil bpd acima da produção realizada. Alternativamente, com o uso da DATA_PREV_SIF com a defasagem estocástica, a meta estabelecida seria 2.147 mil bpd, em linha com a produção realizada. 
Observa-se, portanto, que ao utilizar a média do modelo original para definir a meta de produção tanto em 2015 quanto em 2016 o tomador de decisão estaria, inconscientemente, assumindo um risco maior do que estabelecido na sua diretriz, visto que o resultado da análise de risco original é otimista por conta do viés embutido pelos projetos nas Datas de Entrada de novos poços.

O uso do sistema de inferência fuzzy proposto neste trabalho ajusta as previsões feitas pelos projetos gerando novas datas de entrada de poço, e assim permite a geração de uma distribuição de probabilidade da previsão de produção mais conservadora e alinhada com a realidade.

Conforme demonstrado, dado que o decisor se baseia no resultado da previsão de produção de petróleo para definir a meta de produção, a melhoria da precisão nos resultados finais das previsões de produção de petróleo dos anos de 2015 e 2016 contribui para tornar o processo de tomada de decisão mais efetivo. 


\section{6 \\ Conclusão e Considerações Finais}

As motivações que levaram ao desenvolvimento desta dissertação estão relacionadas à previsão de produção de petróleo, que é a principal referência do planejamento de curto prazo das empresas de E\&P. Esta situação problema e o modelo de simulação estocástica utilizado para analisar o risco da previsão da produção foram amplamente caracterizadas, sobretudo destacando a relevância da entrada de novos poços no resultado final da previsão.

Neste contexto, este trabalho propôs desenvolver um sistema de inferência fuzzy para prever a data de entrada em produção de poços de petróleo marítimos, visando aumentar a precisão da previsão de produção de petróleo.

O sistema foi desenvolvido considerando os aspectos empresariais e técnicos relacionados à construção e interligação do poço que podem implicar em uma antecipação ou postergação da entrada em produção de um poço em relação à data previamente planejada pelo projeto

Foi possível observar que os sistemas de inferência fuzzy apresentam uma forma prática e flexível de modelar situações complexas, incertas e mal definidas, utilizando percepções, impressões e avaliações subjetivas para obter as melhores previsões. Este processo se dá a partir da composição de proposições difusas, que formam um conjunto de regras que são agrupadas em uma base de conhecimento. Esta base de conhecimento e o mecanismo de inferência, implementados através de um conhecimento já existente adquirido de especialista da atividade fim, permite que a data de entrada em produção de poços de petróleo marítimos seja prevista de maneira mais eficiente sem que haja a necessidade de simplificações. Foi possível concluir que o uso do sistema de inferência fuzzy proposto neste trabalho ajusta as previsões feitas pelos projetos gerando novas Datas de Entrada de poço que melhor representam a realidade.

Demonstrou-se que o uso do resultado do sistema de inferência fuzzy para a modelagem da variável Data de Entrada eleva a precisão da simulação estocástica. Assim, dado que o decisor se baseia no resultado da previsão de produção de petróleo para definir a meta de produção, a melhoria da precisão nos resultados finais da previsão da produção de petróleo contribui para tornar o processo de tomada de decisão mais efetivo. 
Destaca-se que não foram localizadas na literatura trabalhos similares, tanto no que tange a situação-problema, quanto à abordagem da aplicação de um sistema de inferência fuzzy, o que confere a este estudo um nível de ineditismo.

Além do sistema de inferência fuzzy, este trabalho estabelece, a partir dos conceitos do modelo de simulação estocástica, uma metodologia para a previsão de produção que incorpora as melhorias e recomendações identificadas, visando a formalização do processo de análise de risco da previsão da produção de petróleo garantindo a sua rastreabilidade, repetitividade e precisão, constituindo, portanto, uma importante referência para pesquisas futuras e construção de novas aplicações práticas.

Como forma de sintetizar as contribuições desta dissertação, a Figura 21 apresenta, destacados em vermelho, os pontos de avanço. Estes se referem ao uso de um sistema de inferência fuzzy para determinação da variável Data de Entrada na dimensão Entrada de Novos Poços e à metodologia de modelagem das variáveis das demais dimensões.

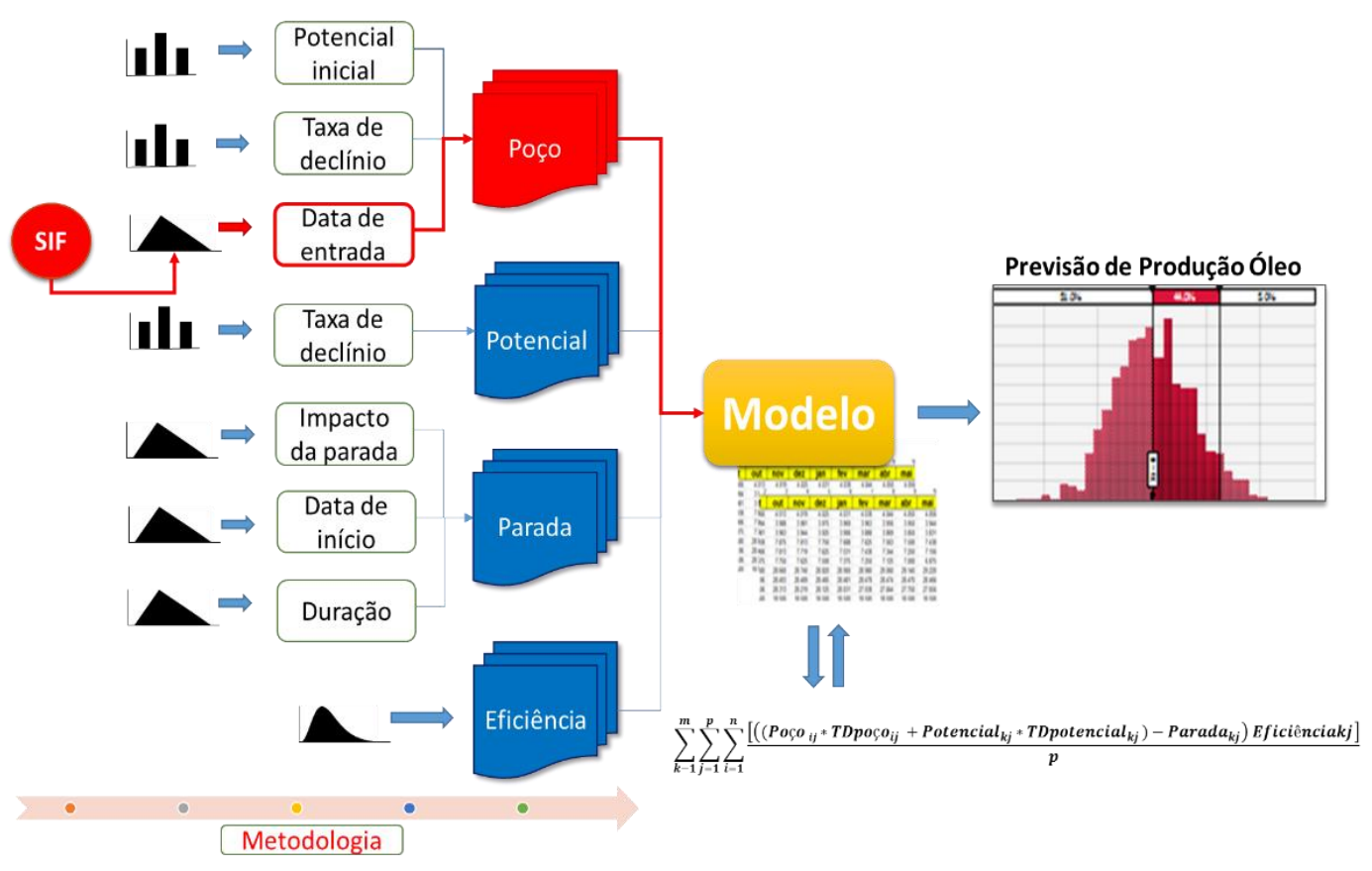

Figura 21 - Contribuições da dissertação.

Como possíveis extensões deste trabalho, sugere-se: 
i. Desenvolvimento de um mecanismo que capture a dinâmica das alterações da influência das dimensões Empresariais e Técnicas na Data de Entrada dos poços para que seja possível regular os pesos das regras linguísticas a partir disto;

ii. Implementação de sistema fuzzy evolucionário ou o método de extração de regras proposto por WANG \& MENDEL (1992) avaliar o ganho de precisão com a perda de interpretabilidade;

iii. Aplicação dos conceitos e estrutura do sistema de inferência fuzzy proposto neste trabalho para problemas similares, como por exemplo para a variável data de início da parada programada;

iv. Investigação de outras variáveis que possam afetar a Data de Entrada em produção de poços visando elevar a precisão do sistema de inferência fuzzy;

v. Implementar técnicas como previsão de séries temporais e bootstrap para modelar com mais precisão a dimensão eficiência e avaliar o ganho de precisão no resultado final da análise de risco na previsão de produção. 


\section{7}

\section{Referências bibliográficas}

ACAROGLU, O.; OZDEMIR, L.; ASBURY, B. A fuzzy logic model to predict specific energy requirement for TBM performance prediction. Tunnelling and Underground Space Technology, v. 23, n. 5, p. 600608, 2008.

AMINZADEH, F. Applications of $\mathrm{Al}$ and soft computing for challenging problems in the oil industry. Journal of Petroleum Science and Engineering, v. 47, n. 1-2, p. 5-14, 2005.

BALLIN, P. R. .; AZIZ, K. .; JOURNEL, A. G. . Quantifying the Impact of Geological Uncertainty on Reservoir Performing Forecast. Symposium on Reservoir Simulation. Anais...New Orleans, Louisiana: 1993

BICKEL, J. E.; LAKE, L. W.; LEHMAN, J. Discretization , Simulation , and Swanson 's ( Inaccurate ) Mean. SPE Economics \& Management, v. 1, n. July 2011, p. 128-140, 2011.

BRASWELL, G. Artificial Intelligence Comes of Age in Oil and Gas. Journal of Petroleum Technology, v. 65, n. 1, p. 50-57, 2013.

CAMPOZANA, F. P. .; BALLIN, P. R. Incerteza na Produção de Petróleo - Uma Proposta Simplificada. Rio de Janeiro: [s.n.].

CARRANZA, E. J. M.; HALE, M. Geologically Constrained Fuzzy Mapping of Gold Mineralization Potential, Baguio District, Philippines Geologically Constrained Fuzzy Mapping of Gold Mineralization Potential, Baguio District, Philippines. Natural Resources Research, v. 10, n. 2, p. 125136, 2001.

CASTRO, A. O. DE S. Seleção de poços de petróleo para a operação de fraturamento hidráulico: uma comparação entre sistemas: fuzzygenético e neuro-fuzzy. [s.I.] Universidade Federal do Rio de Janeiro, 2005.

CASTRO, A. O. DE S.; MATTOS, J. R.; SILVA, S. B. P. Job Risk Análise Probabilística da Previsão de Produção de Óleo. Seminário de Planejamento, Controle e Avaliação do Desempenho do E\&P. Anais...Rio de Janeiro: 2010

CHEN, D. S. et al. Novel Approaches to the Determination of Archie Parameters I: Simplex Method. SPE Advanced technology series, v. 3, n. 1, p. 44-52, 1995.

CHUNG, T.-H.; CARROLL, H. B. Application of Fuzzy Expert Systems for EOR Project Risk Analysis. SPE Annual Technical Conference and Exhibition. Anais...Dallas, USA: 1995 
COSTA, A. P. A. Quantificação do Impacto de Incertezas e Análise de Risco no Desenvolvimento de Campos de Petróleo. [s.I.] Universidade Estadual de Campinas, 2003.

COZZOLINO, J. A simplified utility framework for the analysis of financial risk. Economics and Evaluation Symposium of the Society of Petroleum Engineers. Anais...Dallas, USA: 1977

DAMSLETH, E.; HAGE, A.; VOLDEN, R. Maximum Information at Minimum Cost: A North Sea Field Development Study With an Experimental Design. Journal of Petroleum Technology, n. December, p. 1350-1356, 1992.

DE LIMA, C. J. T. Processo de tomada de decisão em projetos de exploração e produção de petróleo no brasil: uma abordagem utilizando conjuntos nebulosos. [s.I.] Universidade Federal do Rio de Janeiro, 2003

DEJEAN, J. P.; BLANC, G. Managing Uncertainties on Production Predictions Using Integrated Statistical Methods. SPE Annual Technical Conference and Exhibition. Anais...Houston, Texas, USA: 1999

DIAS, M. A. G. Valuation of exploration and production assets: An overview of real options models. Journal of Petroleum Science and Engineering, v. 44, n. 1-2, p. 93-114, 2004.

DIAS, M. A. G. Análise de investimentos com opções reais-teoria e prática com aplicações em petróleo e em outros setores-vol 2: Processos estocásticos e opções reais em tempo contínuo. Rio de Janeiro: Interciência, 2015.

DING, L. Y.; MEHRA, R. K.; DONNELLY, J. K. Stochastic Modeling in Reservoir Simulation. SPE Reservoir Engineering, v. 7, n. 1, 1992.

DREW, L. J. Grid-drilling exploration and its application to the search for petroleum. Economic Geology, v. 62, p. 698-710, 1967.

FIÉVET, L. et al. A general improved methodology to forecasting future oil production: Application to the UK and Norway. Energy, v. 79, n. C, p. 288-297, 2015.

FILHO, V. J. M. F.; CASTRO, A. O. DE S. Selecting Oil Wells for Hydraulic Fracturing: A Comparison between Genetic-Fuzzy and Neuro Fuzzy Systems. American Journal of Operations Research, v. 4, n. July, p. 202-216, 2014.

GACTO, M. J.; ALCALÁ, R.; HERRERA, F. Interpretability of linguistic fuzzy rule-based systems: An overview of interpretability measures q. 
Information Sciences, v. 181, n. 20, p. 4340-4360, 2011.

GARROUCH, A. A.; LABABIDI, H. M. S.; EBRAHIM, S. A Fuzzy Expert System for the Completion of Multilateral Wells. IADC/SPE Asia Pacific Drilling Technology Conference and Exhibition. Anais...2004

GARROUCH, A. A.; LABBABIDI, H. M. S. Using Fuzzy Logic for UBD Candidate Selection. IADC/SPE Underbalanced Technology Conference and Exhibition, 2003.

GOMIDE, F. A. C.; GUDWIN, R. R.; TANSCHEIT, R. Conceitos fundamentais da teoria de conjuntos fuzzy, lógica fuzzy e aplicações. Proc. 6 th IFSA Congress-Tutorials, n. July, p. 1-38, 1995.

GUILLAUME, S. Designing fuzzy inference systems from data: An interpretability-oriented review. IEEE Transactions on Fuzzy Systems, v. 9, n. 3, p. 426-443, 2001.

GUIMARÃES, A. C. F.; LAPA, C. M. F. Fuzzy inference to risk assessment on nuclear engineering systems. Applied Soft Computing, v. 7, n. 1, p. 17-28, 2007.

HAMIDI, J. K. et al. Application of Fuzzy set theory to Rock engineering classification systems: An illustration of the Rock mass excavability index. Rock Mechanics and Rock Engineering, 2010.

HARBAUGH, J.W., DOVETON, J.H., DAVIS, J. C. Probability Methods in Oil Exploration. New York: Wiley-Interscience, 1977.

HARBAUGH, J. W. Quantitative estimation of petroleum prospect outcome probabilities: an overview of procedures. Marine and Petroleum Geology, v. 1, n. 4, p. 298-312, 1984.

HARRIS, D. P. Mineral Resources Appraisal: Mineral Endowment, Resources and Potential Supply: Concepts, Methods and Cases. Oxford: Oxford University Press, 1984.

HARRIS, D. P. Mineral Exploration Decisions: A Guide to Economic Analysis and Modeling. New York: Wiley, 1990.

HIGGINS, J. G. Planning for Risk and Uncertainty in Oil-Exploration. Long Range Planning, v. 26, n. 1, p. 111-122, 1993.

HURST, A.; BROWN, G. C.; SWANSON, R. I. Swanson's 30-40-30 rule. AAPG bulletin, v. 84, n. 12, p. 1883-1891, 2000.

HUYNH, V. N.; HO, T. B.; NAKAMORI, Y. A parametric representation of linguistic hedges in Zadeh's fuzzy logic. International Journal of Approximate Reasoning, v. 30, n. 3, p. 203-223, 2002. 
INFORM. fuzzyTECH® 5.5 User's ManualOak Brook, ILTrademark of INFORM GmbH, , 2001. Disponível em: <http://www.fuzzytech.com>

JAKOBSSON, K. et al. Bottom-up modeling of oil production: A review of approaches. Energy Policy, v. 64, p. 113-123, 2014.

JENSEN, T. B. Estimation of Production Forecast Uncertainty for a Mature Production License. SPE Annual Technical Conference and Exhibition, 1998.

KANG, Y. K. et al. Diagnosis of feedwater heater performance degradation using fuzzy inference system. Expert Systems with Applications, v. 69, p. 239-246, 2017.

KAUFMAN, G. M. Statistical Decision and Related Techniques in Oil and Gas Exploration. New Jersey: Prentice-Hall, 1963.

KRUMBEIN, W.C., GRAYBILL, F. . An Introduction to Statistical Models in Geology. New York: McGraw-Hill, 1965.

LERCHE, I. (IAN); MACKAY, J. A. Economic risk in hydrocarbon exploration. San Diego, California: Academic Press, 1999.

MAMDANI, E. H. Application of fuzzy logic to approximate reasoning using linguistic synthesis. IEEE Transactions on Computers, v. C-26, n. 12, p. 1182-1191, 1977.

MAMDANI, E. H.; ASSILIAN, S. An experiment in linguistic synthesis with a fuzzy logic controller. International Journal of Man-Machine Studies, v. 7 , n. 1, p. 1-13, 1975.

MCKAY, M. D.; BECKMAN, R. J.; CONOVER, W. J. Comparison of Three Methods for Selecting Values of Input Variables in the Analysis of Output from a Computer Code. Technometrics, v. 21, n. 2, p. 239-245, 1979.

MEGILL, R. E. An Introduction to Risk Analysis. Tulsa: The Petroleum Publ., 1977.

MENDEL, J. M. FUZZY LOGIC SYSTEMS FOR ENGINEERING: A TUTORIAL. IEEE Transactions on Systems, Man and Cybernetics, v. 83, p. 345-377, 1995.

MINISTÉRIO DO TRABALHO E EMPREGO. NR-13 CALDEIRAS, VASOS DE PRESSÃO E TUBULAÇÕESBrasil, 2014. Disponível em: <http://portal.mte.gov.br/data/files/FF80808145B26962014600A0AF41169 F/NR-13 (Atualizada 2014).pdf> 
MOHAGHEGH, S. Virtual-Intelligence Applications in Petroleum Engineering: Part 1 - Artificial Neural Networks. SPE Distinguished Author Series, n. September, p. 64-72, 2000a.

MOHAGHEGH, S. Virtual-Intelligence Applications in Petroleum Engineering: Part 2 - Evolutionary Computing. SPE Distinguished Author Series, 2000b.

MOHAGHEGH, S. Virtual-Intelligence Applications in Petroleum Engineering: Part 3 - Fuzzy Logic. SPE Distinguished Author Series, 2000c.

MONJEZI, M.; REZAEI, M.; YAZDIAN VARJANI, A. Prediction of rock fragmentation due to blasting in Gol-E-Gohar iron mine using fuzzy logic. International Journal of Rock Mechanics and Mining Sciences, v. 46, n. 8, p. 1273-1280, 2009.

MURTHA, J. Some Challenges for Monte Carlo Simulation. The Way Ahead, v. 2, n. 2, p. 13-18, 2015.

MURTHA, J. A. Monte Carlo Simulation: Its Status and Future. Journal of Petroleum Technology, v. 49, n. 4, p. 361-373, 1997.

NEPOMUCENO, F., SUSLICK, S.B., WALLS, M. Managing technological and financial uncertainty: a decision science approach for strategic drilling decisions. Natural Resources Research, v. 8, n. 3, p. 193-203, 1999.

NEWENDORP, P. D. Decision Analysis for Petroleum Exploration. Tulsa, OK: Penn Well Books, 1975.

NEWENDORP, P. D. .; SCHUYLER, J. R. Decision Analysis for Petroleum Exploration. New York: Decision Precision, 2000.

NIKRAVESH, M. Soft Computing and Intelligent Data Analysis in Oil Exploration. Developments in Petroleum Science, v. 51, p. 3-32, 2003.

NIKRAVESH, M. Soft computing-based computational intelligent for reservoir characterization. Expert Systems with Applications, v. 26, n. 1, p. 19-38, 2004.

NIKRAVESH, M.; DOBIE, C. A.; PATZEK, T. W. Field-Wise Water flood Management in Low-Permeability, Fractured Oil Reservoirs: NeuroFuzzy Approach. SPE International Thermal Operations and Heavy Oil Symposium, Bakersfield. Anais...Bakersfield, California, USA: 1997

OLIVEIRA JR. Lógica Difusa: aspectos práticos e aplicações. Rio de Janeiro: Interciência, 1999.

REZAEI, M.; MONJEZI, M.; YAZDIAN VARJANI, A. Development of a fuzzy model to predict flyrock in surface mining. Safety Science, v. 49, n. 2, p. 298-305, 2011. 
RIVERA, V. P.; FARABEE, L. M. Fuzzy Logic Controls Pressure in Fracturing Fluid Characterization Facility. SPE Petroleum Computer Conference. Anais...Dallas, Texas, USA: 1994

ROISENBERG, M.; SCHOENINGER, C.; DA SILVA, R. R. A hybrid fuzzyprobabilistic system for risk analysis in petroleum exploration prospects. Expert Systems with Applications, v. 36, n. 3 PART 2, p. 6282-6294, 2009.

ROSE, P. R. Dealing with Risk and Uncertainty in Exploration: How Can We Improve?'. The American Association of Petroleum Geologists Bulletin V, v. 71, p. 1985-1986, 1987.

ROSE, P. R. Chance of success and its use in petroleum exploration. Em: The Business of Petroleum Exploration. Austin: AAPG Special Publications, 1992. v. 98p. 71-86.

ROSS, S. Simulation. 5th. ed. Los Angeles, USA: Academic Press, 2013.

SAGGAF, M. M.; NEBRIJA, E. L. A fuzzy logic approach for the estimation of facies from wire-line logs. AAPG Bulletin, 2003.

SOUZA, R. C.; PESSANHA, J. F. M.; OLIVEIRA, F. L. C. A residential consumer payment capability index based on fuzzy logic inference. Journal of Intelligent and Fuzzy Systems, v. 25, n. 3, p. 649-657, 2013.

STRIPE, J.A., ARIZAKA, K. E DURANDEAU, M. Integrated Field Development Planning Using Risk Analysis and Decision Analysis to Minimize the Impact of Reservoir and Other Uncertainties: A Case Study. SPE Annual Technical Conference and Exhibition. Anais...Bahrain: 1993

SUGENO, M.; KANG, G. T. Fuzzy modelling and control of multilayer incinerator. Fuzzy Sets and Systems, v. 18, n. 18, p. 329-346, 1986.

SUSLICK, S. B.; SCHIOZER, D. J. Risk analysis applied to petroleum exploration and production: An overview. Journal of Petroleum Science and Engineering, v. 44, n. 1-2, p. 1-9, 2004.

THOMAS, J. E. (ORG. . Fundamentos de engenharia de petróleo. Rio de Janeiro: Interciencia, 2001.

TURKSEN, I. B. Measurement of Membership Functions and their Aquisicion. Fuzzy Set and Systems, v. 40, p. 5-38, 1991.

VARGENS, J. M.; TANSCHEIT, R.; VELLASCO, M. M. B. R. Previsão de produção agrícola baseada em regras linguísticas e lógica fuzzy. Sba: Controle \& Automação Sociedade Brasileira de Automatica, v. 14, n. 
2, p. 114-120, 2003.

WANG, L.-X.; MENDEL, J. M. Generating fuzzy rules by learning from examples. IEEE Transactions on Systems, Man and Cybernetics, $v$. 22, n. 6, p. 1414-1427, 1992.

WILLIAMSON, H. S.; SAWARYN, S. J.; MORRISON, J. W. Monte Carlo Techniques Applied to Well Forecasting: Some Pitfalls. Society of Petroleum Engineers, v. 3, n. 3, p. 26-29, 2006.

ZADEH, L. A. Fuzzy sets. Information and Control, v. 8, n. 3, p. 338353, 1965.

ZADEH, L. A. Fuzzy sets as a basis for a theory of possibility. Fuzzy Sets and Systems, v. 100, p. 9-34, 1999.

ZAHEDI, G. et al. Troubleshooting of crude oil desalination plant using fuzzy expert system. Desalination, v. 266, n. 1, p. 162-170, 2011.

ZHANGGUI, L. et al. Integration of Fuzzy Methods into Geostatistics for Petrophysical Property Distribution Simulation of a Reservoir at Exploration Stage. SPE Asia Pacific Oil \& Gas Conference and Exhibition. Anais...Perth, Australia: 1998

ZHOU, C. et al. Determining Reservoir Properties in Reservoir Studies Using a Fuzzy Neural Network. SPE Annual Technical Conference and Exhibition. Anais...Houston, Texas, USA: 1993

ZHOU, S. M.; GAN, J. Q. Low-level interpretability and high-level interpretability: a unified view of data-driven interpretable fuzzy system modelling. Fuzzy Sets and Systems, v. 159, n. 23, p. 3091-3131, 2008.

ZOVEIDAVIANPOOR, M.; SAMSURI, A.; SHADIZADEH, S. R. Development of a Fuzzy System Model for Candidate-well Selection for Hydraulic Fracturing in a Carbonate Reservoir. SPE Oil and Gas India Conference and Exhibition. Anais...Mumbai, India: 2012 


\section{8 \\ Apêndice A}

\section{1.}

\section{Conjuntos Clássicos e Fuzzy}

Na teoria clássica dos conjuntos, dado um conjunto $A$ em um universo $X$, os elementos deste universo pertencem ou não pertencem àquele conjunto. Isto pode ser expresso pela função característica $f_{A}$ (GOMIDE, et al., 1995):

$$
f_{A}(x)=\left\{\begin{array}{lll}
1 & \text { sse } x & \in X \\
0 \text { sse } x & \notin X
\end{array}\right.
$$

ZADEH (1965) propôs uma generalizando da função característica de modo que ela pudesse assumir um número infinito de valores no intervalo [0,1]. Um conjunto fuzzy $A$ em um universo $X$ é definido por uma função de pertinência $\mu_{\mathrm{A}}$ : $X \rightarrow[0,1]$, e representado por um conjunto de pares ordenados.

$$
A=\left\{\mu_{A}(x) / X\right\} ; x \in X
$$

Onde $\mu_{A}(x)$ indica o grau de compatibilidade de $x$ em relação ao conceito do conjunto $A$. Esta generalização da função característica é uma das principais contribuições da teoria de conjuntos fuzzy, pois permite que um determinado elemento pertença a mais de um conjunto fuzzy, com diferentes graus de pertinência.

Conjuntos fuzzy podem ser definidos em universos contínuos ou discretos, usualmente representados pelas seguintes notações: $\sum_{i=1}^{n} \mu_{A}\left(x_{i}\right) / x_{i}$ se $x$ discreto e $\int_{x} \mu_{A}(x) / x$ se $x$ contínuo. DE LIMA (2003) alerta que os símbolos matemáticos $\left(/,+, \Sigma\right.$ e $\left.\int\right)$ utilizados nas equações não possuem o mesmo significado que na matemática usual, pois não significam as operações de divisão, adição, somatório ou de integração respectivamente. 


\section{2.}

\section{Variáveis Linguísticas}

As variáveis linguísticas são aquelas onde seus valores não são expressos por números e sim por palavras ou sentenças em linguagem natural. Para GOMIDE, et al. (1995) a principal função das variáveis linguísticas é fornecer uma maneira sistemática para uma caracterização aproximada de fenômenos complexos ou mal definidos. Em essência, a utilização do tipo de descrição linguística empregada por seres humanos, e não de variáveis quantificadas, permite o tratamento de sistemas que são muito complexos para serem analisados através de termos matemáticos convencionais.

Uma variável linguística é uma variável cujos valores são nomes de conjuntos fuzzy. Por exemplo, lâmina d'agua em que um poço marítimo está localizado pode ser uma variável linguística assumindo valores: baixo, médio e alto. Estes valores (ou termos linguísticos) são descritos por intermédio de conjuntos fuzzy, representados por funções de pertinência, conforme mostrado na Figura 22.

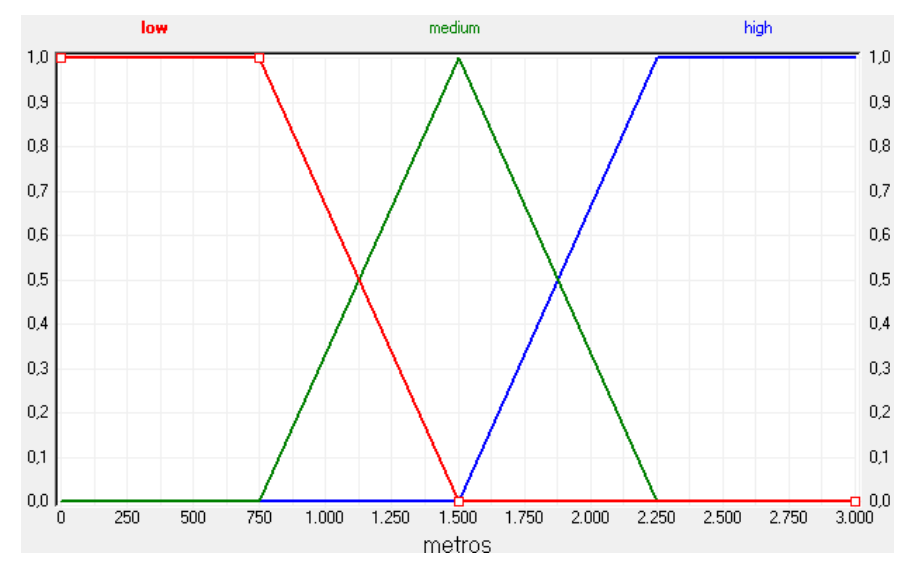

Figura 22 - Representação gráfica da variável linguística lâmina d'água.

Os valores de uma variável linguística podem ser sentenças em uma linguagem especificada, construídas a partir de termos primários (alto, baixo, pequeno, médio, grande, zero, por exemplo), de conectivos lógicos (negação 'não', conectivos 'e' e 'ou'), de modificadores (muito, pouco, levemente, extremamente) e de delimitadores (como parênteses). Estes modificadores (ou Hedges) são operadores semânticos que modificam a natureza de um conjunto 
fuzzy atuando da mesma forma que advérbios e adjetivos atuam em uma sentença. Matematicamente, os Hedges modificam a função de pertinência de conjuntos fuzzy. Ver HUYNH, et al. (2002) para detalhes a aplicação dos Hedges.

Segundo HUYNH, et al. (2002) uma variável linguística é formalmente caracterizada por uma quíntupla $(N, T(N), U, R, M)$, onde:

$N$ : nome da variável

$T(N)$ : conjunto de termos de $\mathrm{N}$, ou seja, o conjunto de nomes dos valores linguísticos de $\mathrm{N}$

$U$ : universo de discurso

$R$ : regra sintática para gerar os valores de $\mathrm{N}$ como uma composição de termos de $T(N)$, conectivos lógicos, modificadores e delimitadores

$M$ : regra semântica, para associar a cada valor gerado por $G$ um conjunto fuzzy em $X$.

Exemplificando com a variável linguística lâmina d'água apresentada na Figura 20, tem-se que:

\section{$N$ : Lâmina d'água}

$T(N)$ : $\{$ baixa, média, alta $\}$

$X: 0$ a 3000 metros

$G$ : Lâmina d'água não baixa e muito alta, por exemplo

$M$ : associa o valor acima a um conjunto fuzzy cuja função de pertinência exprime o seu significado

Aos termos de uma variável linguística, $T(N)$, faz-se corresponder conjuntos fuzzy que por sua vez são definidos por suas funções de pertinência. As funções de pertinência podem ter diferentes formas, dependendo do conceito que se deseja representar e do contexto em que serão utilizadas. Os formatos padrão das funções de pertinência são: Linear, Trapezoidal, Triangular, Formato S, Formato Z, Formato Pi, Gaussiana e Singleton. Em alguns casos, quando as formas padrão não conseguem capturar a semântica de uma variável, é necessário realizar uma representação arbitrária. 


\section{3. \\ Operações com Conjuntos Fuzzy}

Em um sistema fuzzy, os valores assumidos pelas diversas variáveis linguísticas, de forma similar aos conjuntos crisp, podem passar por várias operações, entre elas temos: união, complemento e interseção (CASTRO, 2005).

Com o objetivo de generalização, foram definidos operadores de base axiomática, baseados nos conceitos de norma triangular (t-norma) e co-norma triangular (t-co-conorma). A t-norma (representada por *) e a t-co-norma (representada por $\bigoplus$ ) são operações binárias $[0,1] \times[0,1] \rightarrow[0,1]$ tal que, $\forall x, y, z, w$ $\in[0,1]$ e as seguintes propriedades sejam satisfeitas:

Comutatividade: $\mathrm{x} * \mathrm{y}=\mathrm{y} * \mathrm{x}$ e $\mathrm{x} \oplus \mathrm{y}=\mathrm{y} \oplus \mathrm{x}$

Associatividade: $(\mathrm{x} * \mathrm{y}) * \mathrm{z}=(\mathrm{x} *(\mathrm{y} * \mathrm{z}) \mathrm{e}(\mathrm{x} \oplus \mathrm{y}) \oplus \mathrm{z}=(\mathrm{x} \oplus(\mathrm{y} \oplus \mathrm{z})$

Monotonicidade: $\mathrm{x} \leq \mathrm{y}, \mathrm{w} \leq \mathrm{z}$, então $\mathrm{x} * \mathrm{w} \leq \mathrm{y} * \mathrm{z}$ e $\mathrm{x} \leq \mathrm{y}$, $\mathrm{w} \leq \mathrm{z}$, então $\mathrm{x}$ $\bigoplus \mathrm{w} \leq \mathrm{y} \oplus \mathrm{z}$

Condições de contorno: $\mathrm{x} * 0=0$ e $\mathrm{x} * 1=\mathrm{x}$ e $\mathrm{x} \oplus 0=\mathrm{X}$ e $\mathrm{x} \oplus 1=1$

Segundo (MENDEL, 1995) existem inúmeras t-normas e t-co-normas, mas, em aplicações - principalmente em engenharia -, têm sido utilizados, preponderantemente, os operadores min e produto algébrico para interseção e o operador max para a união.

Destaca-se que as propriedades (Aristotélicas) de conjuntos clássicos: $A \cap A$ '

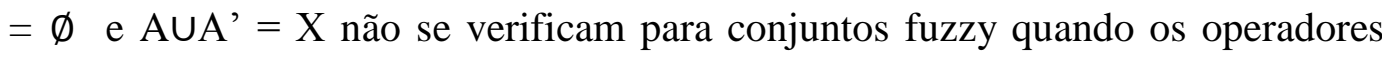
$\max$ e $\min$ são utilizados, i.e:

$$
\begin{aligned}
& \mu_{A \cap A^{\prime}}(x)=\mu_{A}(x) \wedge\left(1-\mu_{A}(x)\right) \neq 0 \rightarrow A \cap A^{\prime} \neq \varnothing \\
& \mu_{A \cup A^{\prime}}(x)=\mu_{A}(x) \vee\left(1-\mu_{A}(x)\right) \neq 1 \rightarrow A \cup A^{\prime} \neq \mathrm{X}
\end{aligned}
$$

Todavia, esta não é uma limitação, mais sim um dos principais diferenciais da lógica fuzzy. Uma das formas de descrever as diferenças entre a teoria de conjuntos clássicos (crisp) e a teoria de conjuntos fuzzy é justamente explicando que estas duas propriedades não se aplicam aos conjuntos fuzzy. Consequentemente, qualquer outra estrutura matemática válida para o mundo 
crisp, como a Teoria da Probabilidade, deve ser estruturada de maneira diferente para o mundo fuzzy. Ver Mendel (1995) para exemplo demonstrativo.

\section{4.}

\section{Lógica de Inferência Tradicional e Fuzzy}

Na lógica proposicional há um importante mecanismo (regra) de inferência chamado Modus Ponens. O Modus Ponens tem a seguinte estrutura:

Premissa 1: x é A

Premissa 2: se (x é A) então (y é B)

Consequência: y é B

O Modus Ponens é associado à implicação de $A$ em $B(A \rightarrow \mathrm{B})$, usando as proposições $p$ e $q$ da lógica tradicional, pode ser expresso por $((p \wedge(p \rightarrow q)) \rightarrow q$ (MENDEL, 1995).

A extensão da lógica tradicional para a lógica fuzzy foi efetuada através da simples substituição das funções características por funções de pertinência fuzzy, à semelhança da extensão de conjuntos ordinários para conjuntos fuzzy. Assim, a declaração condicional se $x$ é $A$ então $y$ é $B$ tem uma função de pertinência $\mu_{A \rightarrow B}(x, y)$ que mede o grau de verdade da relação de implicação entre $x$ e $y$. Pela simples extensão para funções de pertinência bivalentes da lógica proposicional para a lógica fuzzy, teremos:

$$
\begin{aligned}
& \operatorname{Se}(p \rightarrow \mathrm{q}) \leftrightarrow \sim[p \wedge(\sim \mathrm{q})], \\
& \text { Então } \mu_{A \rightarrow B}(x, y)=1-\min \left[\mu_{A}(x), 1-\mu_{B}(y)\right] \\
& \operatorname{Se}(p \rightarrow \mathrm{q}) \leftrightarrow[(\sim p) \vee \mathrm{q}], \\
& \text { Então } \mu_{A \rightarrow B}(x, y)=\max \left[1-\mu_{A}(x), \mu_{B}(y)\right]
\end{aligned}
$$

Quanto à inferência, o modus ponens é estendido para o modus ponens generalizado, descrito da seguinte forma:

Premissa 1: $x$ é $A^{*}$

Premissa 2: se $x$ é $A$ então $y$ é $B$

Consequência: $y$ é $B^{*}$ 
No modus ponens generalizado, o conjunto fuzzy $A^{*}$ não é necessariamente o mesmo que $A$ (antecedente da regra), assim como $B^{*}$ não é necessariamente o mesmo que o consequente $B$. Na lógica clássica, uma regra será ativada somente se a Premissa 1 for exatamente o antecedente da regra, e o resultado será exatamente o consequente dessa regra. Na lógica fuzzy, uma regra será disparada se houver um grau de compatibilidade diferente de zero entre a Premissa 1 e o antecedente da regra; o resultado será um consequente com grau de similaridade não nulo em relação ao consequente da regra. $\mathrm{O}$ modus ponens generalizado é definido por:

$$
\mu_{B^{*}}(y)=\text { supremo }_{x \in A^{*}}\left[\mu_{A^{*}}(x) * \mu_{A \rightarrow B}(x, y)\right]
$$

Se os universos forem discretos e finitos, o operador supremo torna-se max, logo:

$$
\mu_{B^{*}}(y)=\max _{x \in A^{*}}\left[\mu_{A^{*}}(x) * \mu_{A \rightarrow B}(x, y)\right]
$$

Conforme demostrado por Mendel (1995), observa-se, entretanto, que a utilização de implicações inspiradas na lógica tradicional pode levar a conclusões sem muito sentido quando o enfoque são aplicações em engenharia - onde a noção de causa e efeito tem um papel relevante. Em virtude disto, a necessidade fez com que fossem definidas outras implicações, mesmo rompendo o vínculo com a lógica proposicional. No modus ponens generalizado, a t-norma mais utilizada é min, dando origem à regra de inferência max-min (ou sup-min). Ver Mendel (1995) para detalhes da limitação da aplicação lógica tradicional em problemas de engenharia.

\section{5.}

\section{Sistemas de Inferência Fuzzy}

Os sistemas de inferência fuzzy utilizam como base de raciocínio a lógica fuzzy e podem inferir alternativas baseadas em proposições vagas e incompletas. Estas proposições difusas formam um conjunto de regras que são agrupadas em uma base de conhecimento que modela o comportamento do fenômeno. Para uma 
perfeita transformação do conhecimento dos especialistas em regras fuzzy que utilizem os termos linguísticos, as funções de pertinência correspondentes, suas inter-relações e implicações podem ser definidas através de entrevistas ou da compilação do conhecimento teórico existente sobre o assunto (CASTRO, 2005). TURKSEN (1991) apresenta métodos experimentais para aquisição deste conhecimento.

Um sistema de inferência fuzzy é composto por etapas que se relacionam conforme a Figura 23 (MENDEL, 1995).

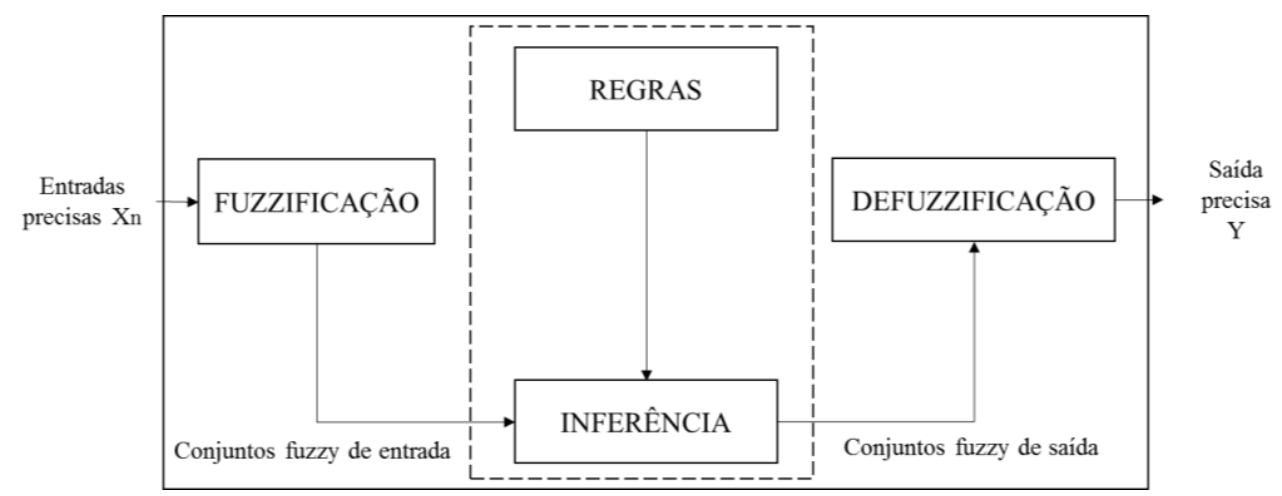

Figura 23 - Estrutura do geral de um SIF. Fonte: Adaptado de Mendel, 1995.

A primeira etapa é a fuzzificação, onde as entradas precisas (ou crisp) são transformadas em conjuntos fuzzy através da avaliação da compatibilidade com os conceitos preestabelecidos para as variáveis de entrada (variáveis linguísticas e seus termos linguísticos). Nesta etapa ocorre a ativação das regras.

Em seguida ocorre o processo de inferência que considera os conjuntos fuzzy gerados na fuzzificação e os conjuntos de regras para gerar conjunto fuzzy de saída através da ativação das regras de implicação. Na inferência ocorrem as operações com conjuntos fuzzy, i.e., combinação dos antecedentes das regras, implicação e modus ponens generalizado.

As regras podem ser fornecidas por especialistas em forma de sentenças linguísticas, e se constituem em um aspecto fundamental no desempenho de um sistema de inferência fuzzy. O desempenho do sistema de inferência fuzzy depende diretamente da consistência das regras que definem as relações lógicas entre as variáveis da situação-problema. Extrair regras de especialistas na forma 
de sentenças do tipo SE-ENTÃO pode não ser uma tarefa fácil, por mais conhecedores que eles sejam do problema em questão. Alternativamente ao uso de especialistas para a definição da base de regras, existem métodos de extração de regras de dados numéricos. Estes métodos são particularmente úteis em problemas de classificação e previsão de séries temporais (WANG \& MENDEL, 1992).

Por fim, ocorre a filtragem ou interpretação das informações dos conjuntos fuzzy obtidos como saída da inferência novamente em valores crisp. O método de defuzzificação deve levar em consideração o objetivo e os conceitos do sistema para, por exemplo, considerar a ativação de todas as regras ativadas ou somente o conjunto com maior ativação. Os métodos de defuzzificação mais utilizados são: Máximo, Média dos Máximos, Centróide (ou Centro de Gravidade), Altura e Altura Modificada.

\section{6.}

\section{Tipos de Sistemas de Inferência Fuzzy}

Os principais tipos de sistema de inferência fuzzy são as estruturas propostas por Mamdani (MAMDANI, 1977; MAMDANI \& ASSILIAN, 1975) e Takagi-Sugeno (SUGENO \& KANG, 1986).

Em sistemas de inferência fuzzy do tipo Mamdani a aplicação das regras e a defuzzificação são feitas conforme descrito nos itens anteriores. Por exemplo, um sistema com duas variáveis e duas regras do tipo: se $x$ é $A_{l}$ e y é $B_{l}$, então $z=C_{l}$; se $x$ é $A_{2}$ e $y$ é $B_{2}$, então $z=C_{2}$ terá o seu comportamento conforme ilustrado na Figura 24.

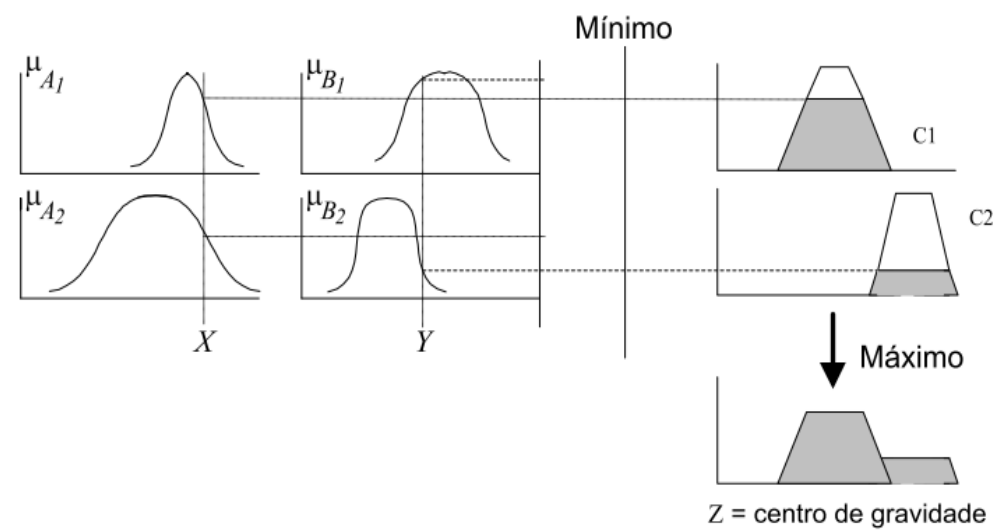

Figura 24 - Estrutura de um sistema de Inferência Fuzzy do tipo Mamdani. Fonte: (CASTRO, 2005). 
O sistema do tipo Takagi-Sugeno difere do tipo Mamdani quanto aos conjuntos fuzzy de saída, que são valores discretos, e ao processo de defuzificação que se dá segundo uma ponderação (CASTRO, 2005). A Figura 25 ilustra o sistema do tipo Takagi-Sugeno com as regras definidas conforme descrito abaixo.

Se $x$ é $A_{l}$ e $y$ é $B_{1}$, então $z_{1}=p_{1} x+q_{1} y+r_{1}$

Se $x$ é $A_{2}$ e $y$ é $B_{2}$, então $z_{2}=p_{2} x+q_{2} y+r_{2}$

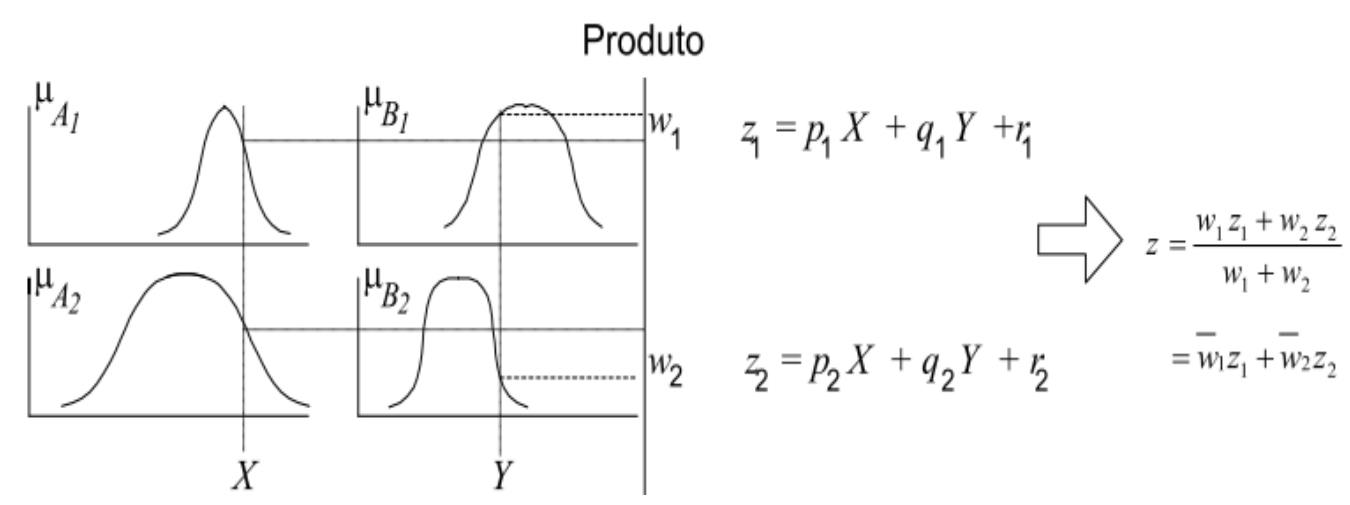

Figura 25 - Estrutura de um sistema de Inferência Fuzzy do tipo Takagi-Sugeno. Fonte: (CASTRO, 2005).

O sistema de inferência fuzzy do tipo Mamdani foi o utilizado neste trabalho devido à sua maior capacidade explicativa, quando comparado ao sistema de inferência fuzzy proposto por Takagi-Sugeno, dado que este sistema gera como saída não conjuntos fuzzy, mas funções das entradas do sistema (e.g. combinações lineares), que no geral são pouco explicativas. 